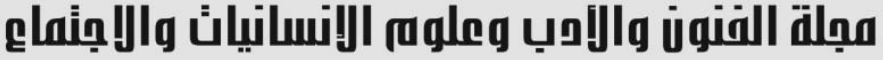

\section{روئة شرعية قانونية حول تعديلات برلمان إقليم كوردستان في النفقة الزوجية}

\author{
د. إسماعيل أبابكر علي البامرني

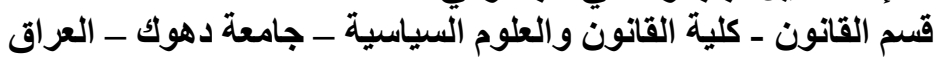 \\ الايميل: Ismael.ali@uod.ac
}

إن المشرع في إقليم كوردستان أجرى تعديلات عديدة على مو اد خاصة بالنفقة الزوجية لم تكن بحاجة إلى تعديل وكان البعض منها جذريا وتثير الكثير من الإشكاليات. ومن تللك التعديلات إلزام الزئل الزوجة بالإنفاق على نفسها

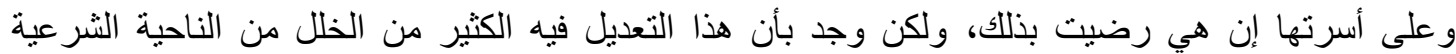

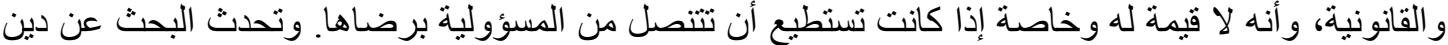

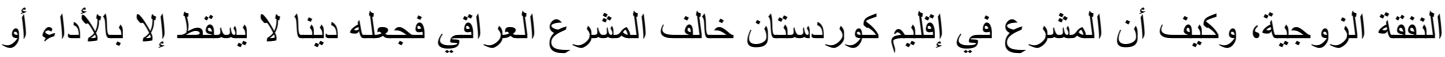

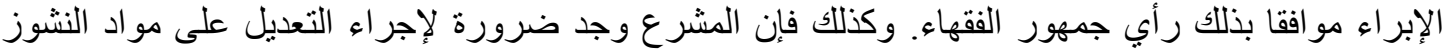
وتأثير ذلك في النفقة الزوجية، ولوحظ بأن توجه المشرع إقليم كوردستان كان مغاير الموقف جمهور الفقهاء،

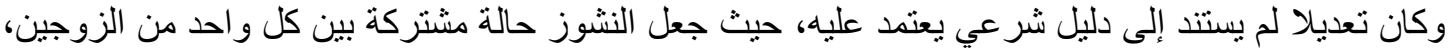

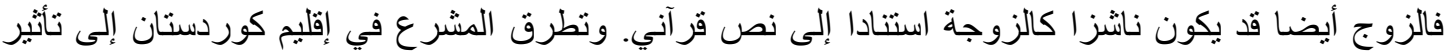

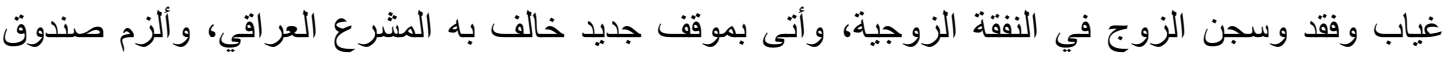

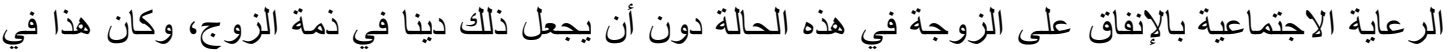

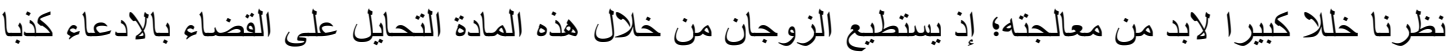

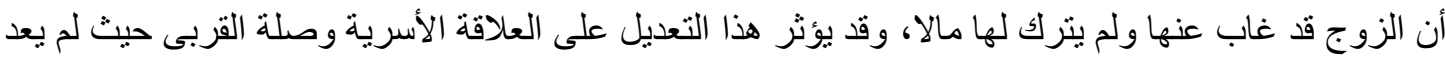

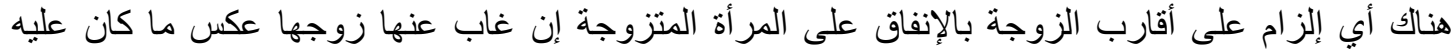

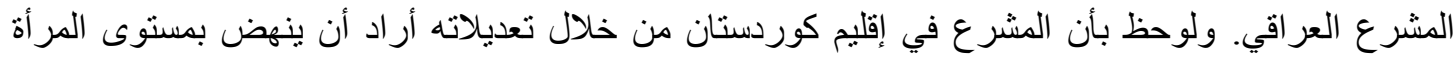
ويتضح ذللك من خلال إثر الك الزوجة في المسؤولية على الانفاق وكذلك في تعديلاته على مو اد النشوز. 


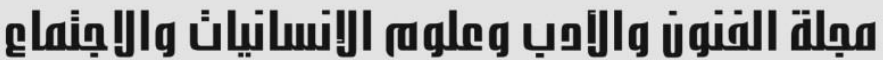

Journal of Arts, Literature, Humanities and Social Sciences www.jalhss.com

\section{Legal Vision about Amendments of Kurdistan Region Parliament's In Marital Alimony}

\author{
Dr. Ismail Aba Bakr Ali Al-Baramni \\ Department of Law - College of Law and Political Science \\ Duhok University - Iraq \\ Email: Ismael.ali@uod.ac
}

\begin{abstract}
The legislator in the Kurdistan Region of Iraq made amendments on marital alimony articles, some of articles didn't need amendments. then some of these amendments give raise and problems. as obligating the wife to spend on herself and her family if she accepts. Those amendment has a lot of flaws in view of sharia and law., and that it has no value.

The search talk about how the legislator broke the Iraqi legislator, making alimony a strong debt that does not fall except by payment or discharge, according to the majority of jurists.

The legislator made amendments on articles of disobedience "nushuz" and effect of this on marital alimony, it was noted that the view of the legislator of Kurdistan Region was contrary to the opinion of the majority of jurists, and he didn't depend on legal evidence, he made disobedience a common case between each of spouses based on a Quranic text.

The legislator talked about effects of the absence, loss and imprisonment of husband on marital alimony. So, he brought a new different view of Iraqi legislator, and obligated the Social Welfare Fund to spend on the wife in this case without making it a debt in the husband's custody, and this was in our view a major imbalance that must Treat it. It gives a big opportunity to spouses for fraud, so this amendment may impact on family relationship, as there is no relatives shall have obligation to spend on the married woman if her husband is absent contrary to point of Iraqi legislator.

It was noted that the legislator in the Kurdistan Region through his amendments wanted to advance the level of women and through wife responsibility also in amendments on disobedience "nushuz".
\end{abstract}

Keywords: Marital maintenance, Kurdistan Parliament, disobedience. 


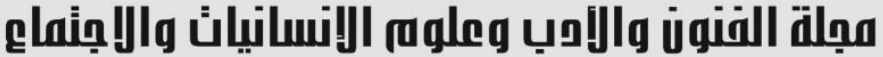

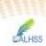

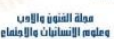

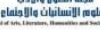

Journal of Arts, Literature, Humanities and Social Sciences www.jalhss.com

إن المشرع في إقليم كوردستان قد أجرى العديد من التعديلات على القو انين العر اقية النافذة في إقليم كوردستان.

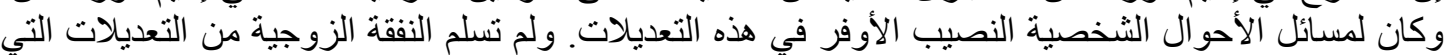

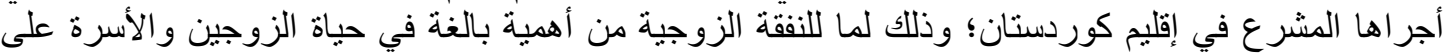

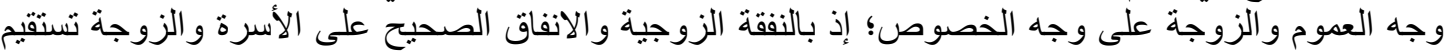

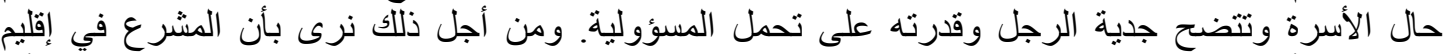

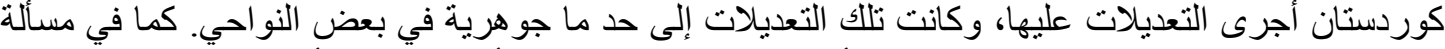

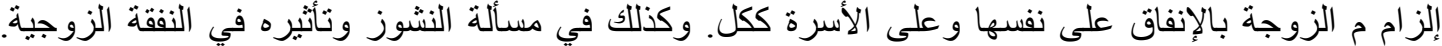

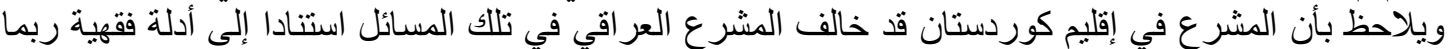

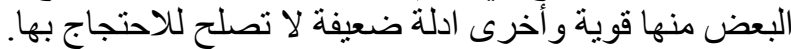

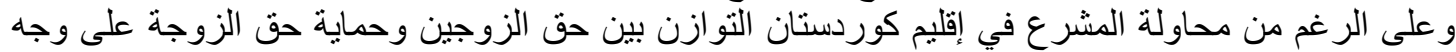

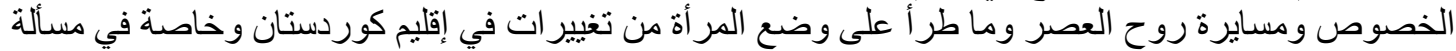

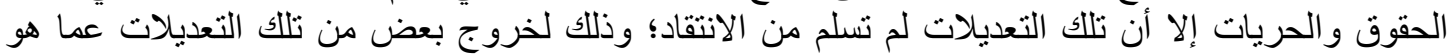

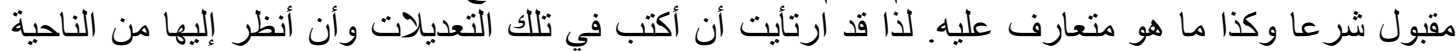

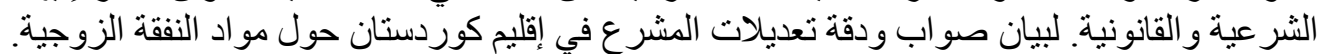

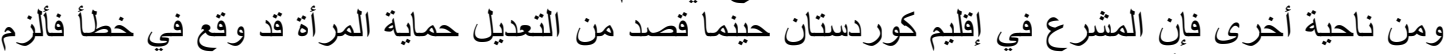

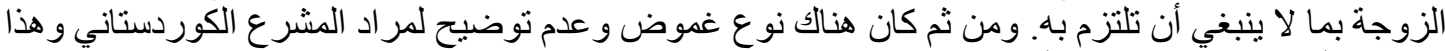

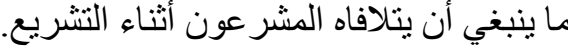

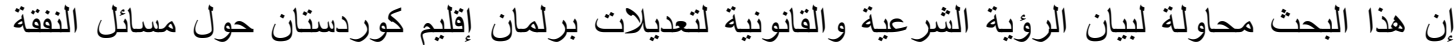

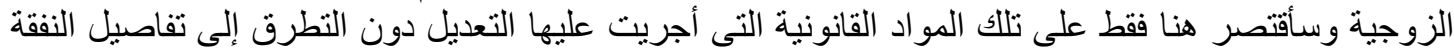

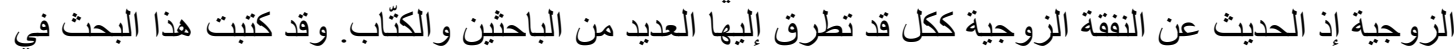

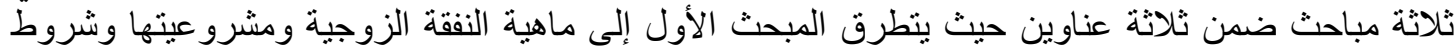

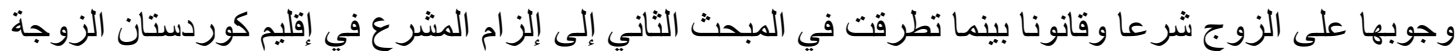

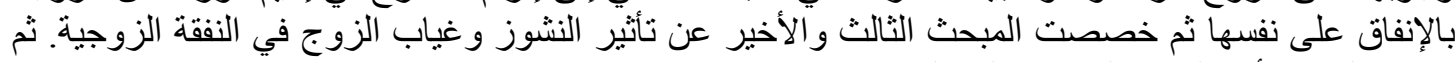
ختمت البحث بأهم النتائج الني توصلت إليها.

\section{المبحث الأول \\ ماهية النفقة الزوجية وشروط الاولوجوبها}

تعريف النفقة الزوجية: النفقة لغة

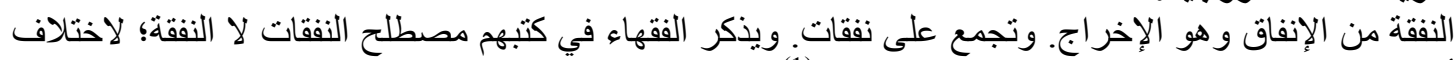

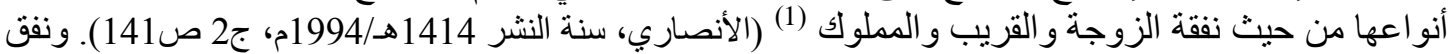

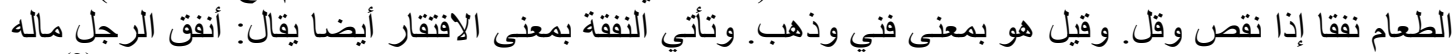

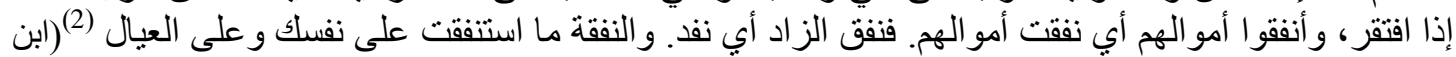

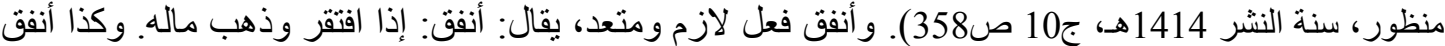

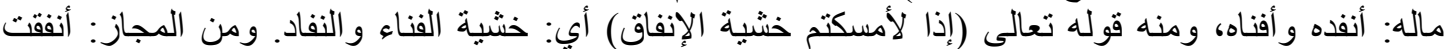

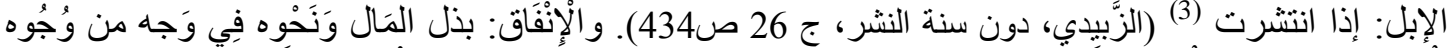

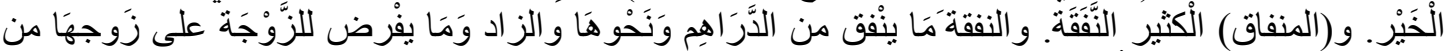

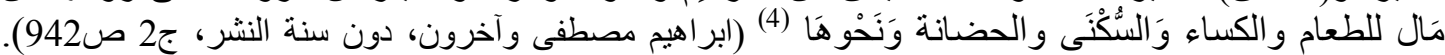

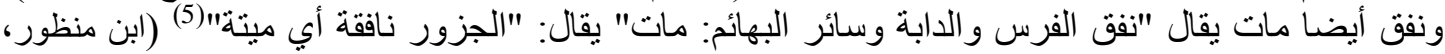




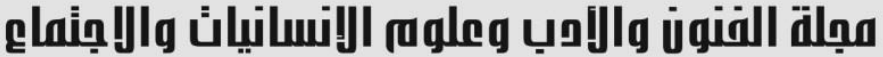 \\ Journal of Arts, Literature, Humanities and Social Sciences} www.jalhss.com

للفقهاء تعريفات عدة حول النفقة وهذا الاختلاف ربما ناتج من نظرتهم إلى طبيعة النفقة ومشتملاتها. وسنتطرق

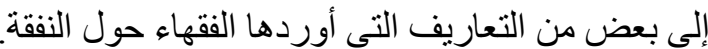

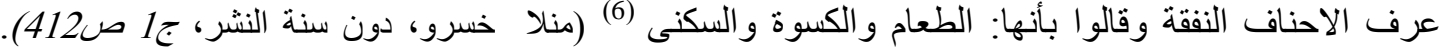

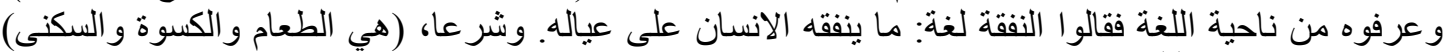

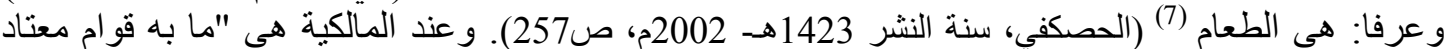

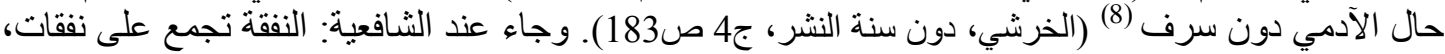

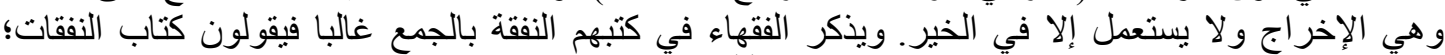

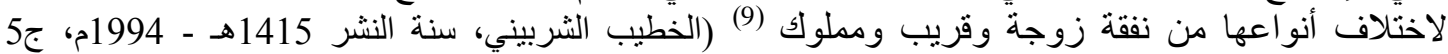

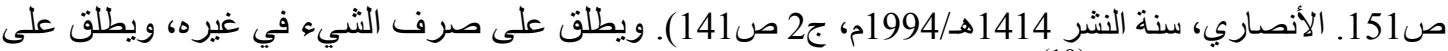

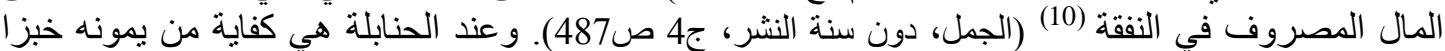

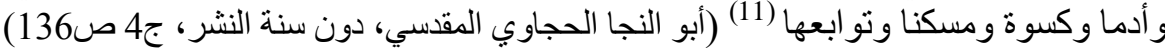

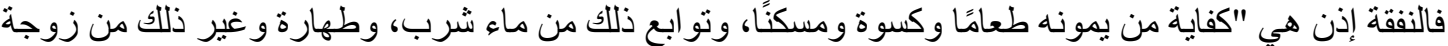

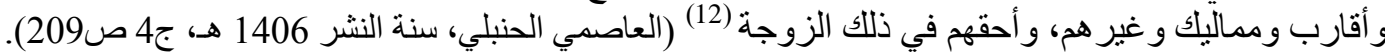

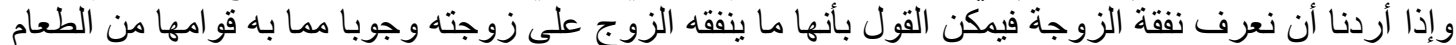
و والثراب و المسكن و غير ذلك من مشتملات النفة النقة.

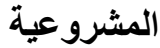
اتفق الفقهاء على مشروعية النفقة الزوجية وأنها حق من حقوق الزوجة ولئ ويستدل على ذللك بالكتاب والسنة

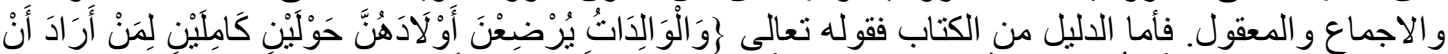

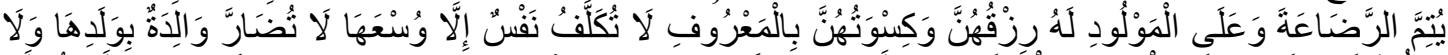

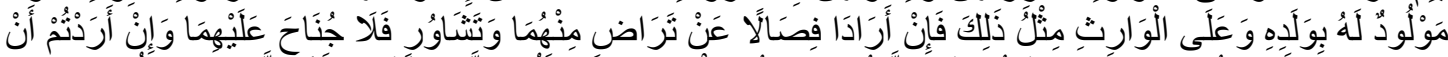

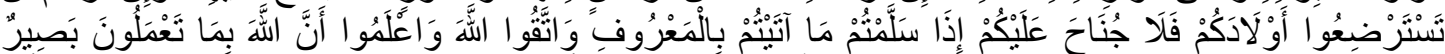

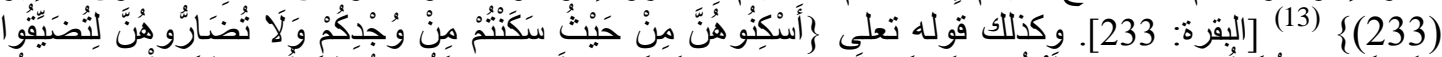

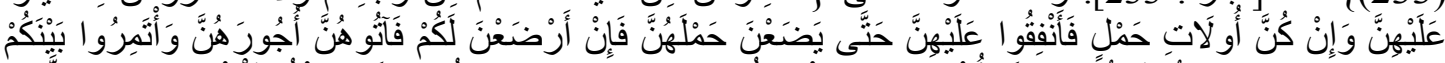

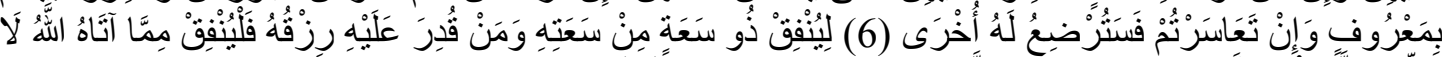

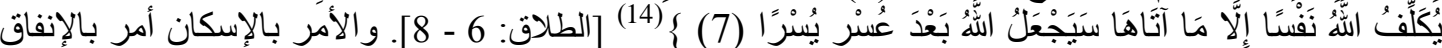

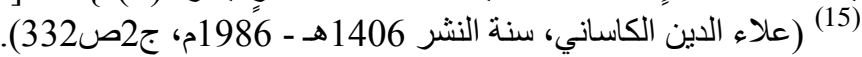

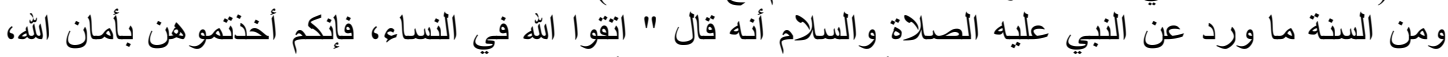

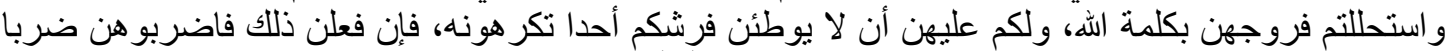

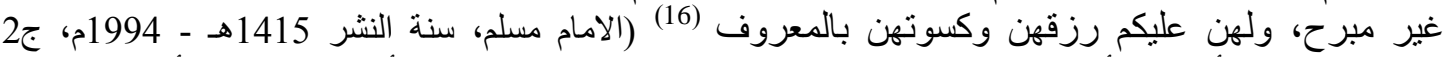

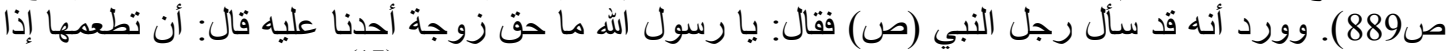

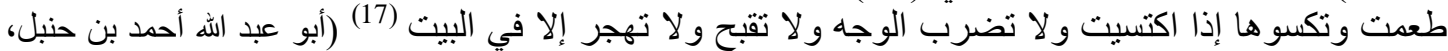

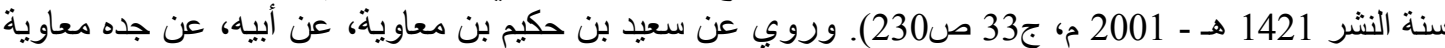

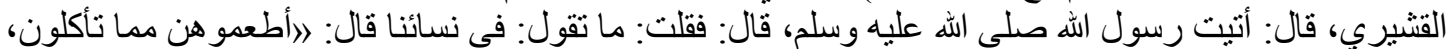

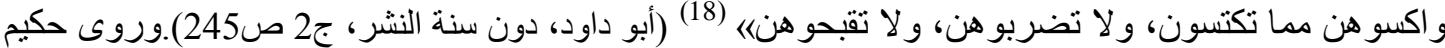

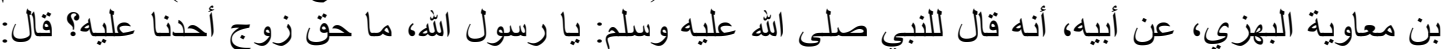

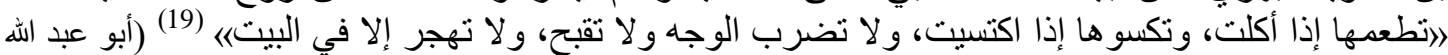

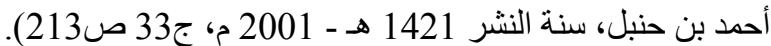

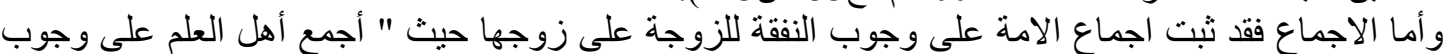

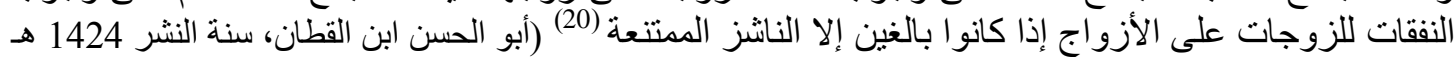

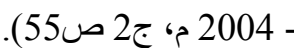

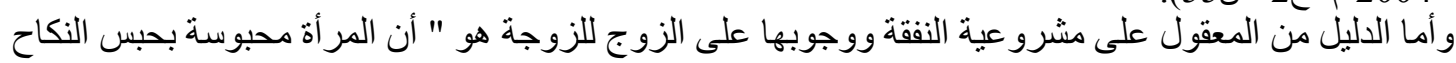

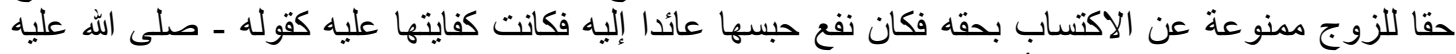

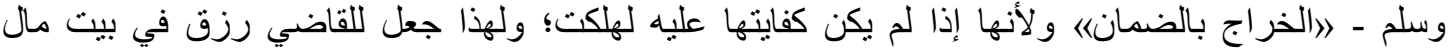




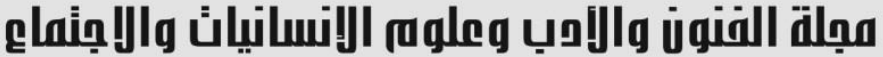 \\ Journal of Arts, Literature, Humanities and Social Sciences} www.jalhss.com

المسلمين لحقهم؛ لأنه محبوس لجهنهم ممنوع عن الكسب فجعلت نفقته في مالهم وهو بيت المال كذا هينا (21)

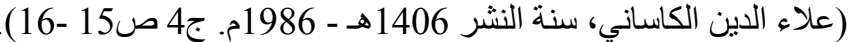

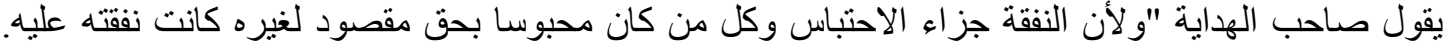

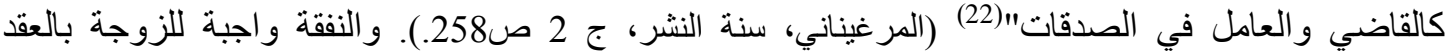

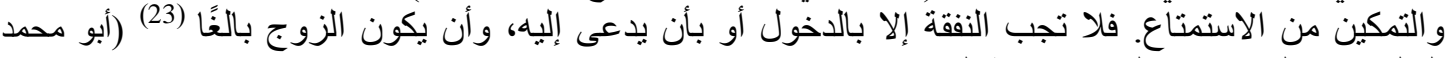

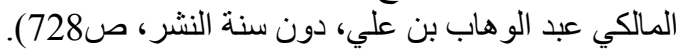

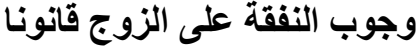

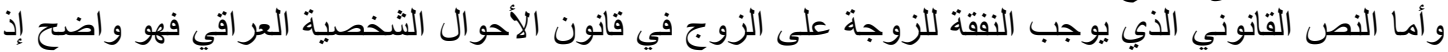

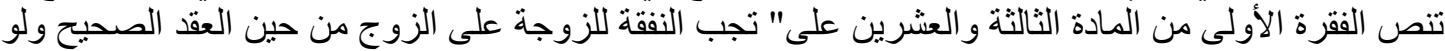

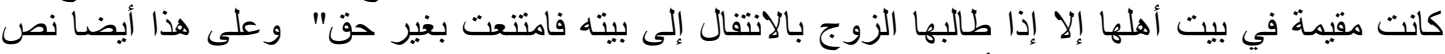

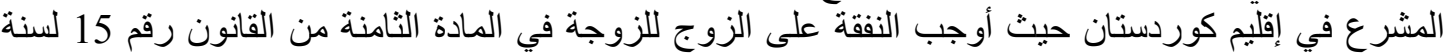

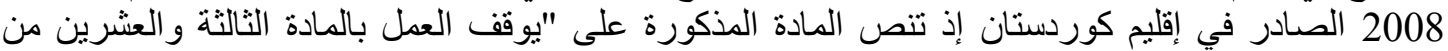

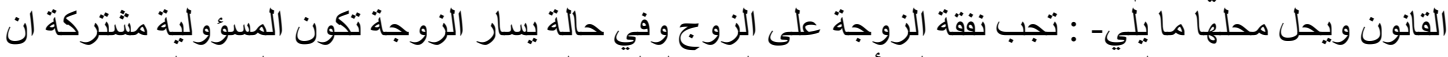

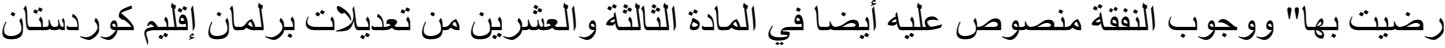

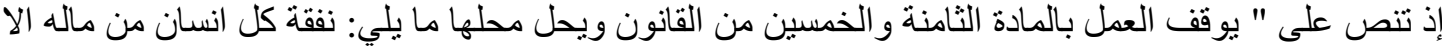

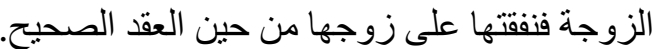

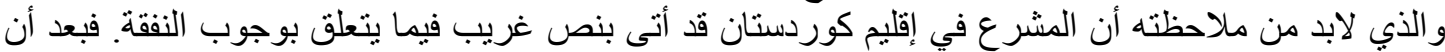

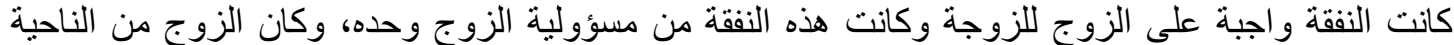

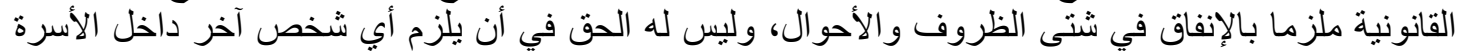

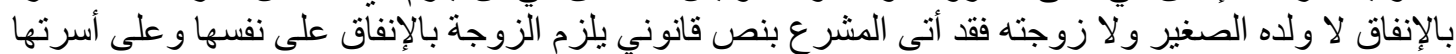

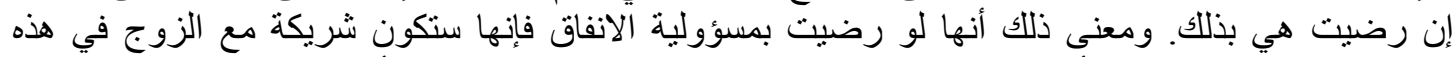

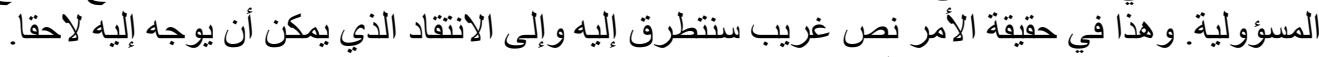

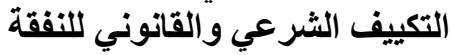

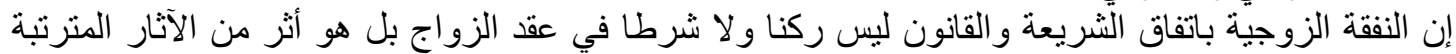

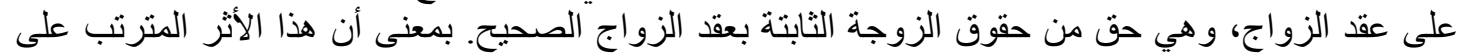

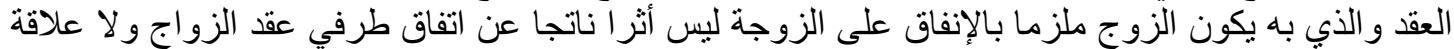

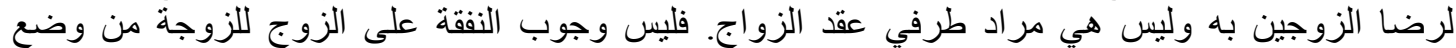

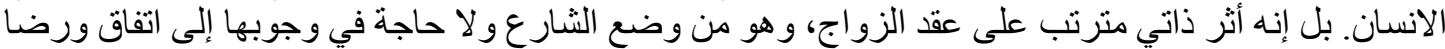

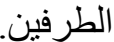

سبب وجوب النفقة الزوجية

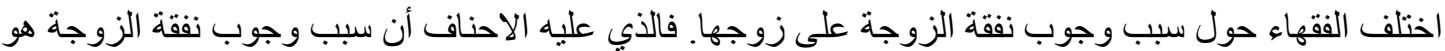

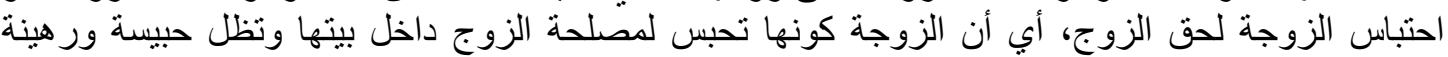

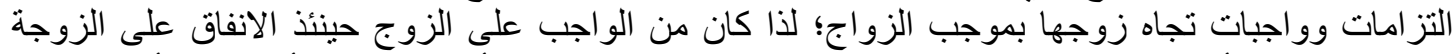

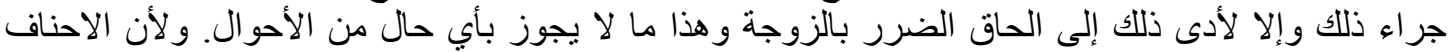

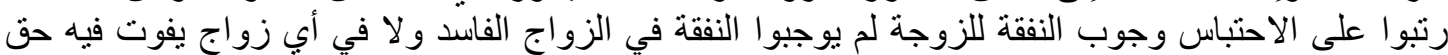

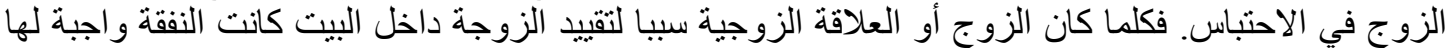

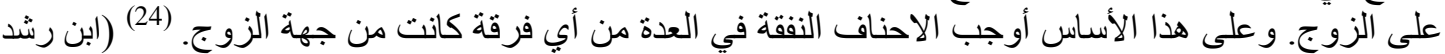

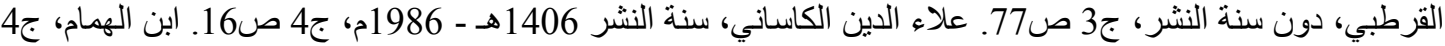

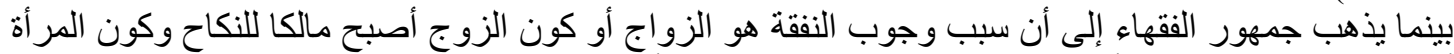

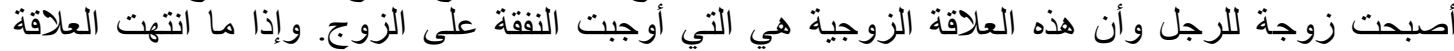

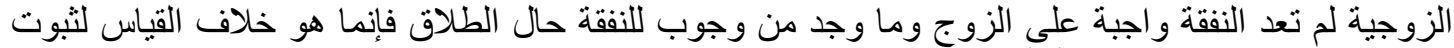

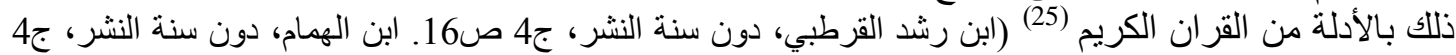

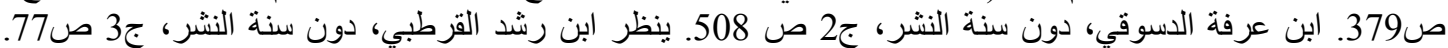




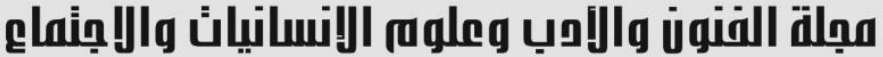 \\ Journal of Arts, Literature, Humanities and Social Sciences} www.jalhss.com

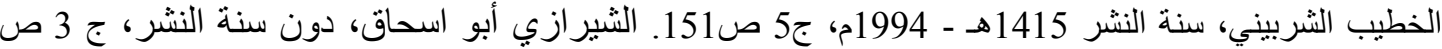

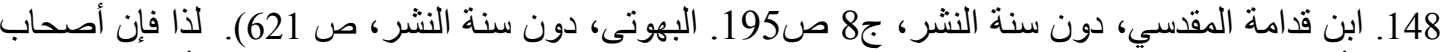

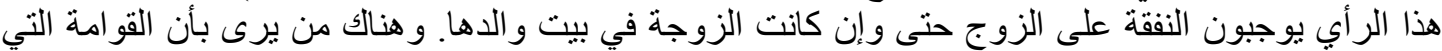

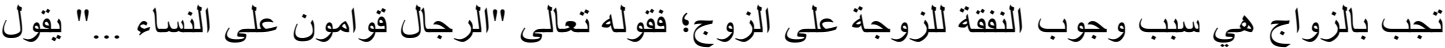

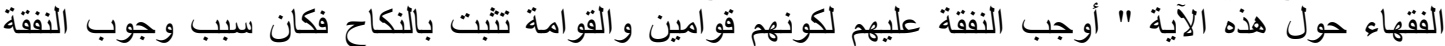

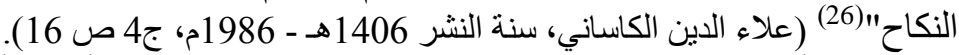

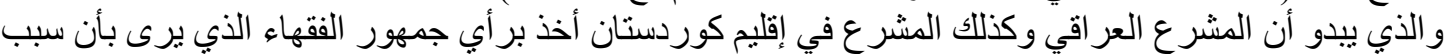

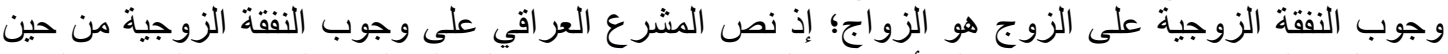

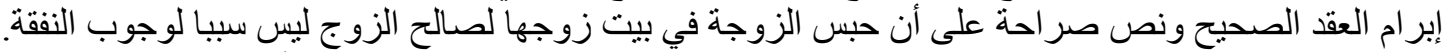

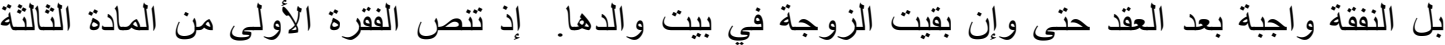

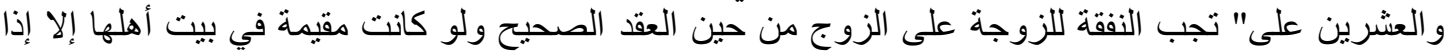

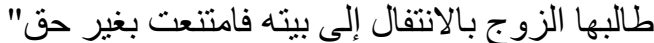

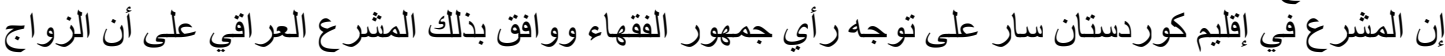

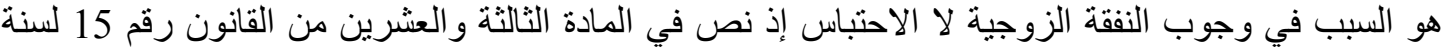

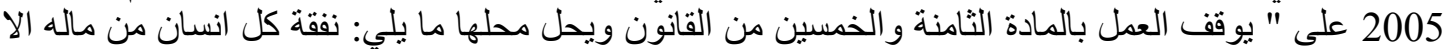

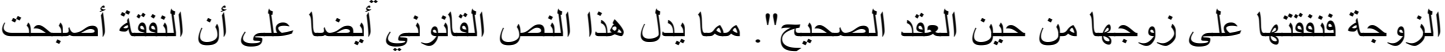

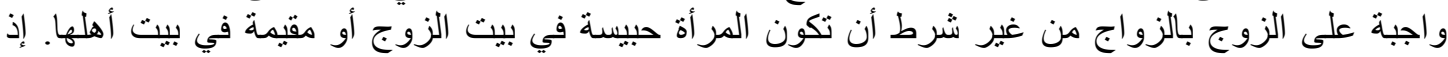

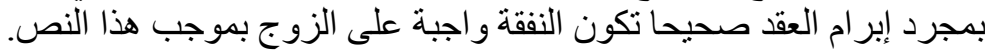
إنه من المدكن ان يكون هذا النص القانوني دليلا على وقت وجوب الزئ النفقة قانونا، وهو وقت ابر ام العقد لا وقت

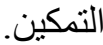
شروط وجوب النفقة الزوجية

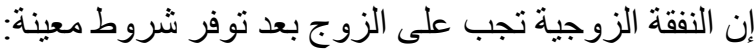
او لان: العقد الصحيح ثانيا: عدم امتتاعها عن الانتقال إلى بيت الزوجية. فإن امتنعت عن الانتقال بلا عذر فلا نفقة لها بالاتفاق.

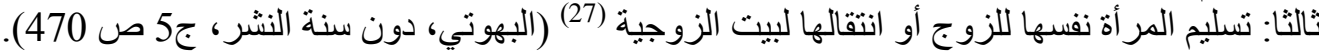

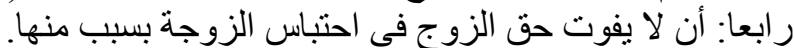

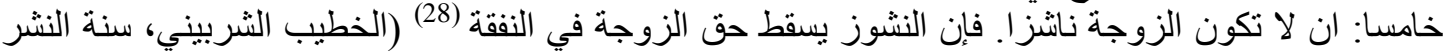

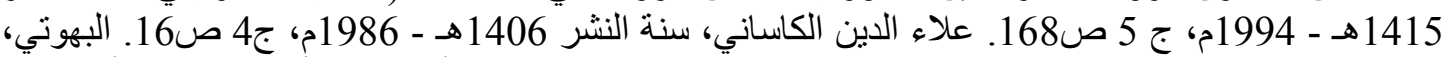

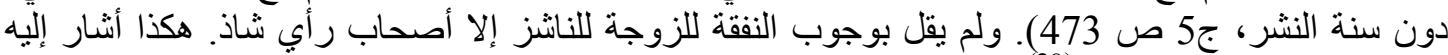

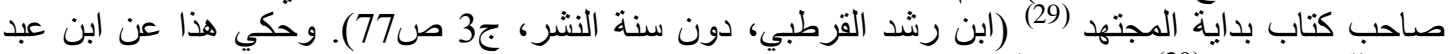

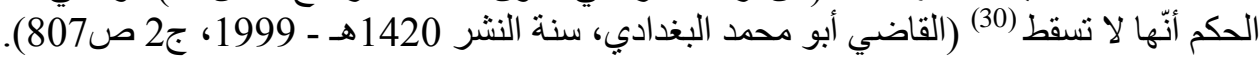

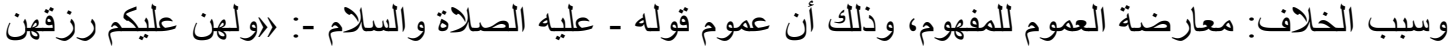

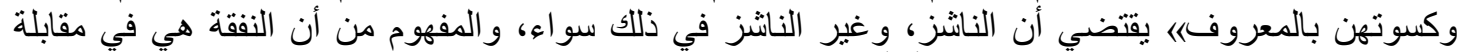

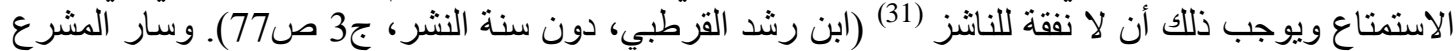

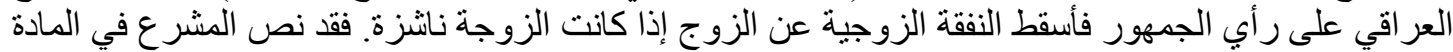

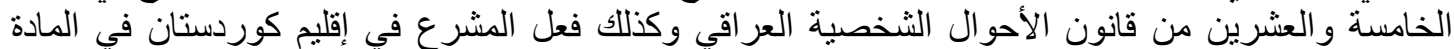

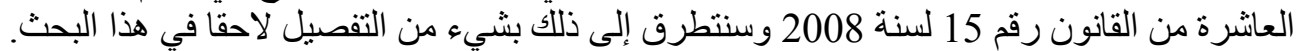

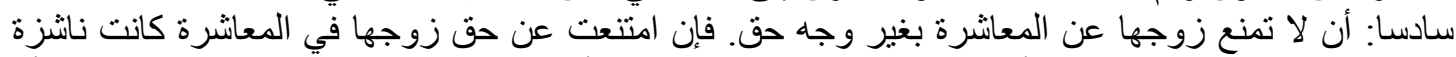

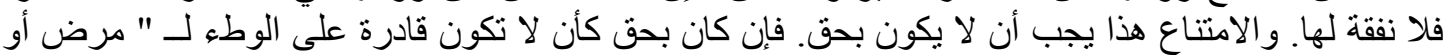

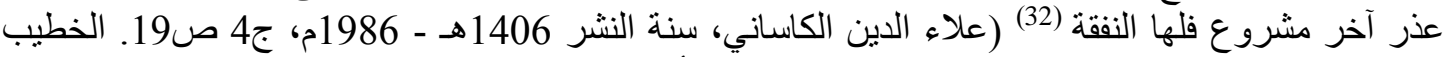

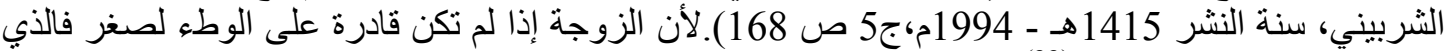

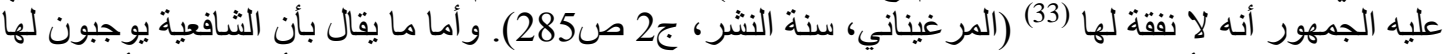

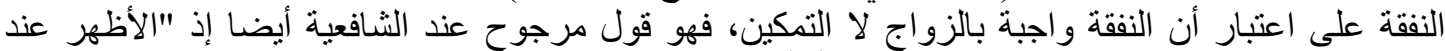
الثنافعية أن لا نفقة لصغيرة لا تحتمل الوطء (34) (الخطيب الثربيني، سنة النشر 1415هـ - 1994م، ج5 


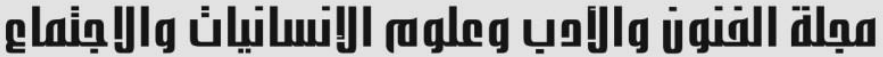

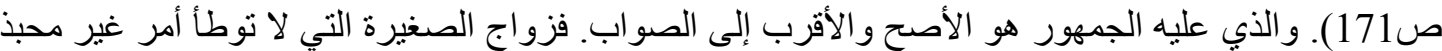

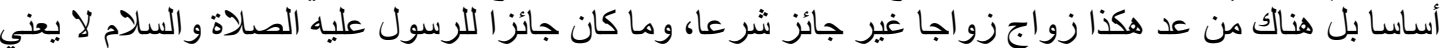

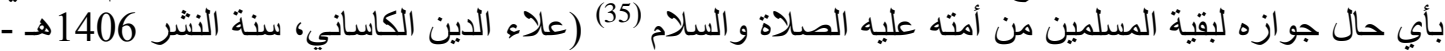

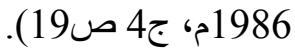
و أما إن لم يكن الوطء ممكنا في حق الزوجة لسبب راجع إلى الزوج فلها النفقة (36) (البهوتي، دون سنة النشر،

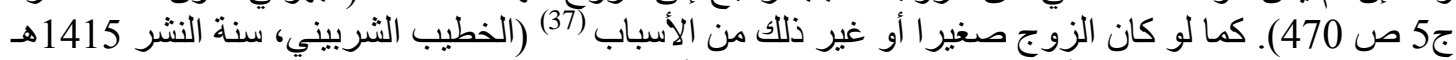

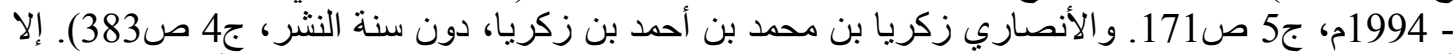

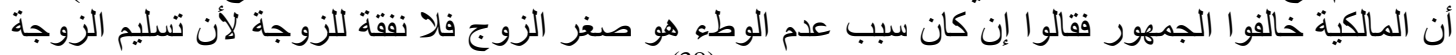

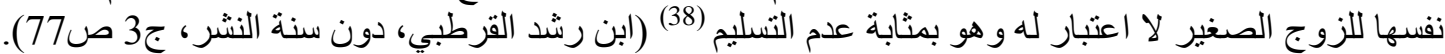

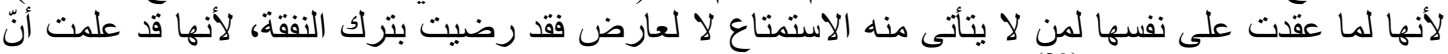

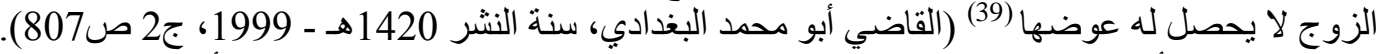

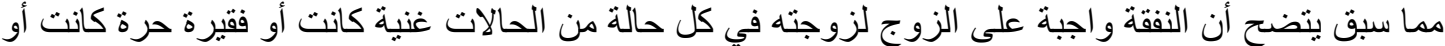

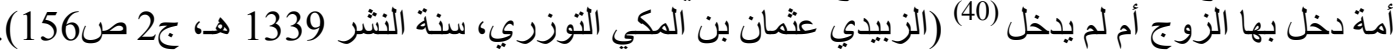

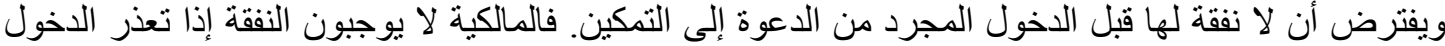

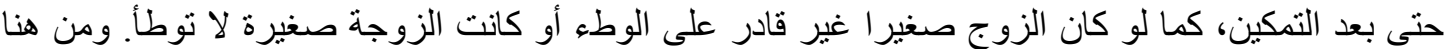

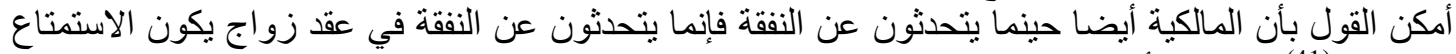

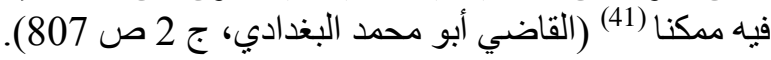

\section{مسؤولية الزوجة الثباني عن الانفاق}

الأصل أن النفقة واجبة على الزوج للزوجة والأو لاد و هذا أمر مجمع عليه و لا خلاف في ذلاك. عليه فلا نفقة على الزي

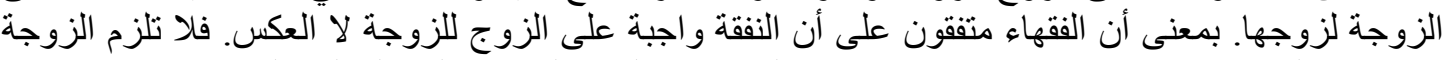

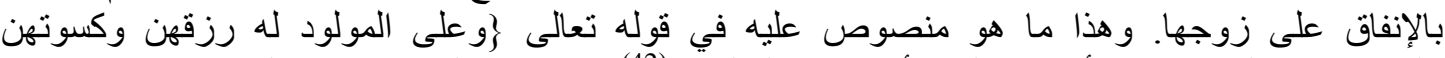

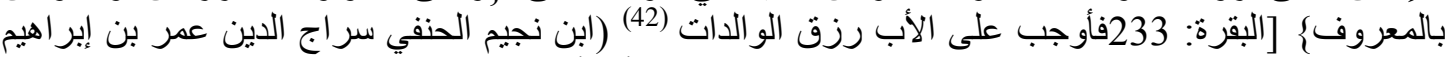

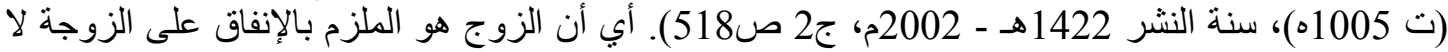
الزوجة على زوجها.

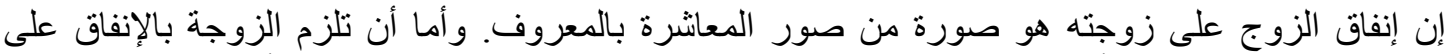

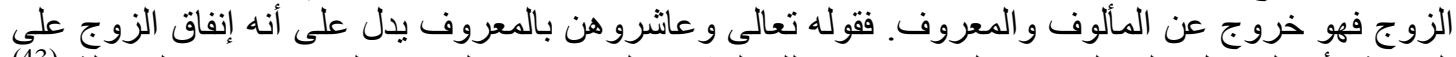

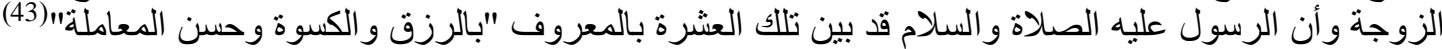

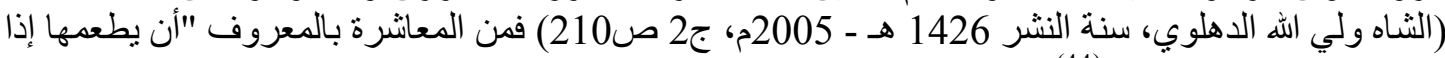

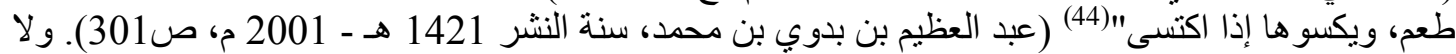

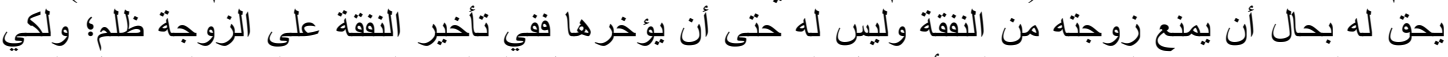

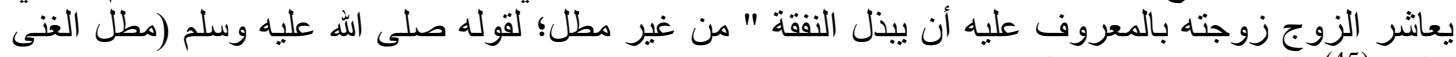

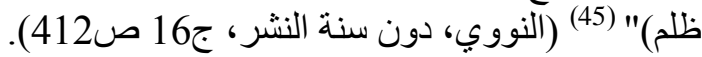

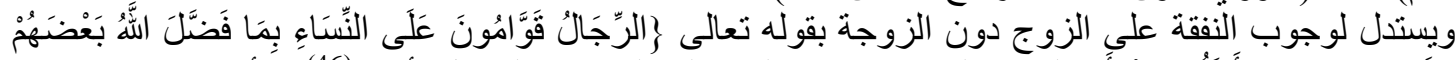

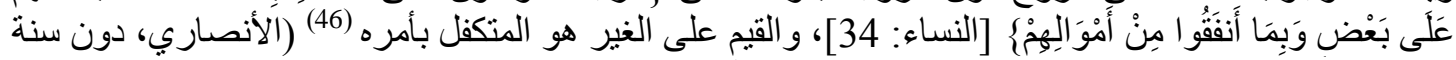

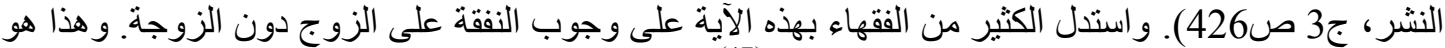

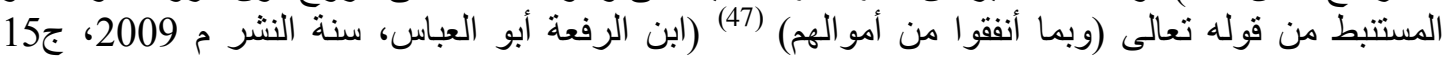

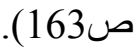

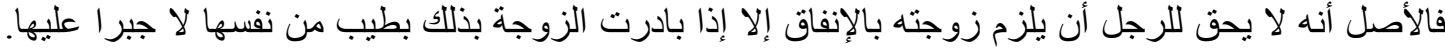

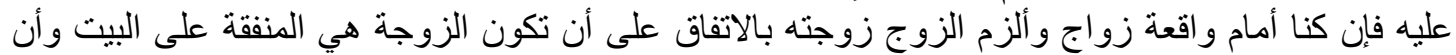




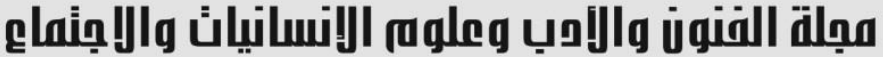

,

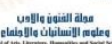

Journal of Arts, Literature, Humanities and Social Sciences www.jalhss.com

Volume (54) July 2020
العدد (54) يوليو 2020

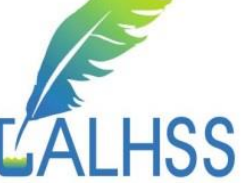

الزوجة ما قبلت بهذا الاتفاق إلا اضطرارا فإن هكذا اتفاق لا يصح ويدخل في باب أكل أموال الناس بالباطل وليس بالرضا وطيب النفس.

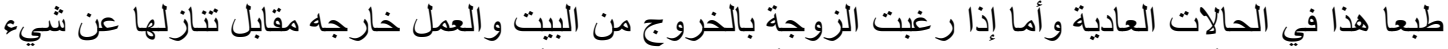

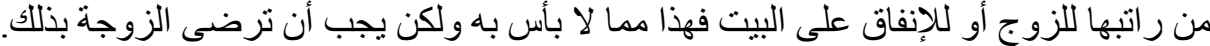

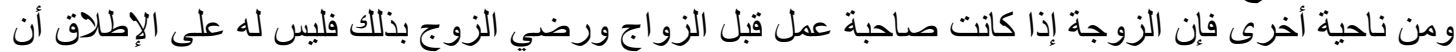

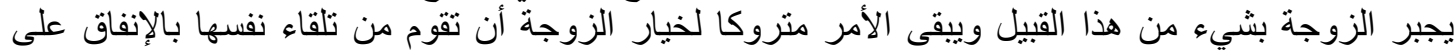

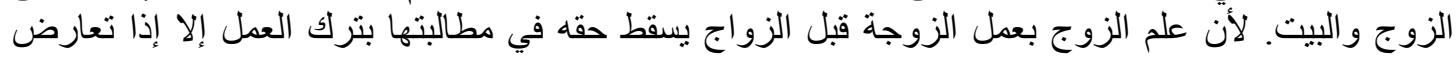

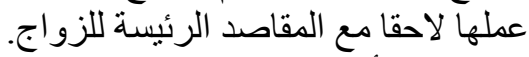

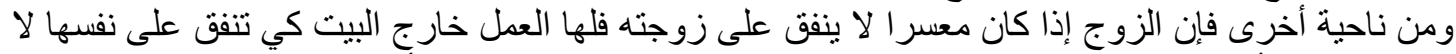

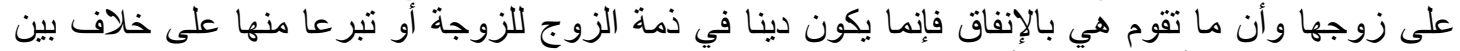

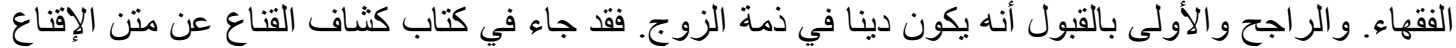

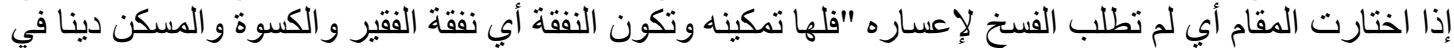

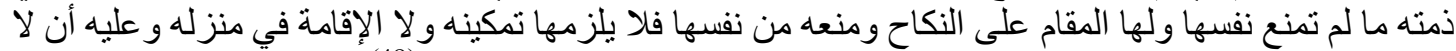

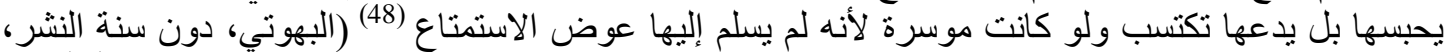

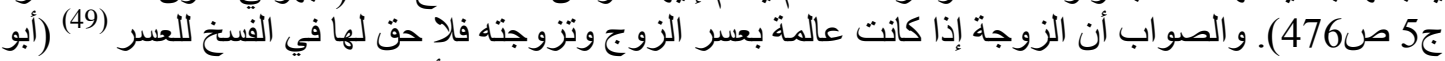

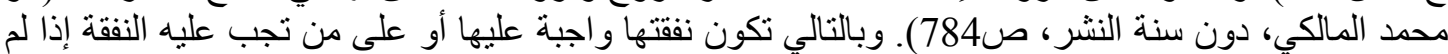

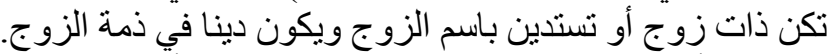

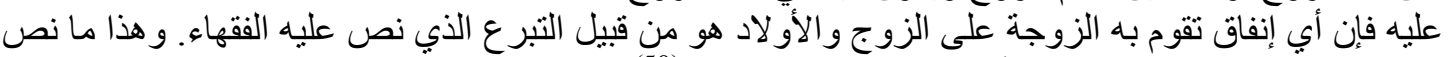

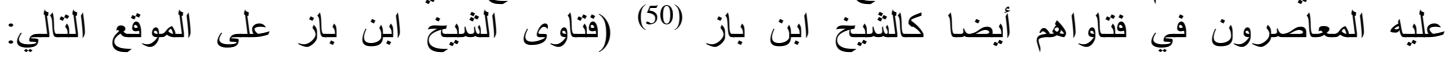

(ttps://binbaz.org.sa/fatwas إن الثرع و القانون يعتبره دينا في ذمة الزوج فقد نص المشرع الثران العر اقي في المادة الثثلاثين من قانون الأحوال

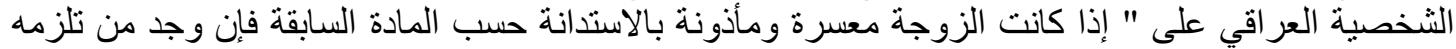

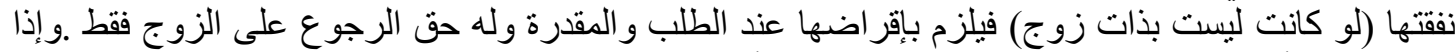

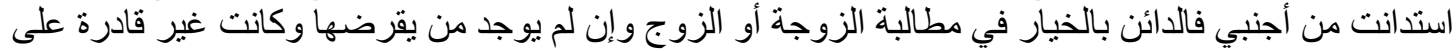

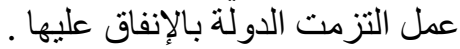
و أما المشرع في إقليم كوردستان فقد عدّل مسألة النفقة الزوجية من كونها نفقة واجبة على الزئل الزوج فقط.

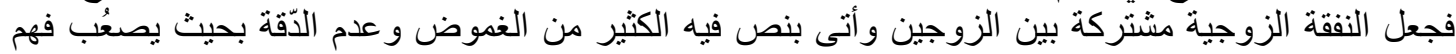

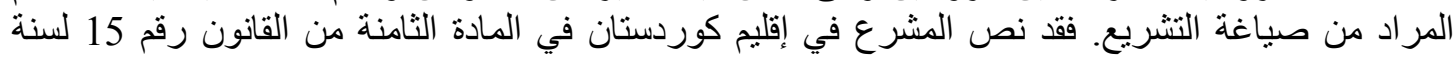

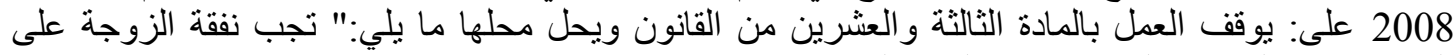

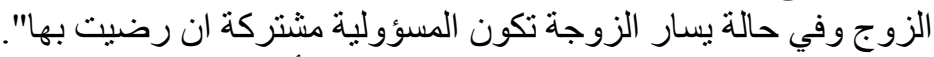

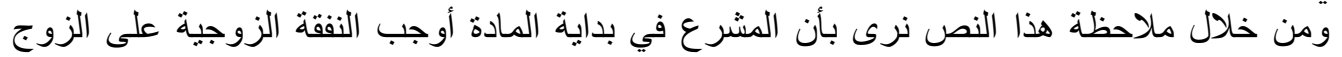

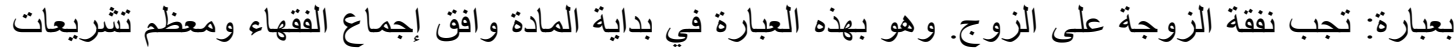

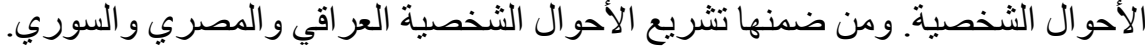

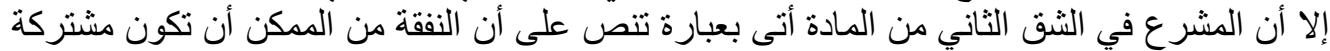

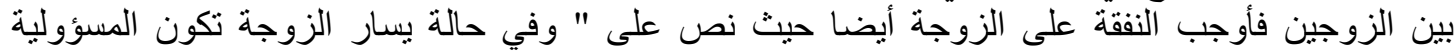

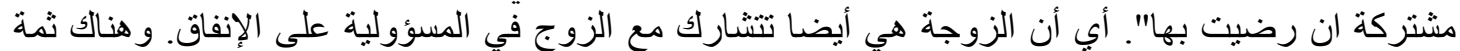
ملاحظات إيجابية تورد على هذا النص وأخرى الزوهي سلبية سنتطرق إليها في النقاط النالية:

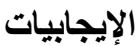

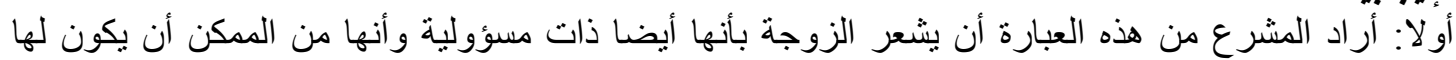

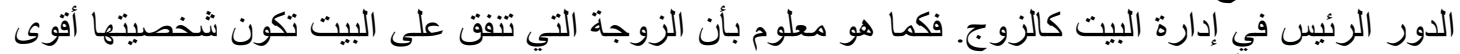

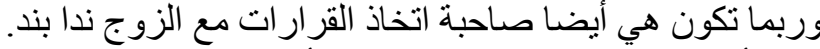

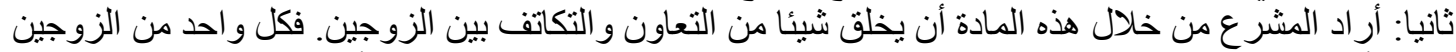
ملزم بأن يعين الآخر فيما يقدر عليه. وامتناعه عن المعاونة مع القدرة فيه شيء من الأنانية و عدم المبالاة. 


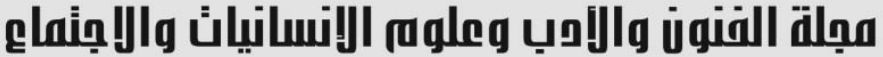 \\ . \\ Journal of Arts, Literature, Humanities and Social Sciences} www.jalhss.com

ثالثا: ربما أراد المشرع بهذه العبارة أن يضع العقبات و العر اقيل أمام الطلاق عند هذين الزوجين فيما إذا كانت

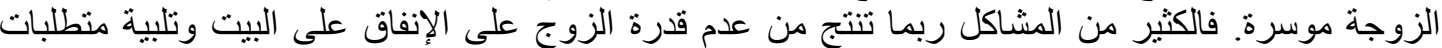

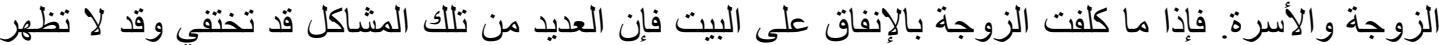

رابعا: ربما في هذا الإلز ام شيء من التوازن في عملية الاسر اف داخل البيت. فإذاذا ما كلفت الزوجة الزئ أيضا بالإنفاق

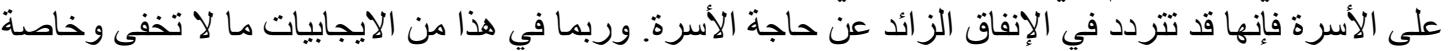

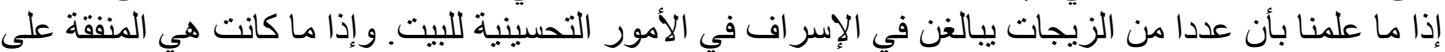

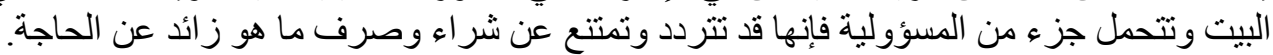

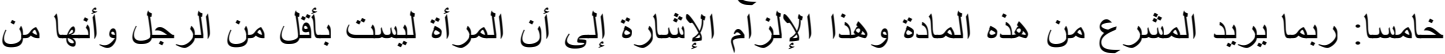

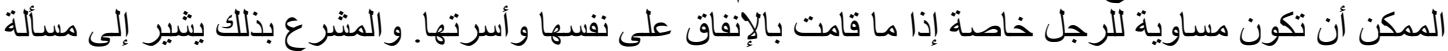

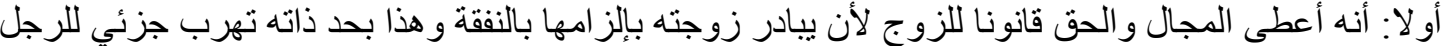

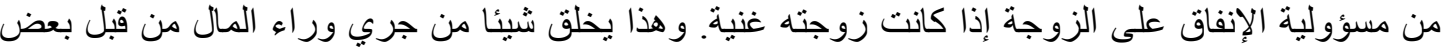

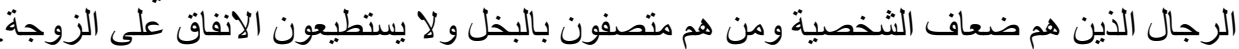

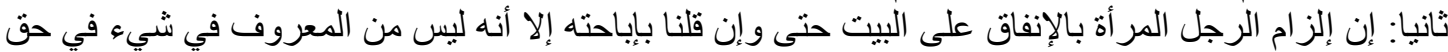

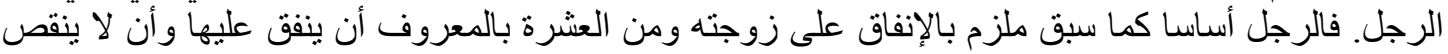
من حقها شيئا. ثالثا: إن إلزام المرأة بالإنفاق هو تنقيص من حقها في النفقة. إذ الزوجة بالعقد عليها تستحق النفقة سواء أكانت

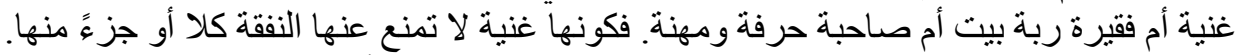

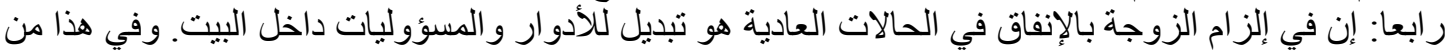
العبثية و الفوضى التي لا لإن يمكن إنكار ها. خامسا: إن المر أة ليست كالرجل فيما لإلو كلفت بالإنفاق، فالرجل مكلف في شتى الأحوال بالإنفاق إلا في حالات

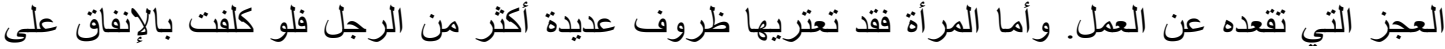

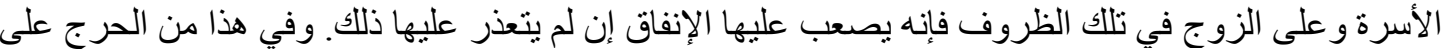

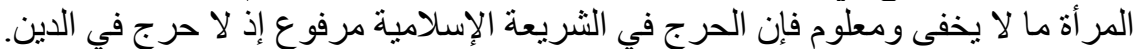

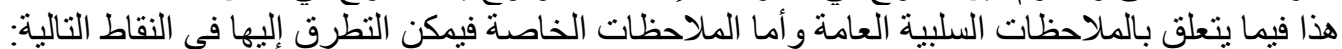

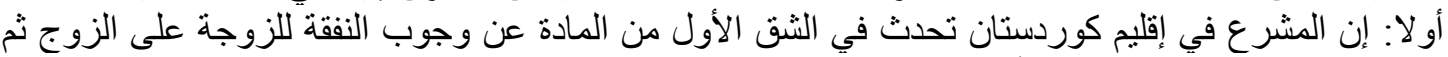

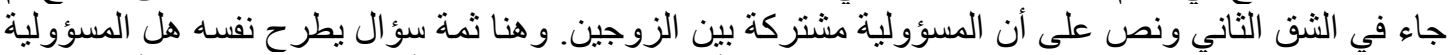

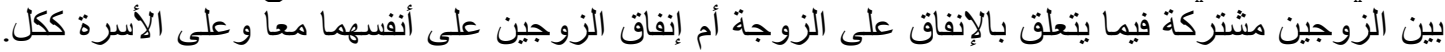

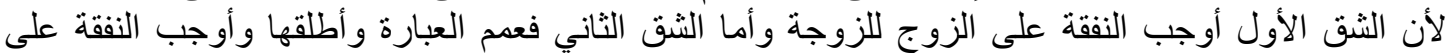

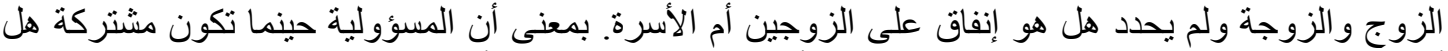

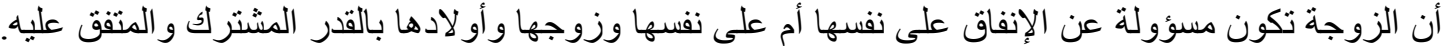

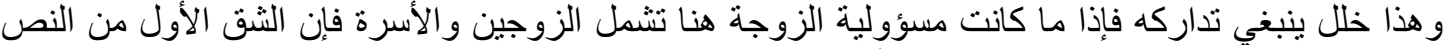

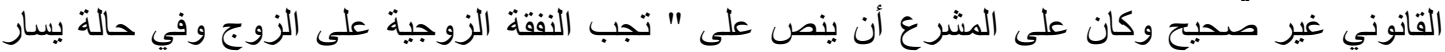

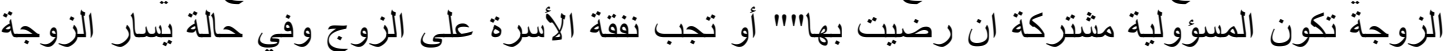

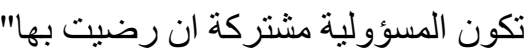

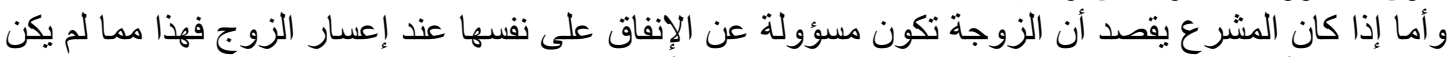

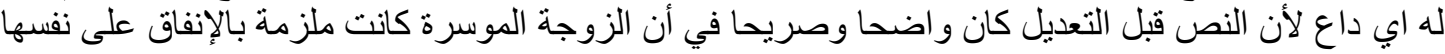

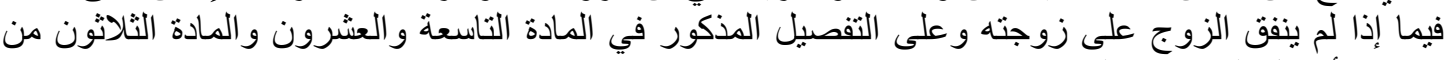

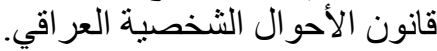

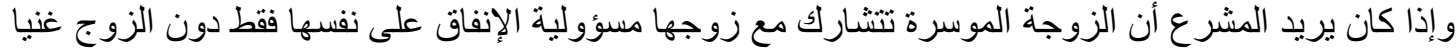

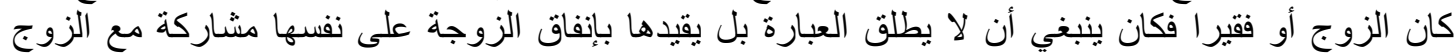

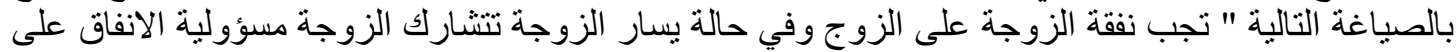




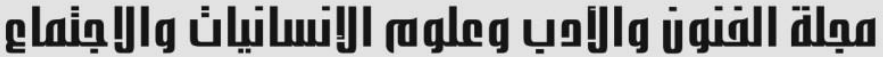 \\ . \\ Journal of Arts, Literature, Humanities and Social Sciences} www.jalhss.com

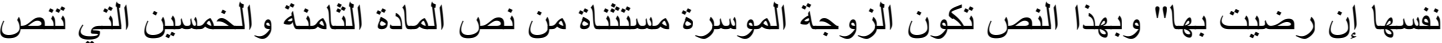

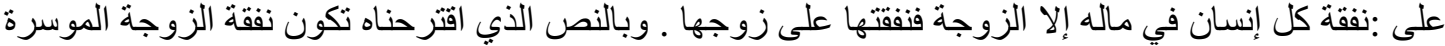

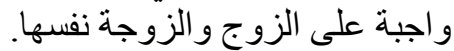

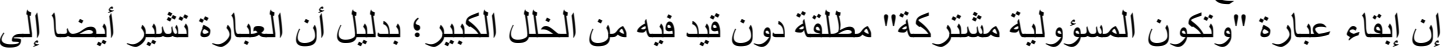

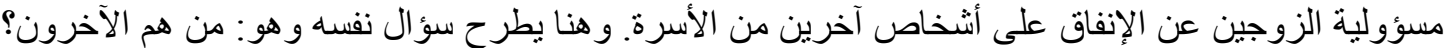

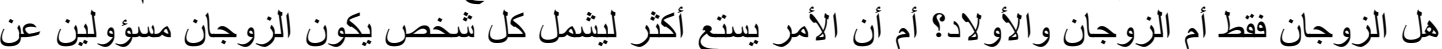

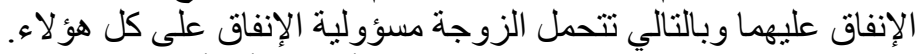

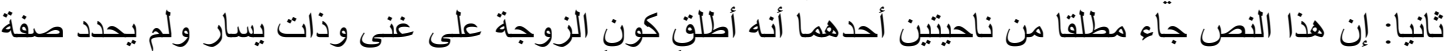

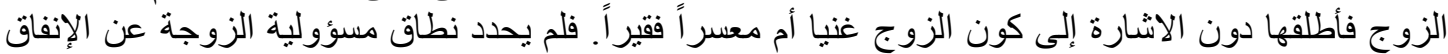

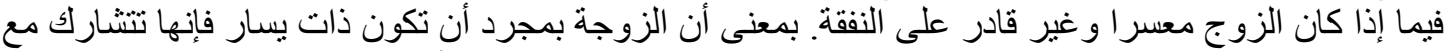

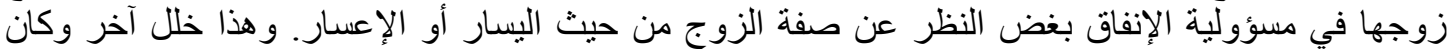

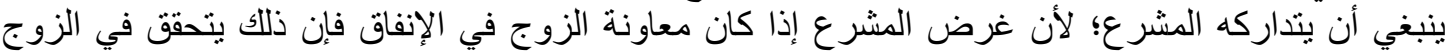

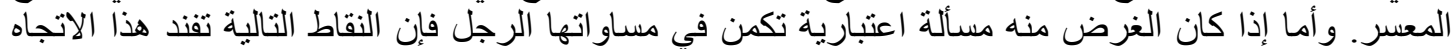

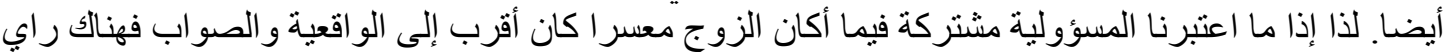

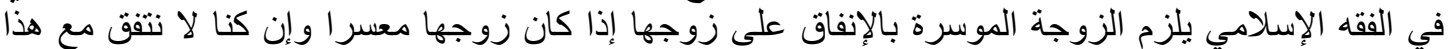

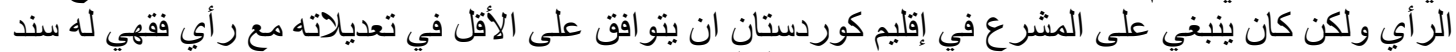

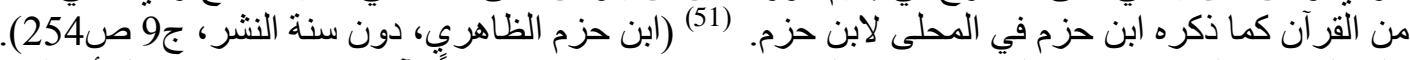

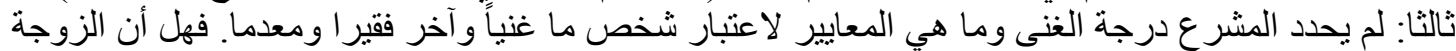

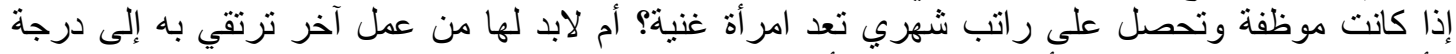

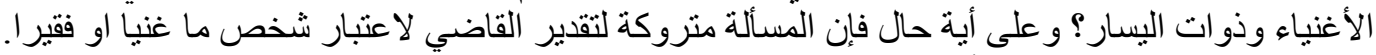

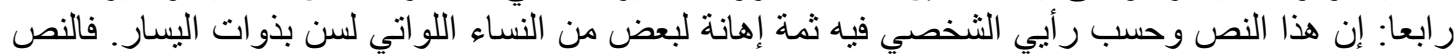

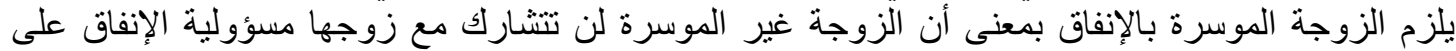

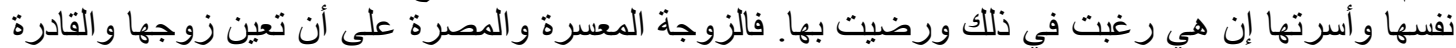

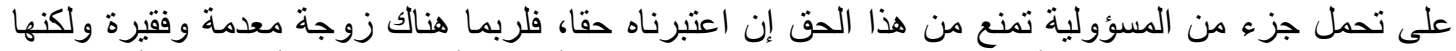

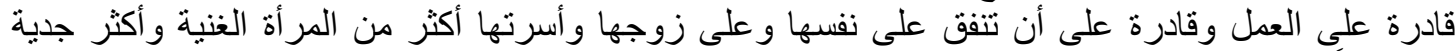

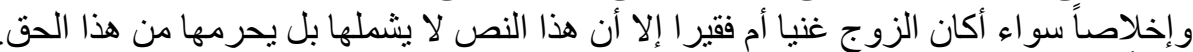

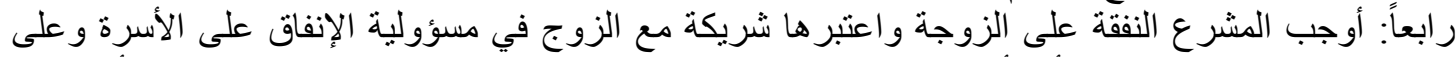

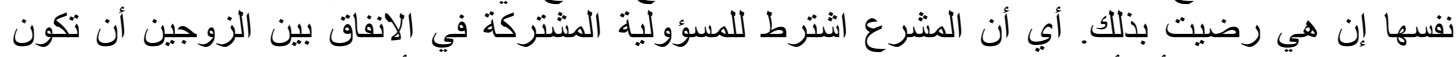

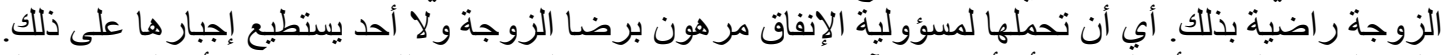

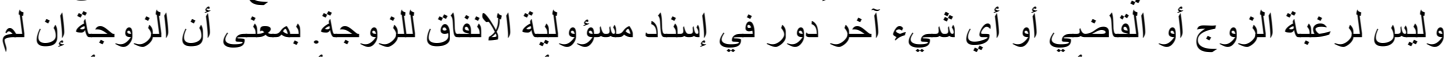

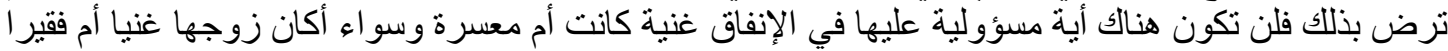

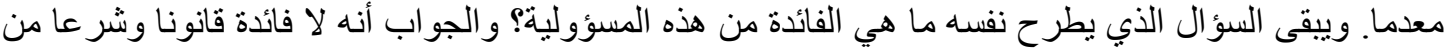

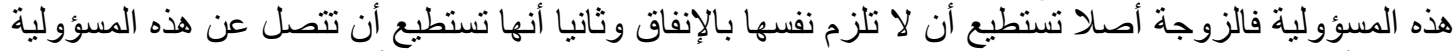

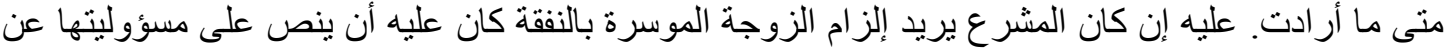

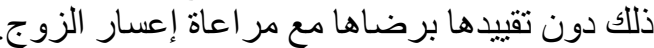

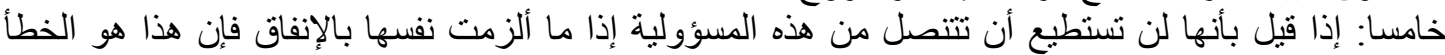

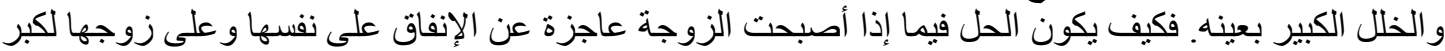

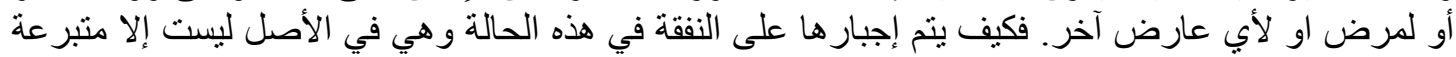

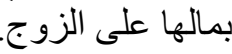
لما مرّ يمكن القول بإن الانتقادات السابقة تقلل من القيمة القانونية والثر عية لهذا النص بالصيغة التي أتى بها

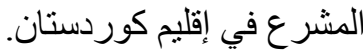




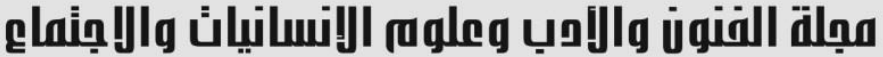

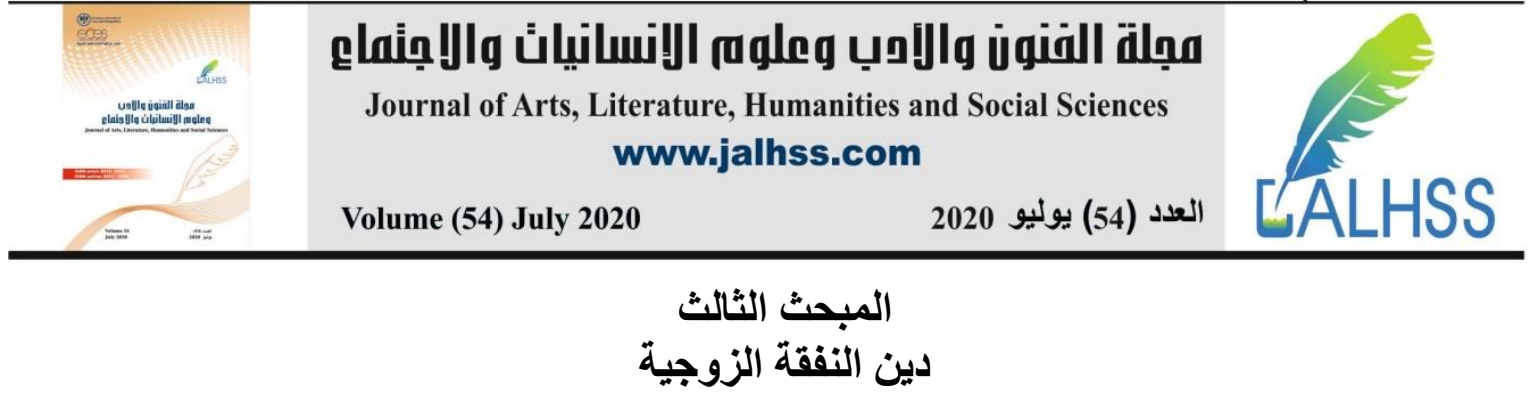

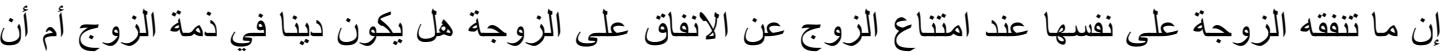

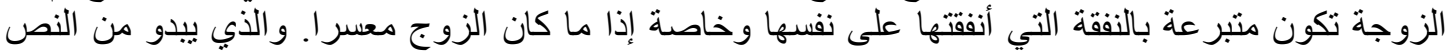

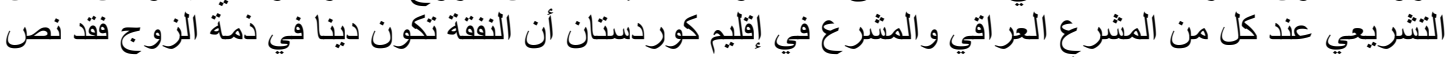

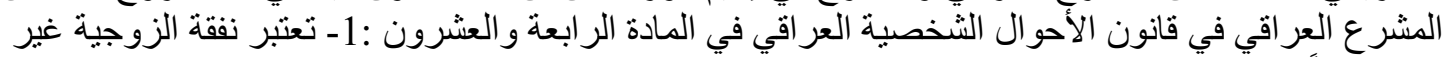

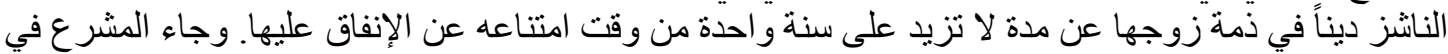

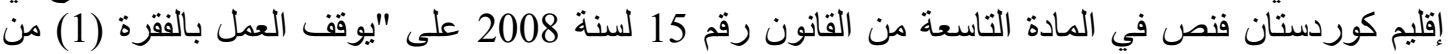

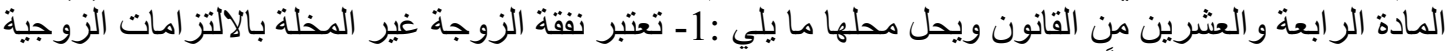

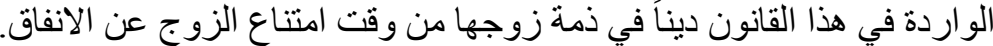

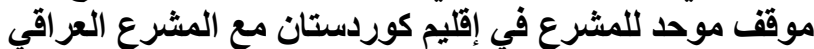

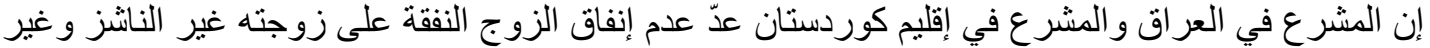

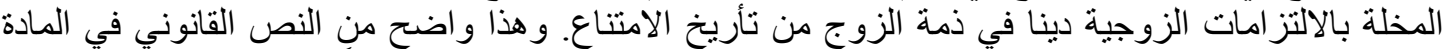

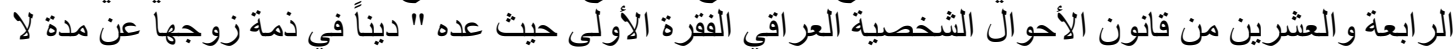

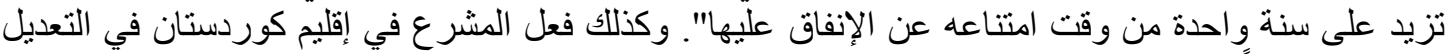

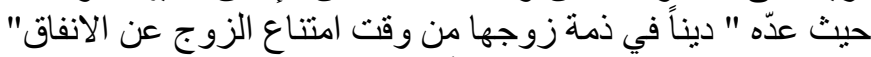

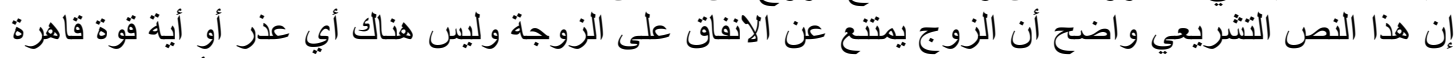

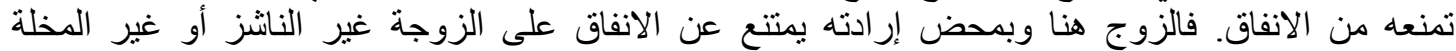

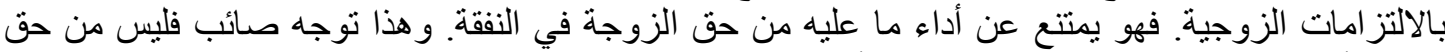

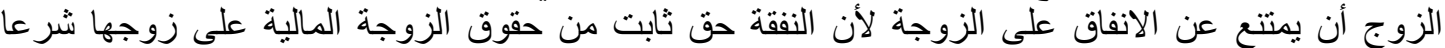

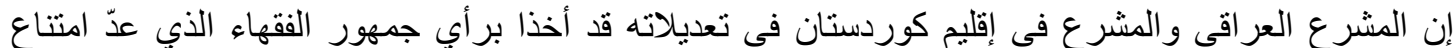

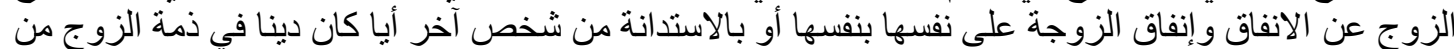

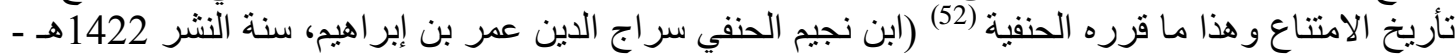

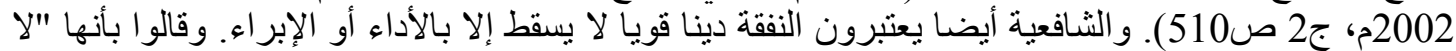

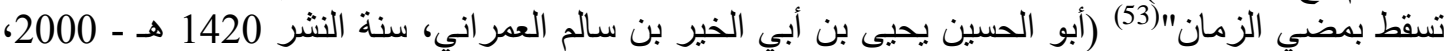

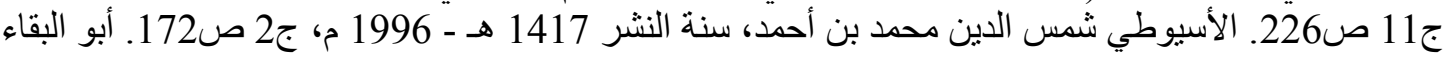

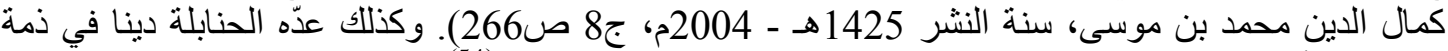

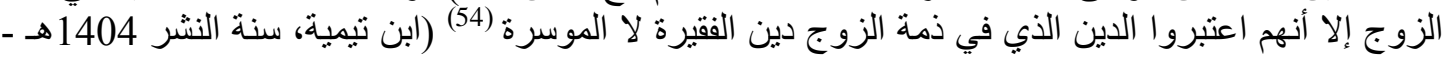

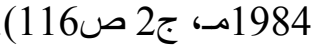
أما المالكية فلا يعتبرون امتتاع الزوج عن الانفاق دينا في ذمة الزوج إذإذا كان امتتاعه لعذر وجعلوا الإعسار

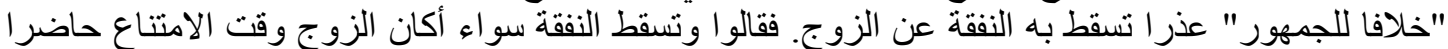

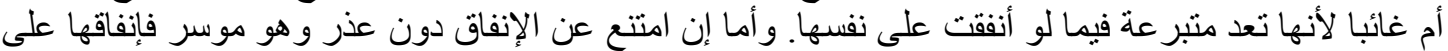

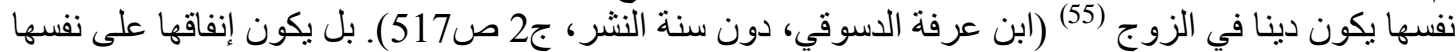

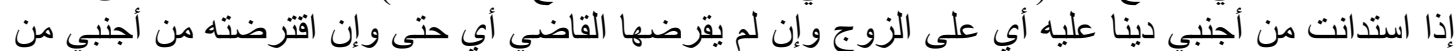

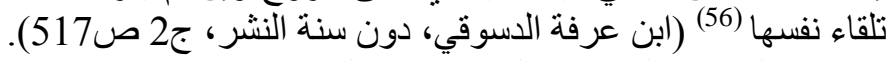

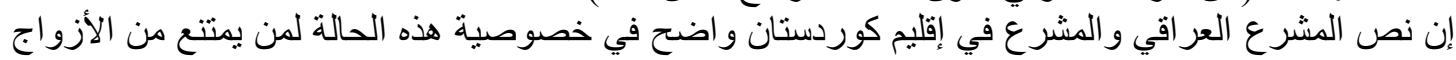

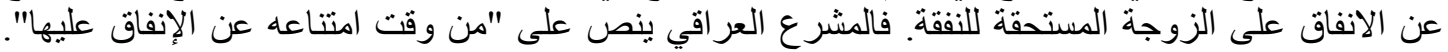

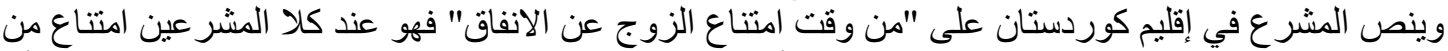

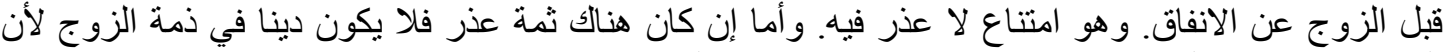
الزوجة لا تستحق النفقة إذ امتناعه عن الانفاق يكون حينذاك المتاك امتناعا بحق. 


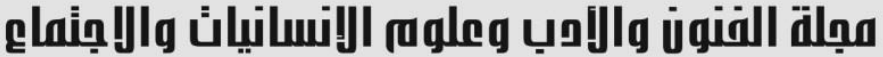

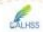 \\ Journal of Arts, Literature, Humanities and Social Sciences} www.jalhss.com

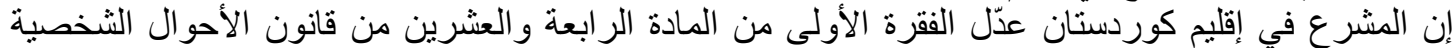

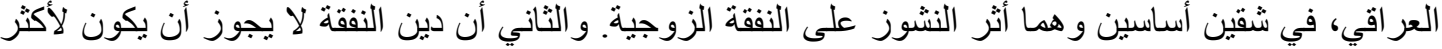

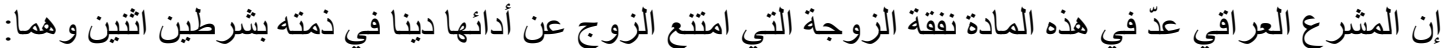

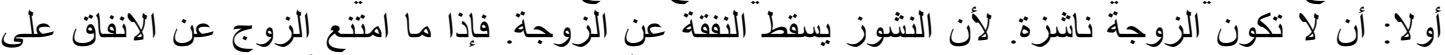

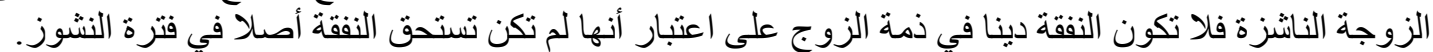

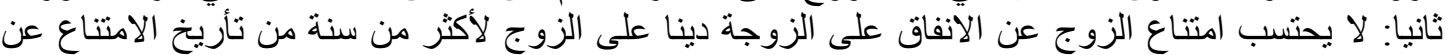

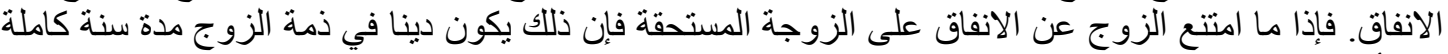

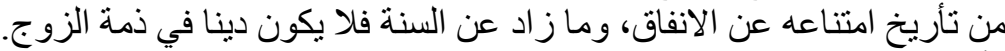

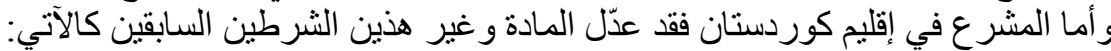

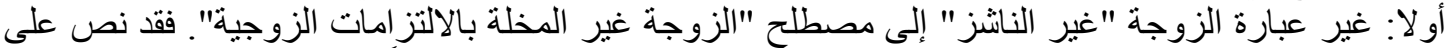

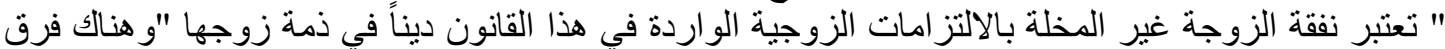

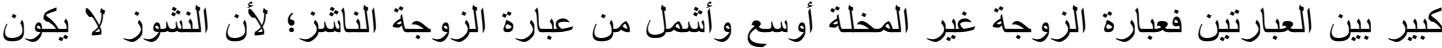

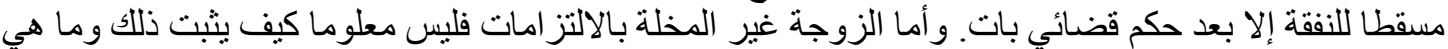

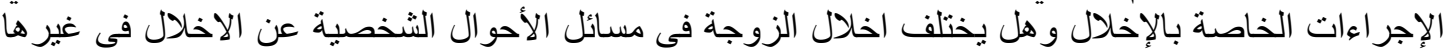

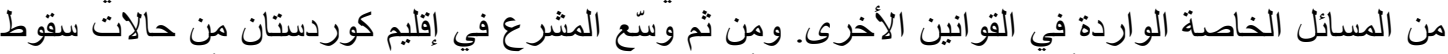

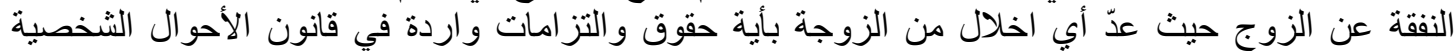

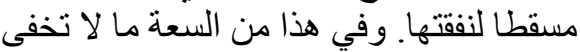

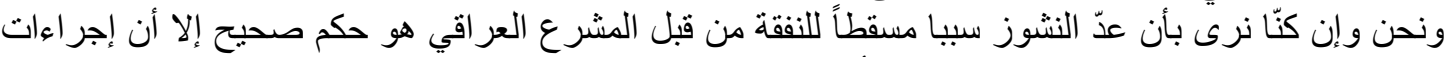

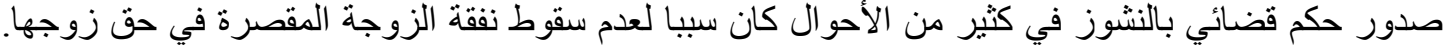

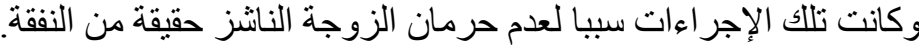

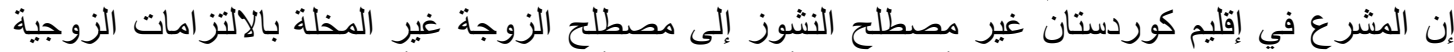

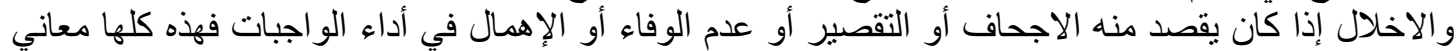

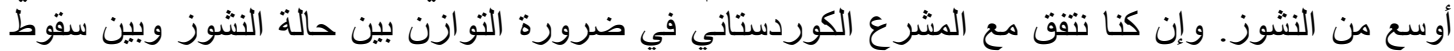

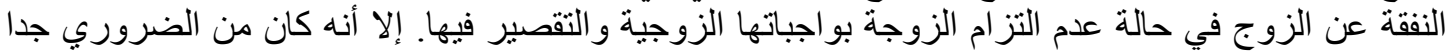

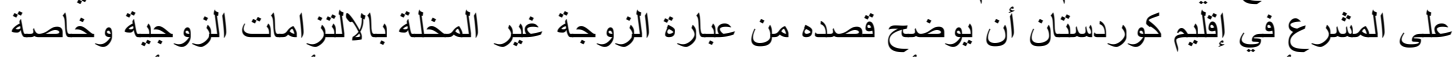

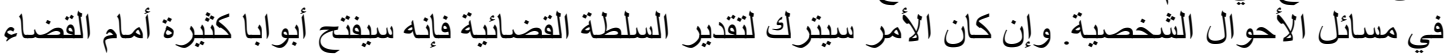

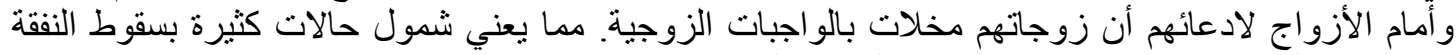

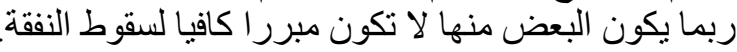

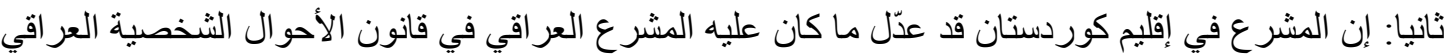

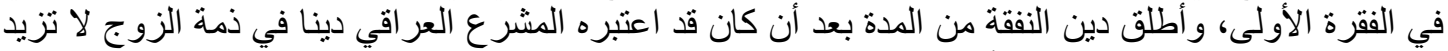

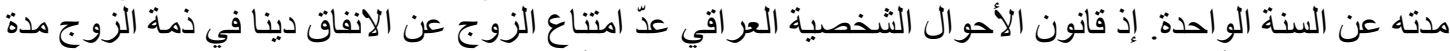

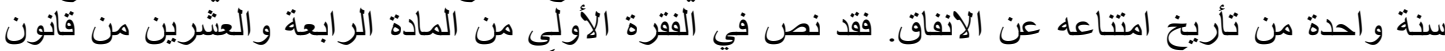

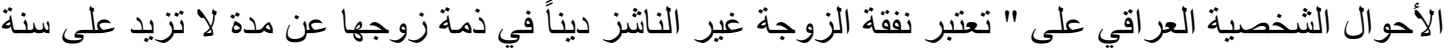

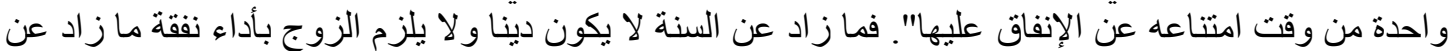

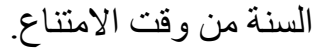

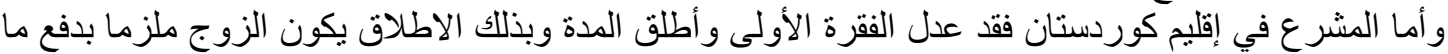

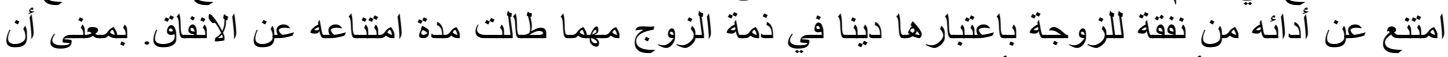

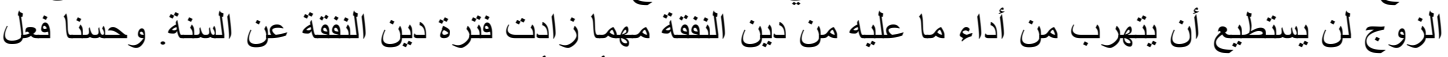

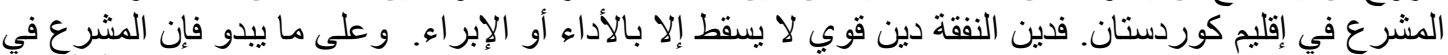

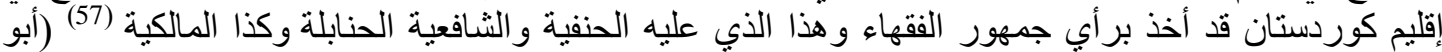

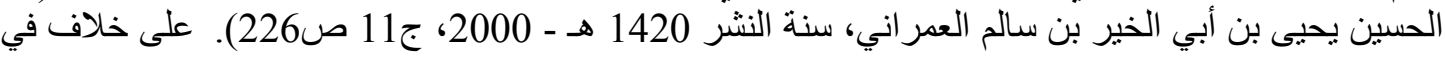




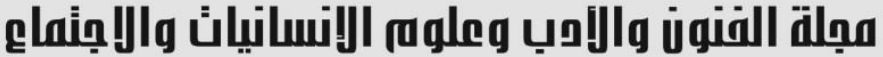 \\ Journal of Arts, Literature, Humanities and Social Sciences
}

\section{www.jalhss.com}

تفاصيل دين النفقة عند الحنفية (58) (أبو بكر بن علي بن محمد الحدادي العبادي الزبيدي، سنة النشر 1322هـ،

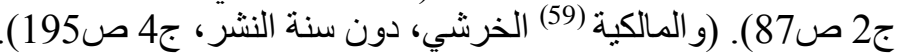

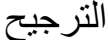

وفي حقيقة الأمر إن الترجيح بين موقفي المشرعين العر اقي والمشرع في إقليم كوردستان وبيان الصائب منهما

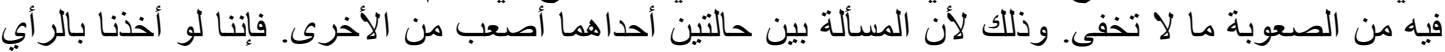

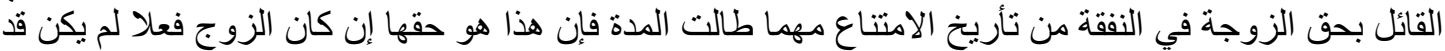

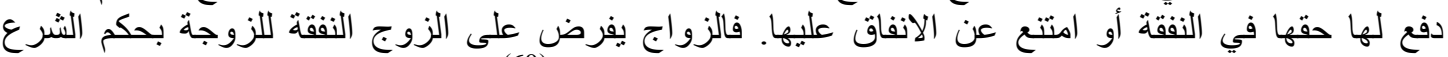

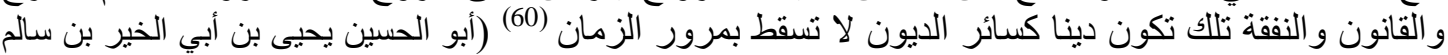

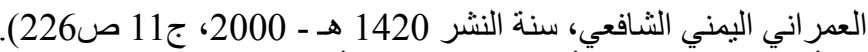

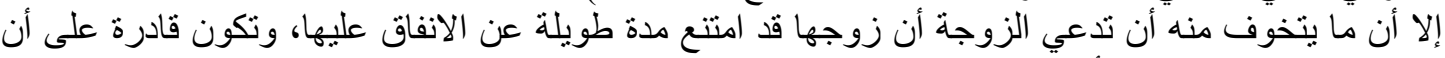

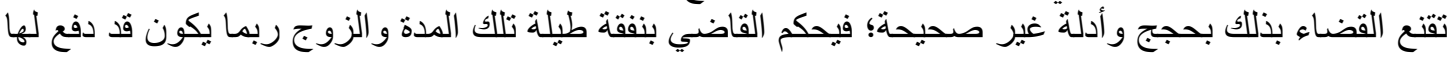

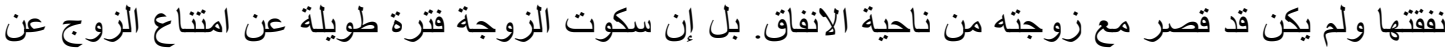

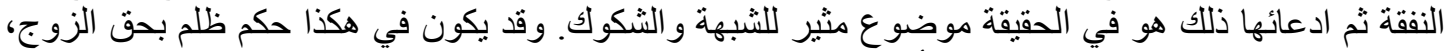

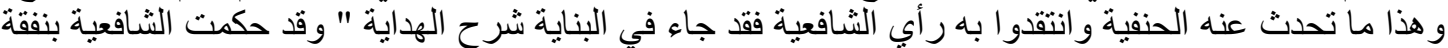

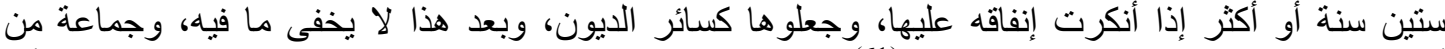

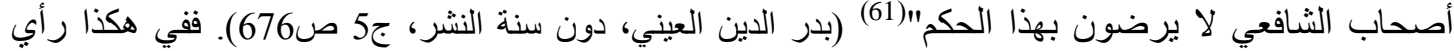

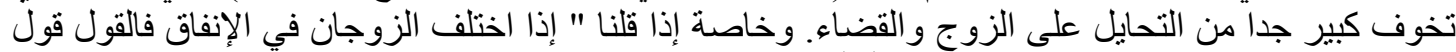

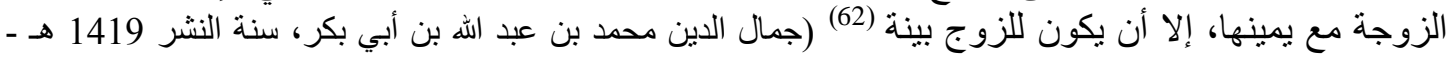

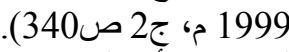

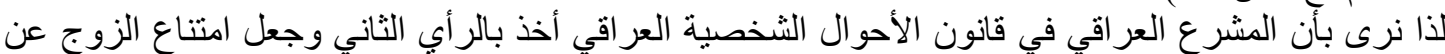

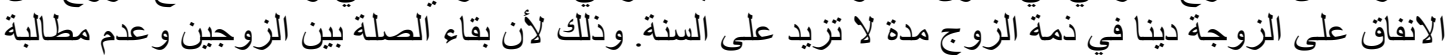

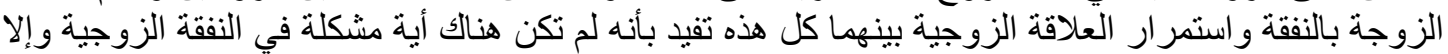

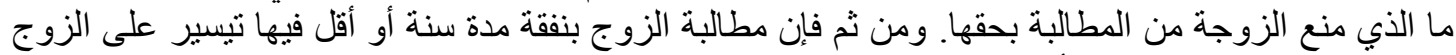

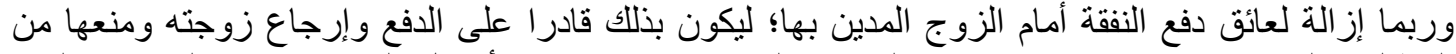

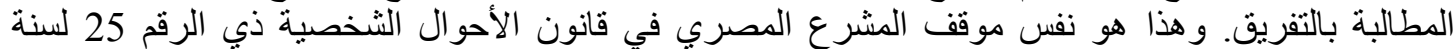

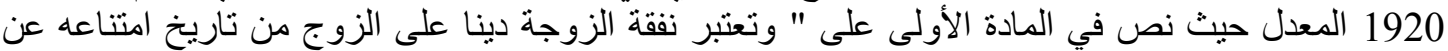

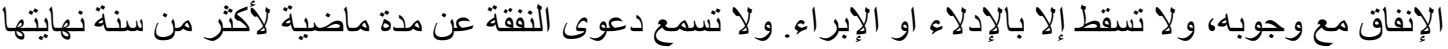

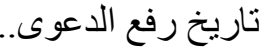
وبهذا أخذ المشر ع السعوري في المادة الثامنة و السبعين من قانون الأحو ال الشخصية السوري حيث نص على " 2

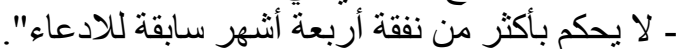
وبهذا أيضا أخذ قانون الأحوال النخصية الامار اتي حيث نص في في المادة النادية السابعة والستين على " تعتبر نفقة

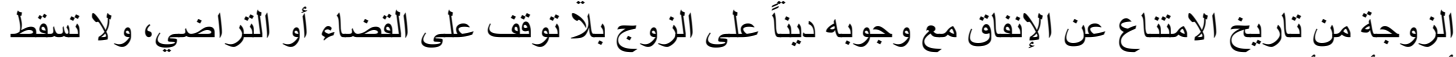

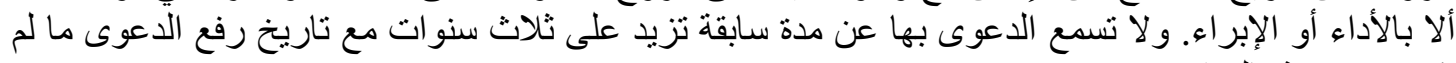

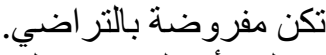

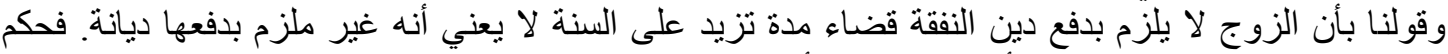

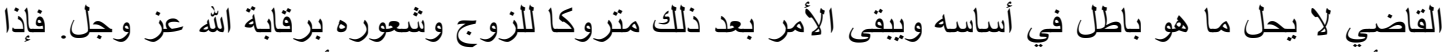
وجد أنه مع حكم القاضي لم يؤد دين النفقة كاملا للزوجة فيبقى ذلك دينا في ذمته و عليه أن يؤديه لها. لألها.

\author{
المبحث الرابع \\ تأثير النشوز وغياب الزوج في النفقة
}




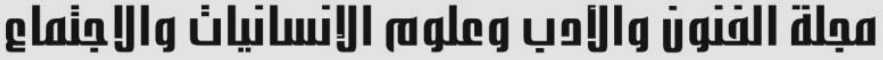

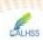

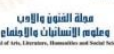

Journal of Arts, Literature, Humanities and Social Sciences www.jalhss.com

Volume (54) July 2020
العدد (54) يوليو 2020

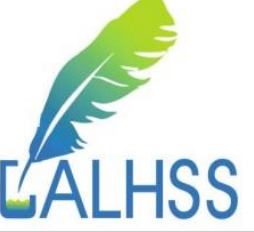

إن التعديل الذي أجراه المشرع على مواد النشوز هي أيضا جذرية ولن نتطرق إلى كل تفاصيل النشوز وما

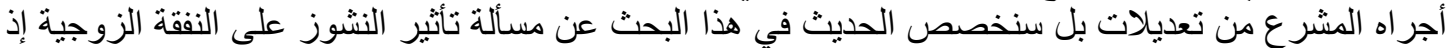

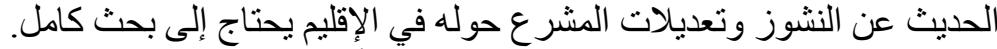

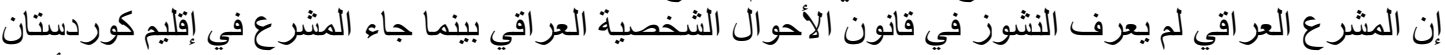

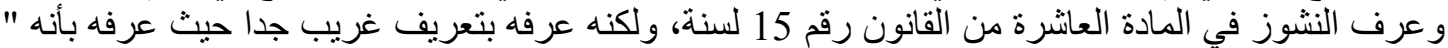

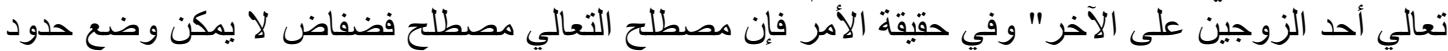

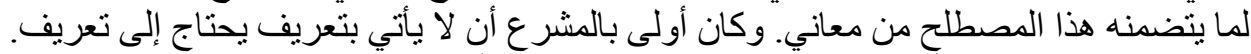

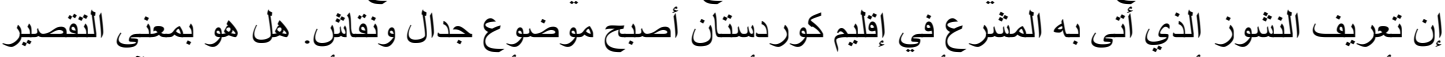

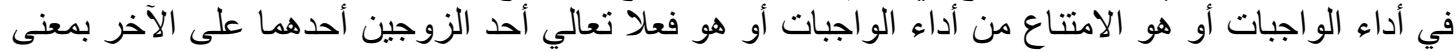
التكبر و إهانة الطرف الآخر وقلة الآلة احتر امه له له.

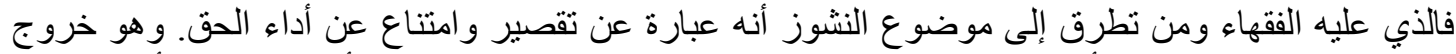

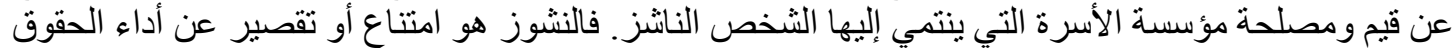

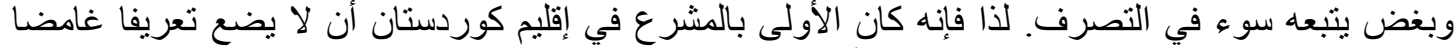

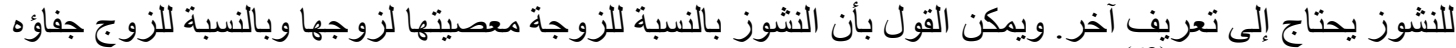

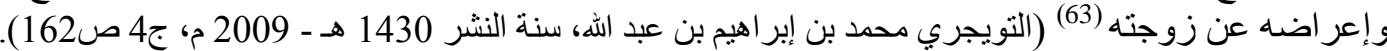
حرمان الزوجة الناثز من النفقة الزوجية

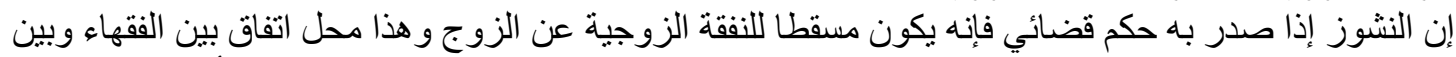

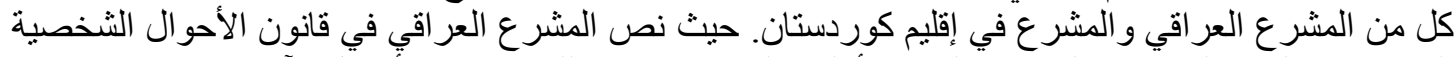

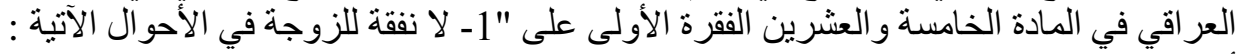

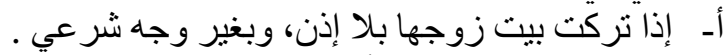

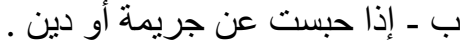

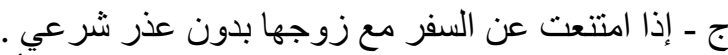

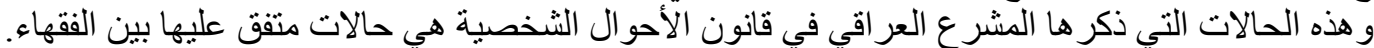

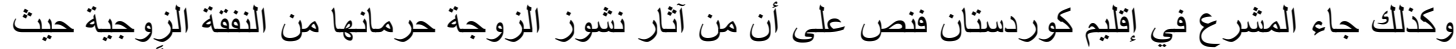

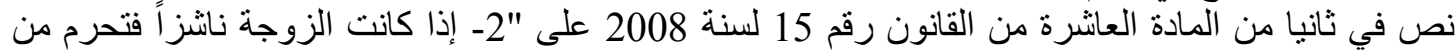

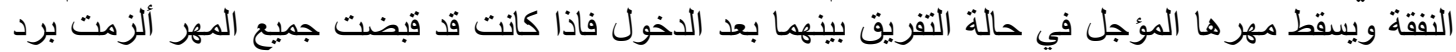

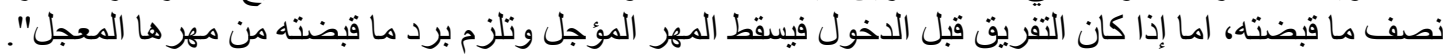

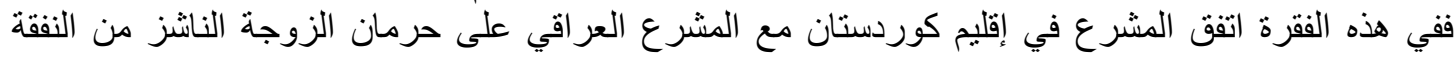

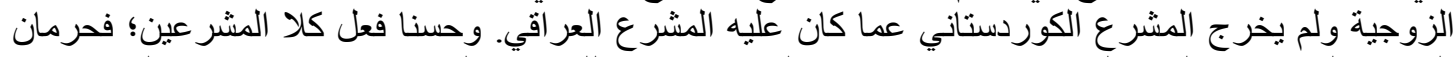

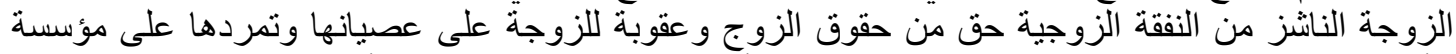

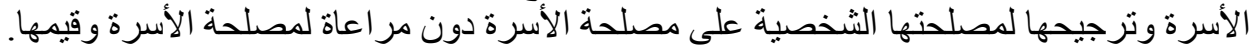

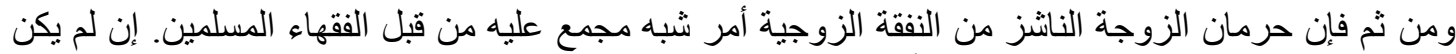

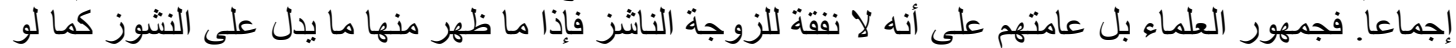

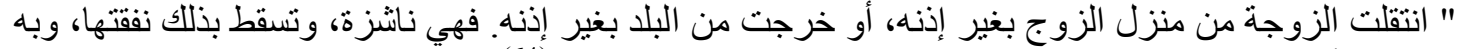

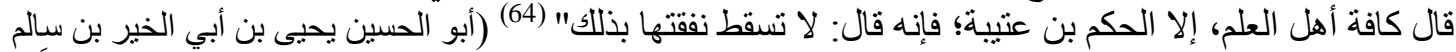

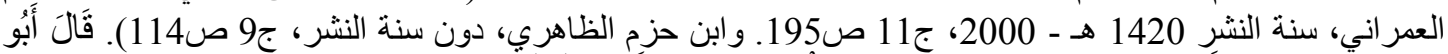

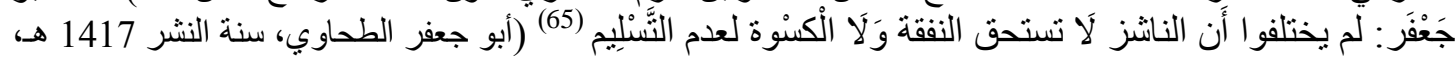

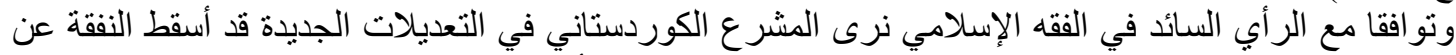

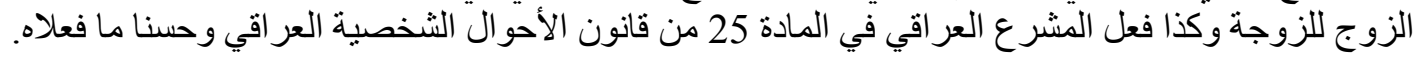

\section{تغيير جذري في التعديل "نثوز الزوج "}




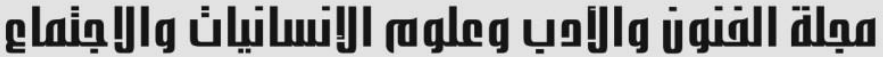

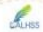 \\ Journal of Arts, Literature, Humanities and Social Sciences} www.jalhss.com

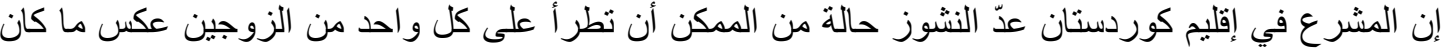

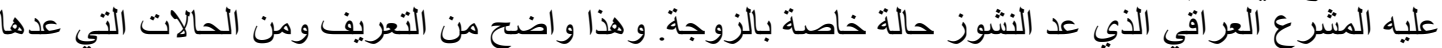

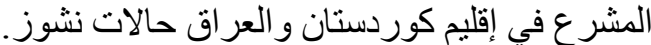

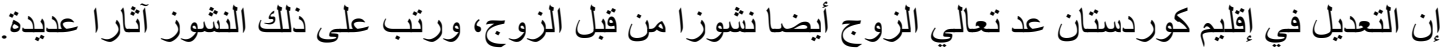

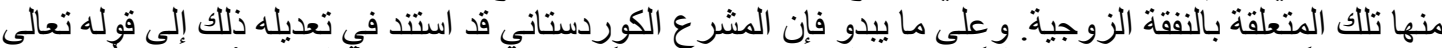

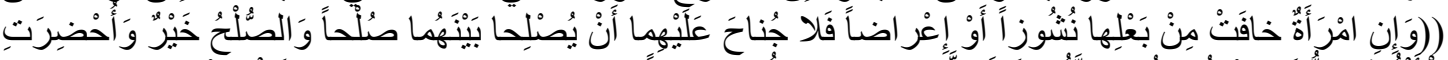

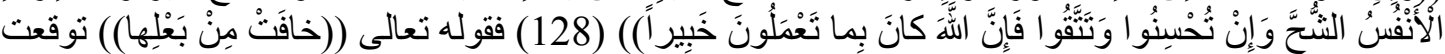

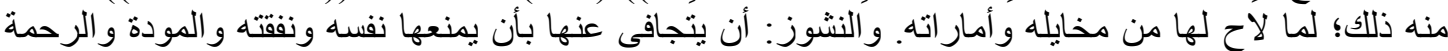

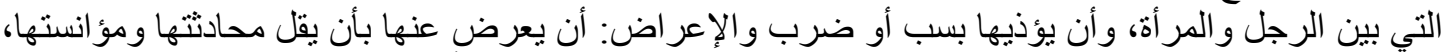

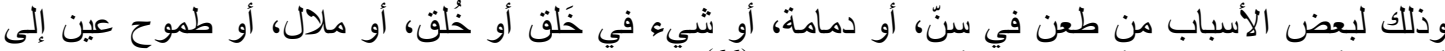

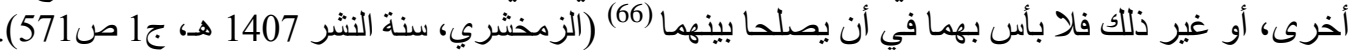

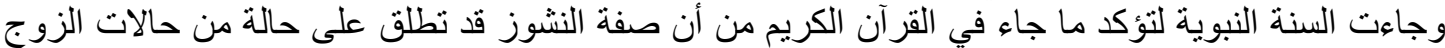

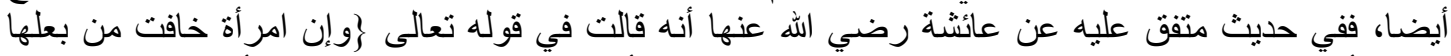

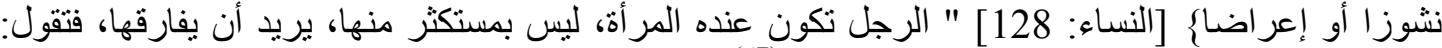

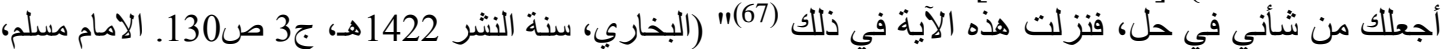

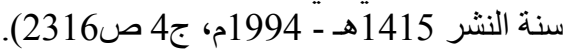

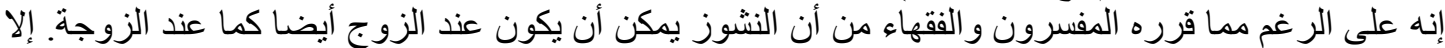

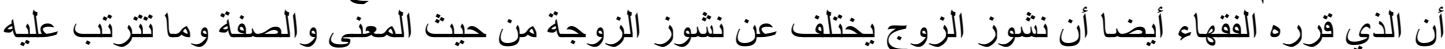

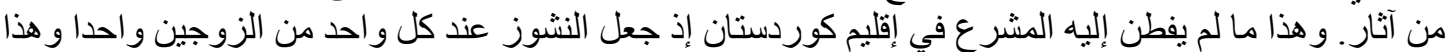

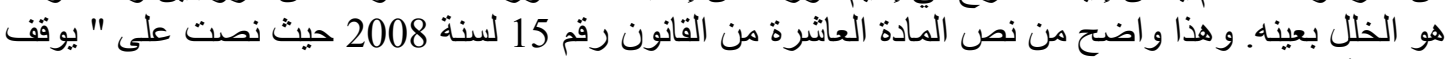

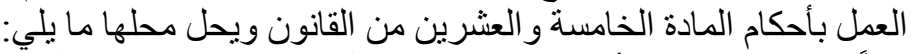
اولاً النشوز هو تعالي أحد الزوجين والزين على الآخر كما في الحالات الزات الآتية: 1

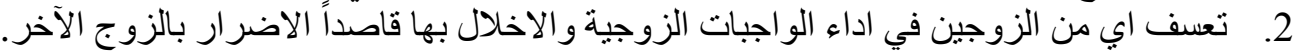

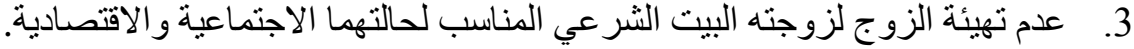

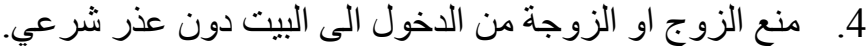

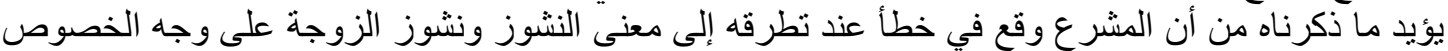

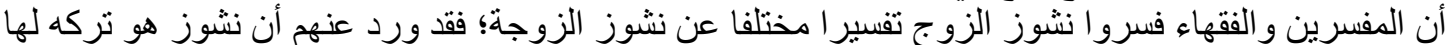

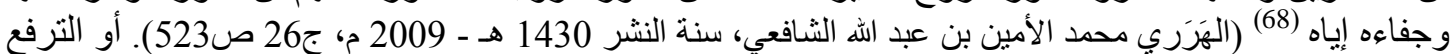

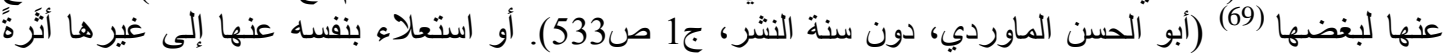

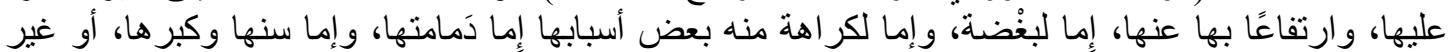

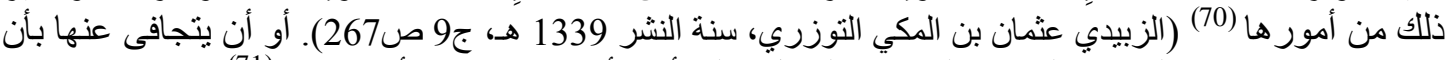

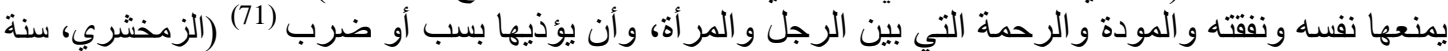

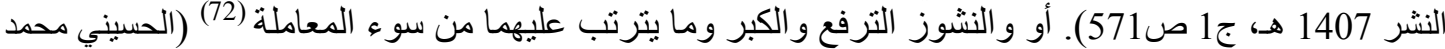

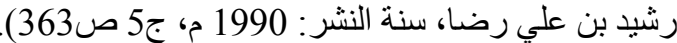

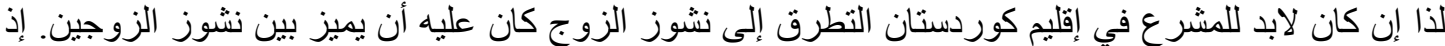

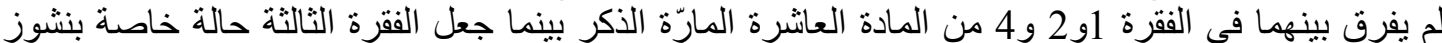

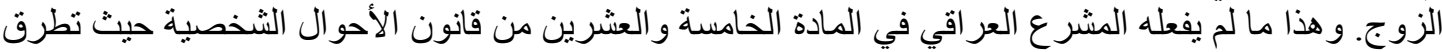

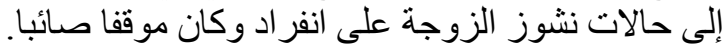

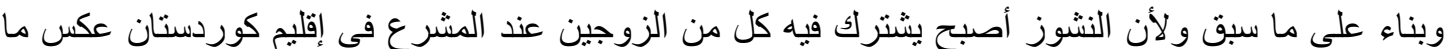

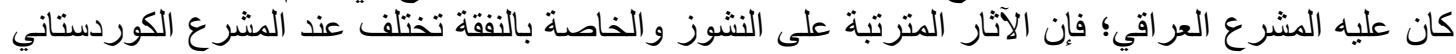
عما كان عليه المشرع العر اقي. 


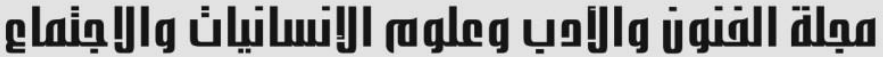

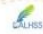 \\ Journal of Arts, Literature, Humanities and Social Sciences} www.jalhss.com

إن المشرع في إقليم كوردستان قد وصف حالة جديدة في النشوز وهي نشوز الزورج لذا فقد كان لهذه الحالة تأثيرا

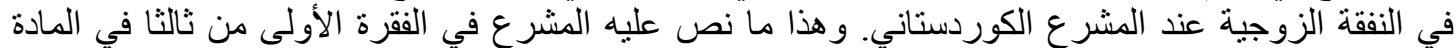

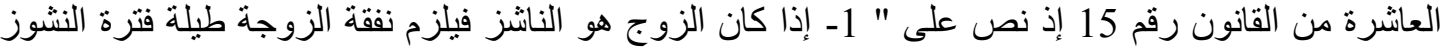

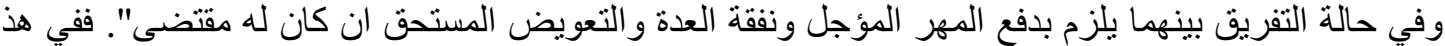

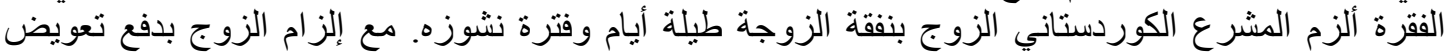

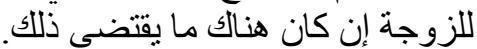

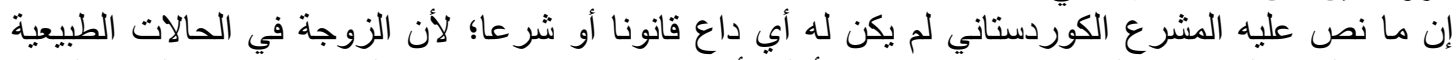

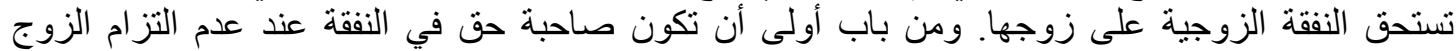

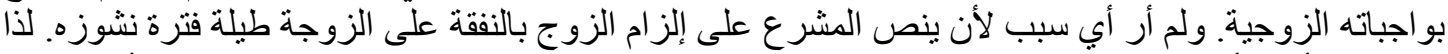

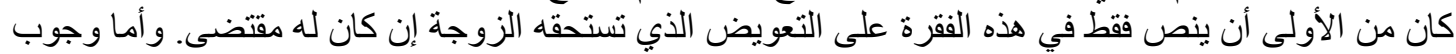

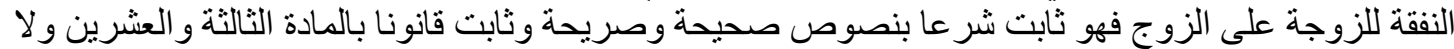

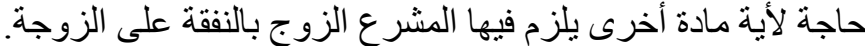

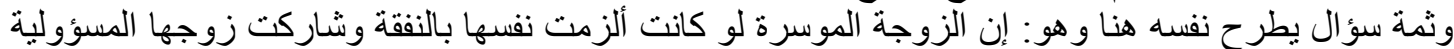

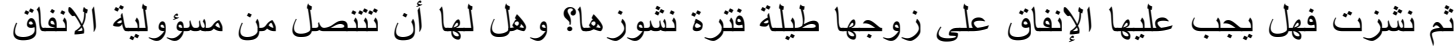

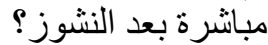

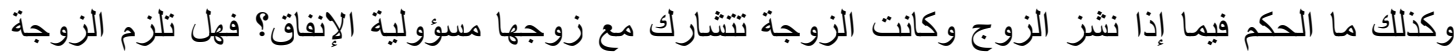

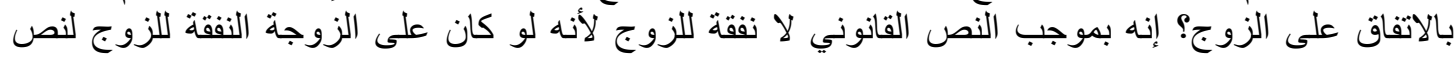

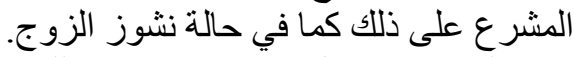

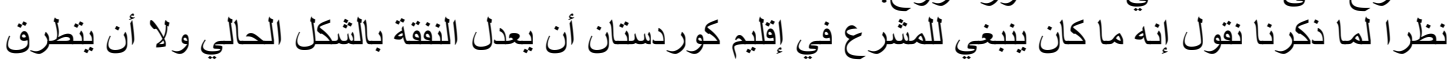

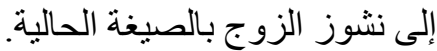

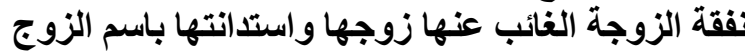

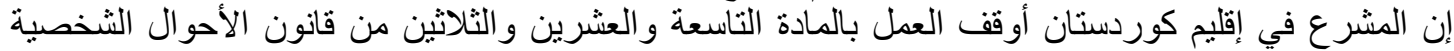

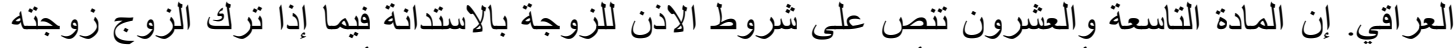

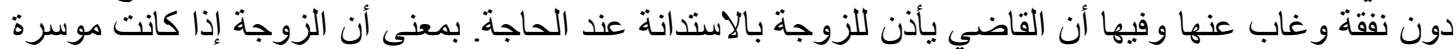

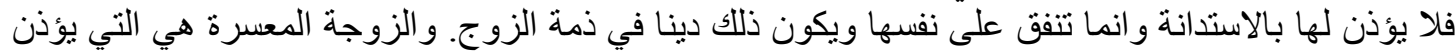

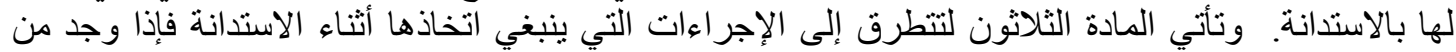

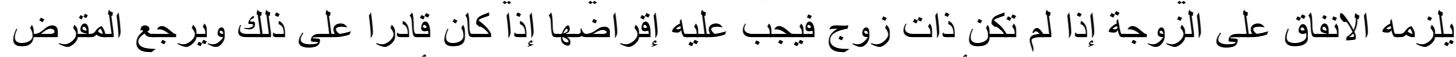

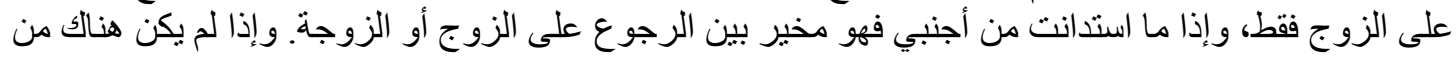

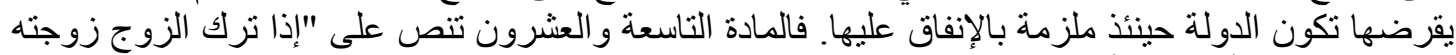

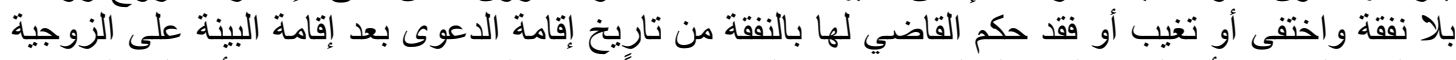

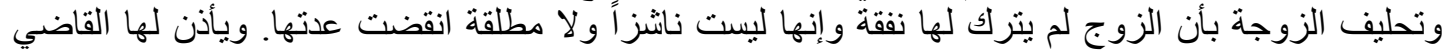

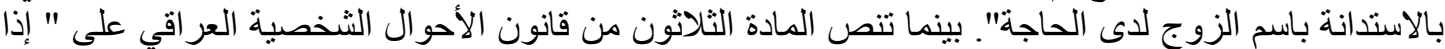

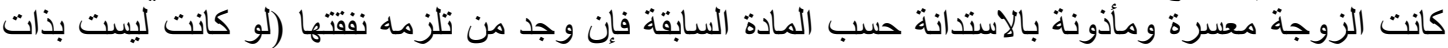

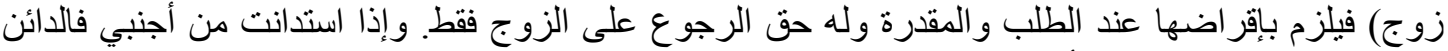

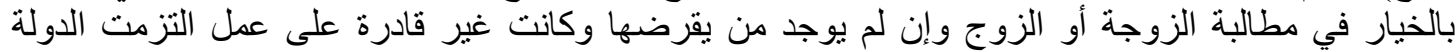

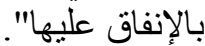

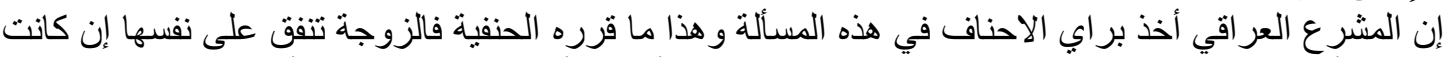

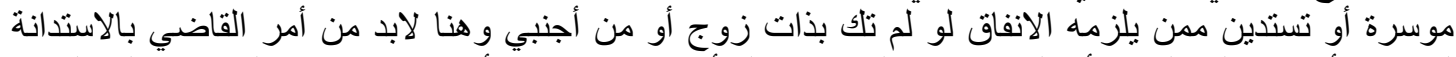

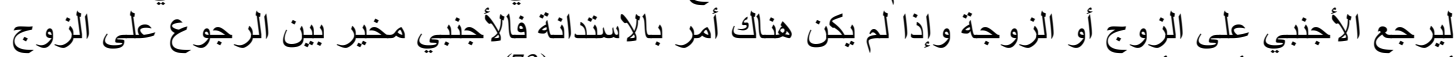

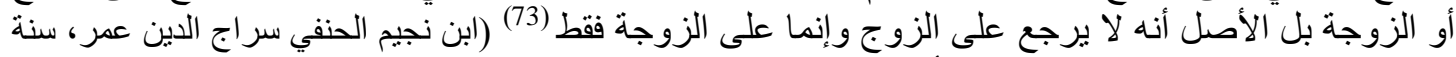

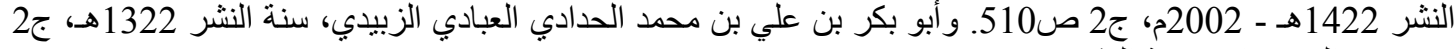

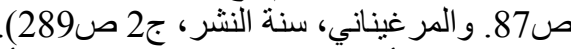

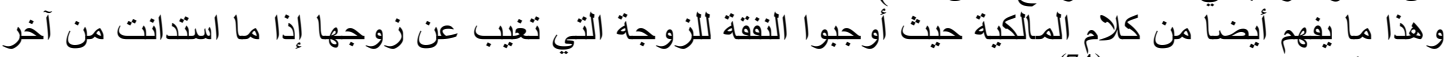

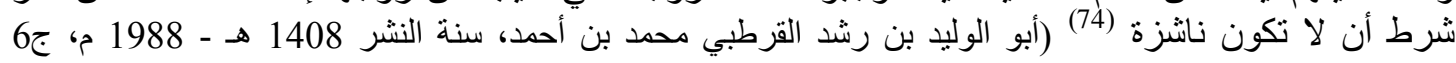




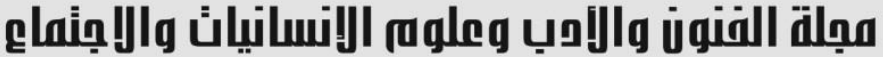

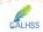 \\ Journal of Arts, Literature, Humanities and Social Sciences} www.jalhss.com

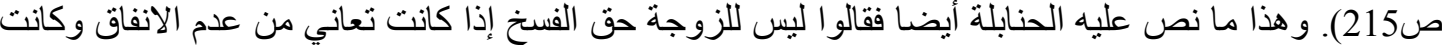

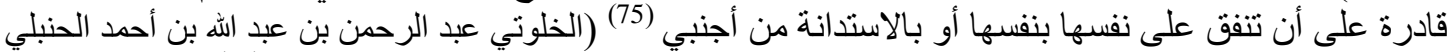

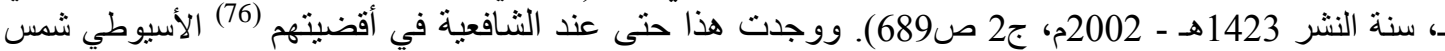

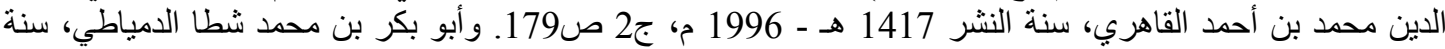

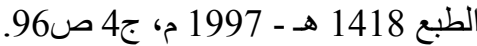

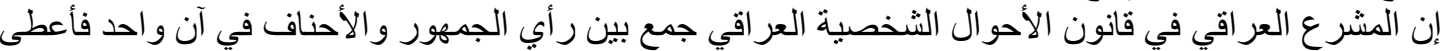

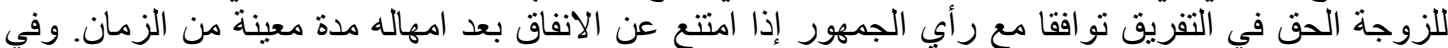

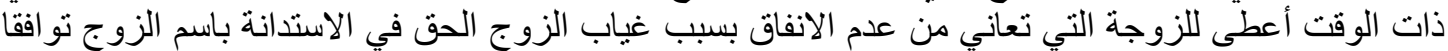

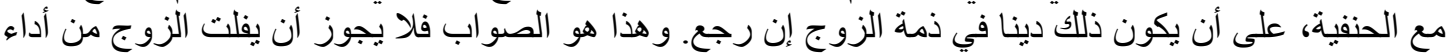

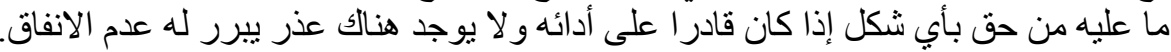

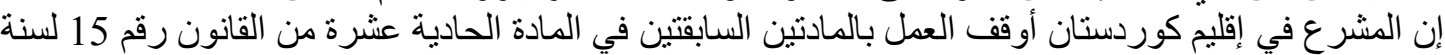

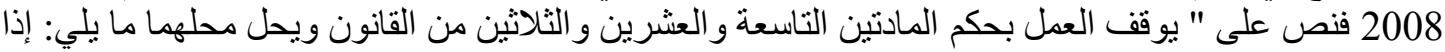

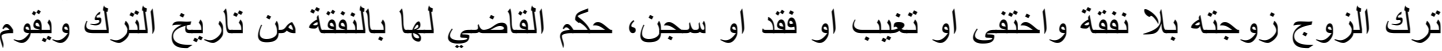

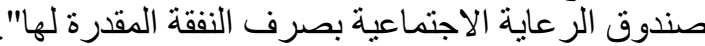

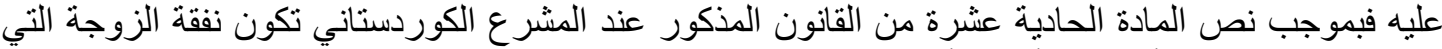

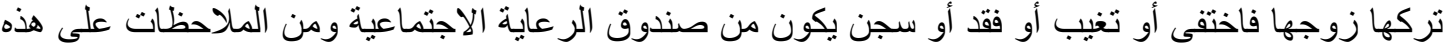

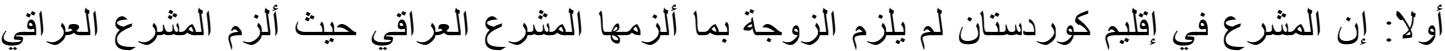

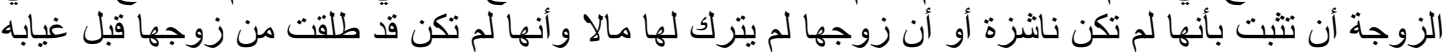

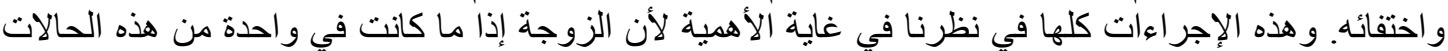

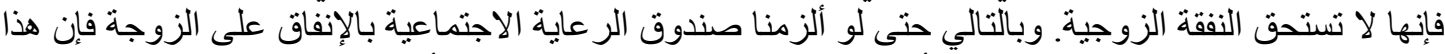

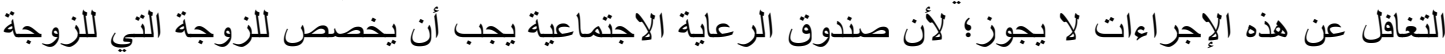

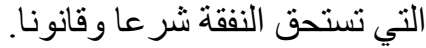

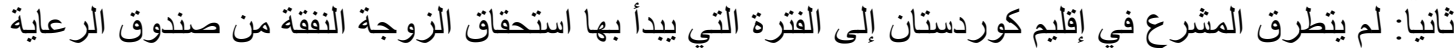

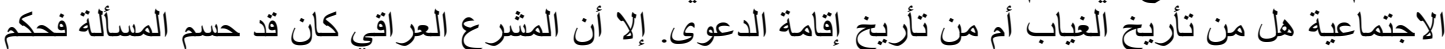

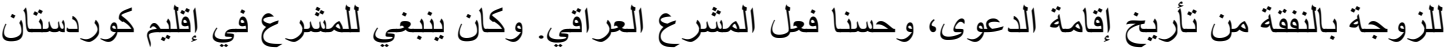

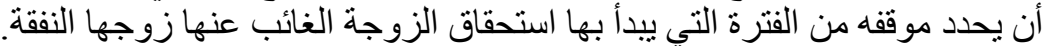

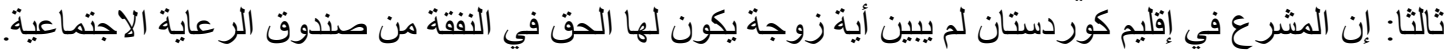

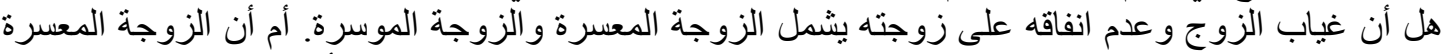

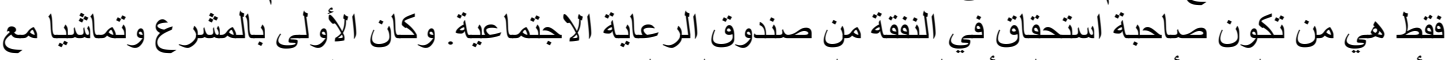

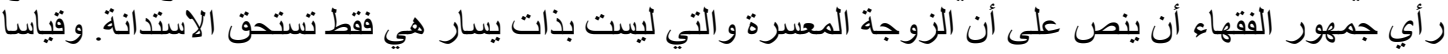

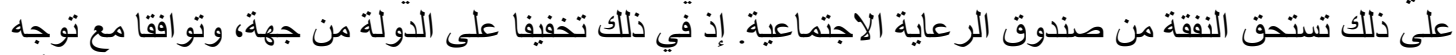

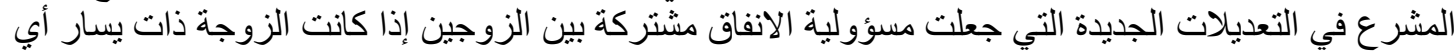

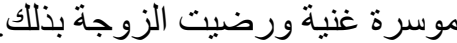

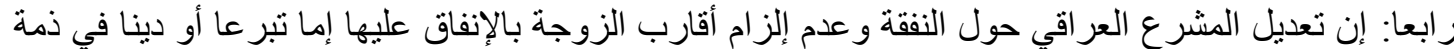

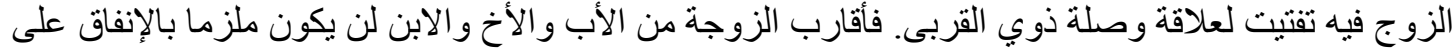

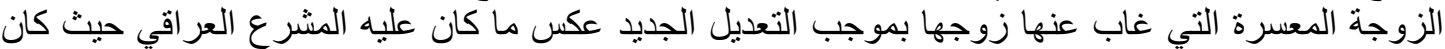

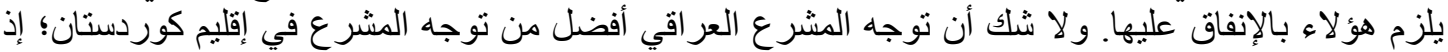

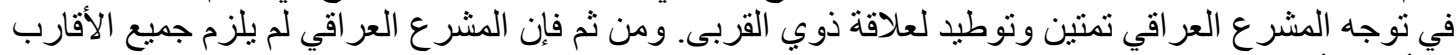

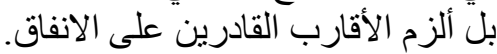

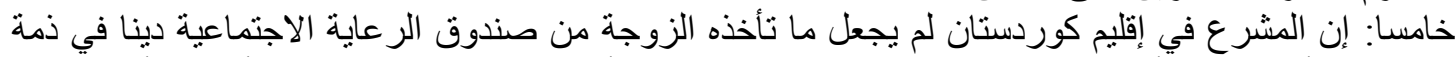

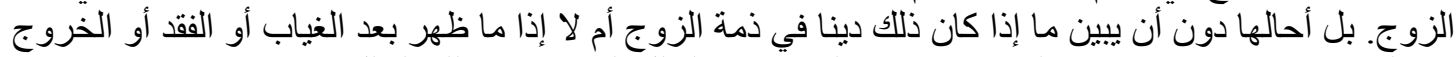
من السجن. وهذا بحد ذاته يثير الكثير من الإشكاليات وفيه الخلل الكبير ومن ذلان للك الخلل: 


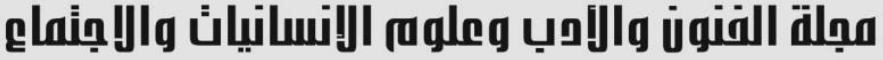

Journal of Arts, Literature, Humanities and Social Sciences www.jalhss.com

1- أنه ليس من المنطق أن تتكفل الدولة بالإنفاق على الزوجة نيابة عن الزوج تبرعا، وخاصة إذا ما كان غيابه

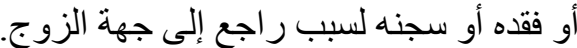

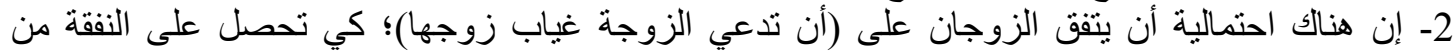

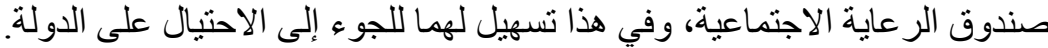

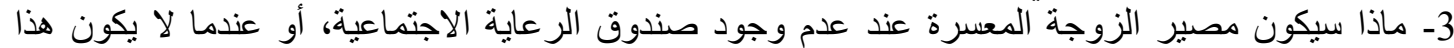

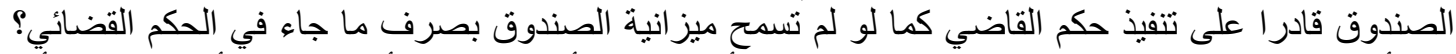

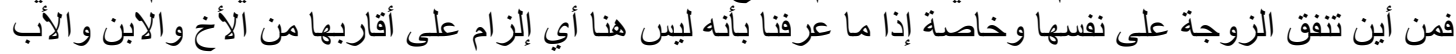
بالإنفاق عليها بموجب التبن التعديلات الجديدة.

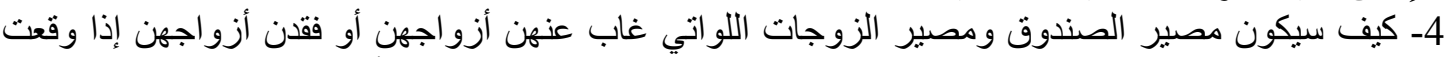

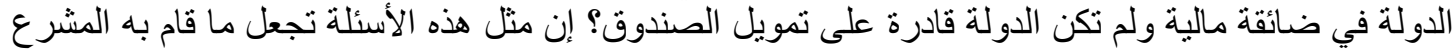

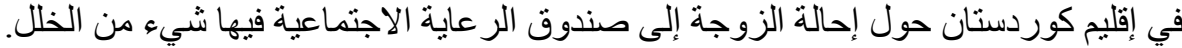

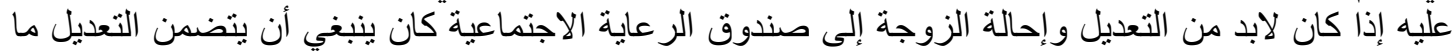

أو لاً: إن ما يصر فاله الصندوق على الزوجة كنفقة يكون دينا في ذمة الزو ج.

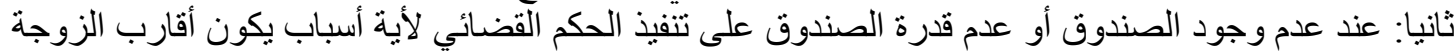

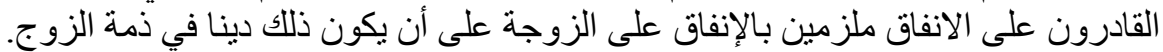

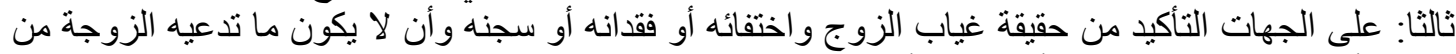

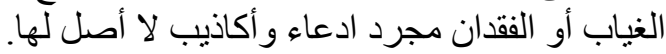

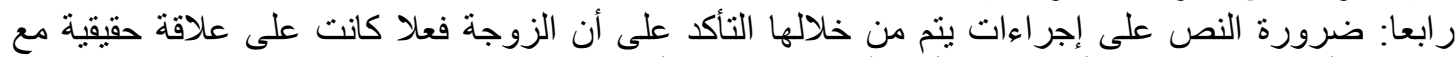

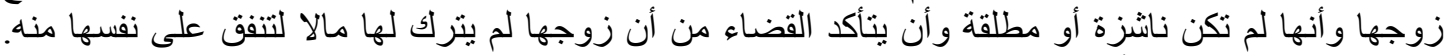

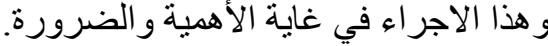

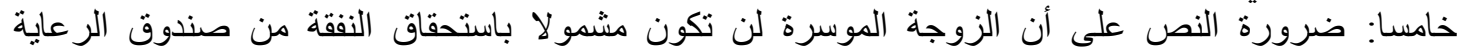
الاجتماعية.

الخاتمة بعد ان انتهيت من كتابة هذا البحث أود أن الخص النتائج والتوصيات في النقاط التالية:

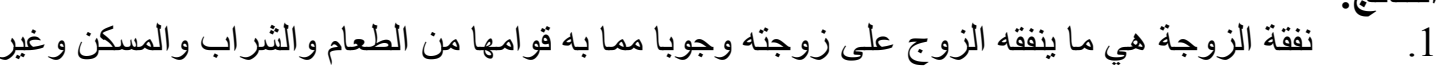
ذللك من مشتملات النفقة. 2. النفقة مشروعة وو اجبة على الزوج للزوجة بنص القرآن الكريم و السنة الصحيحة بإجماع العلماء دون

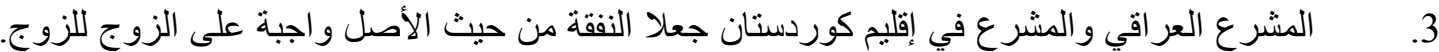

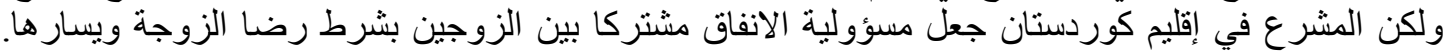

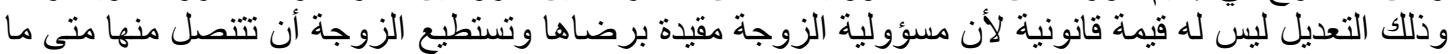

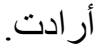

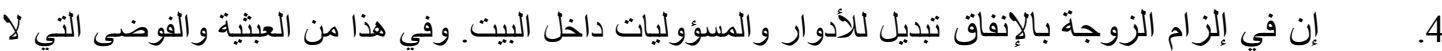

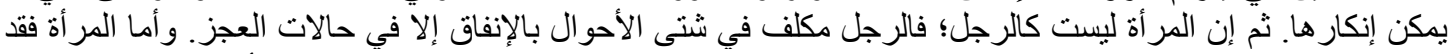

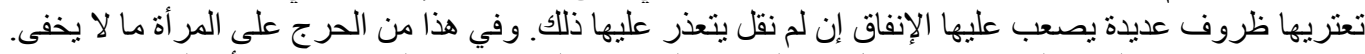
5.

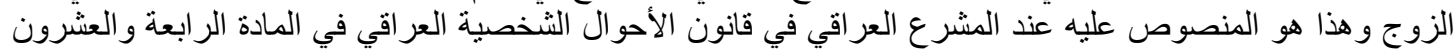

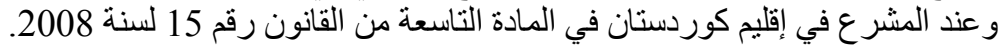

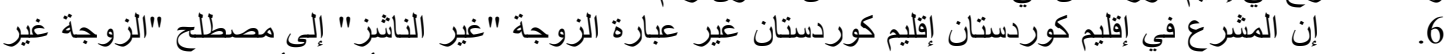

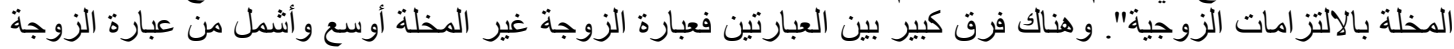




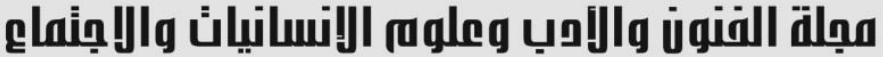 \\ Journal of Arts, Literature, Humanities and Social Sciences} www.jalhss.com

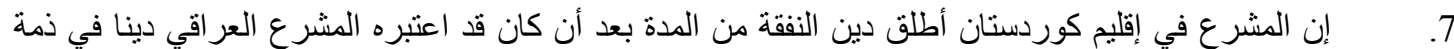

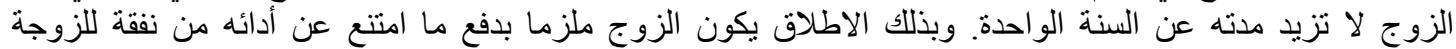

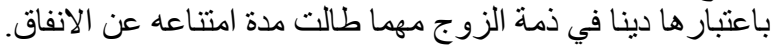

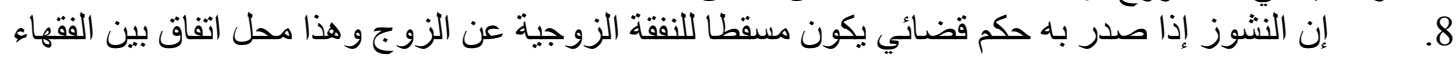
وبين كل من المشرع العر اقي و المشرع في إنقليم كوردستان.

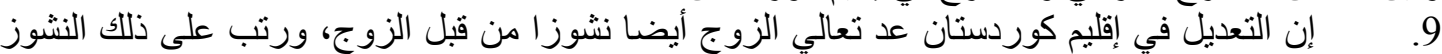

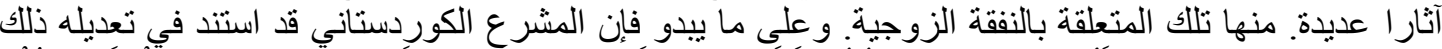

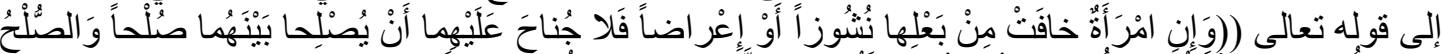

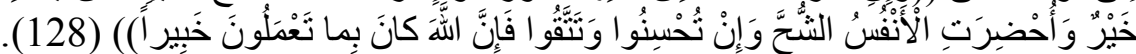

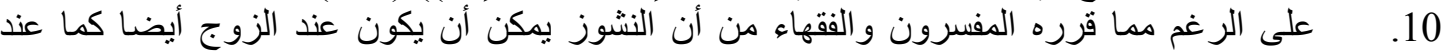

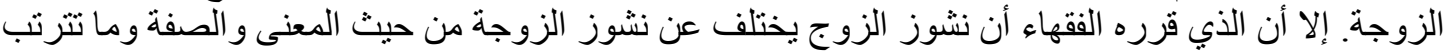

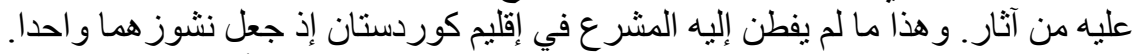

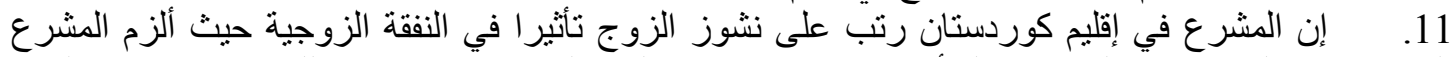

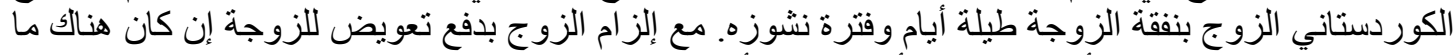

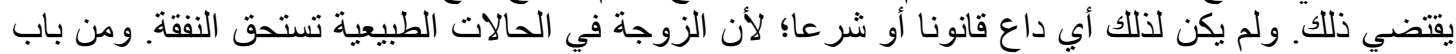

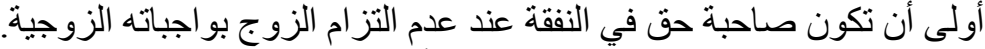

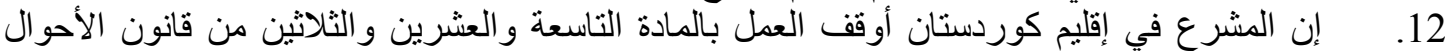

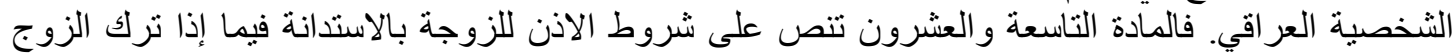

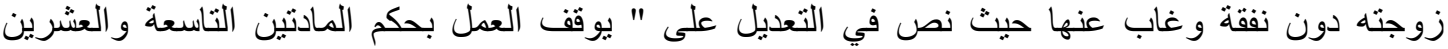

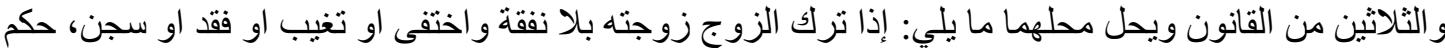

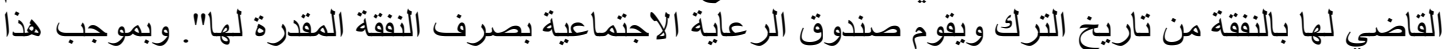

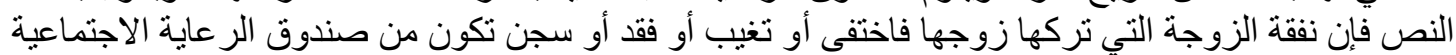

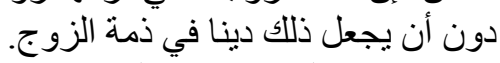

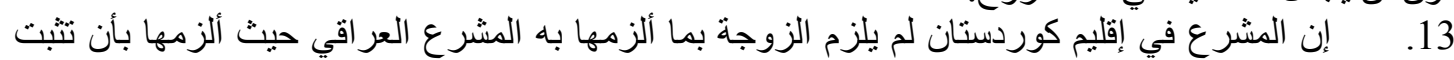

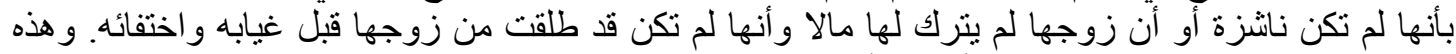

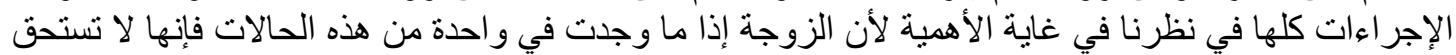

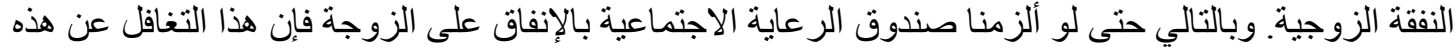

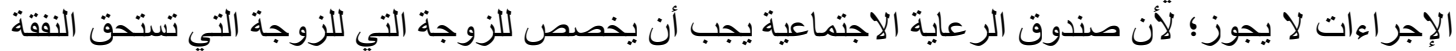

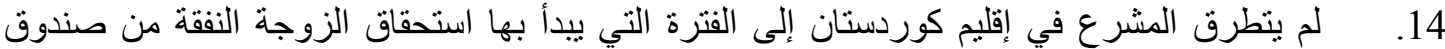

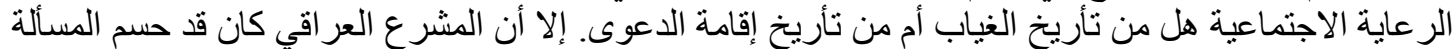

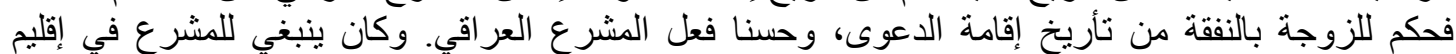

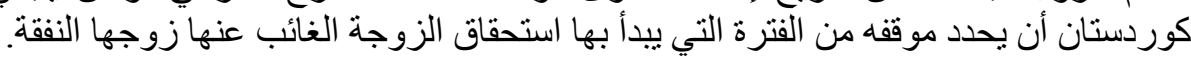

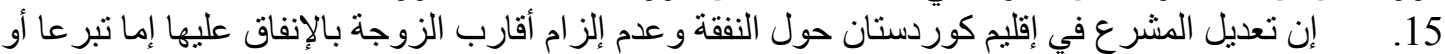

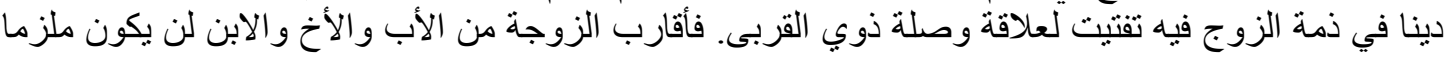

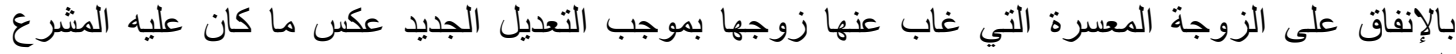

إن إيقاء عبارة "وتكون المسؤولية مشتركة" مطلقة دون قيد فيه من الخلل الكبير؛ بدليل أن العبارة تشير أيضا

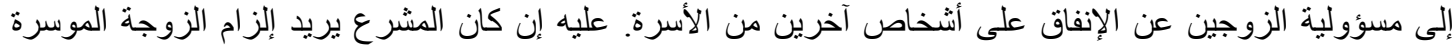

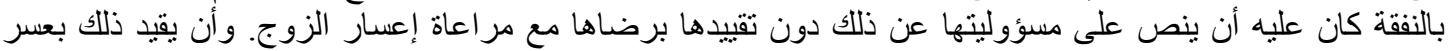

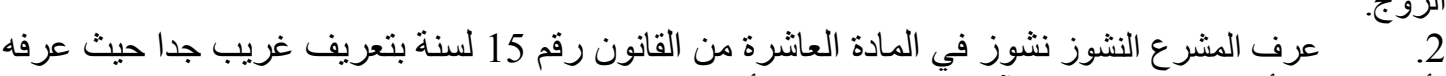

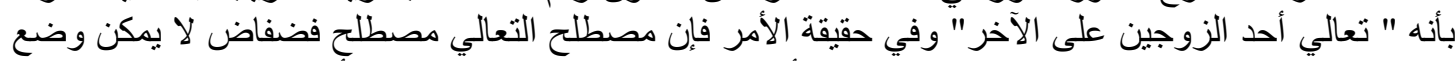

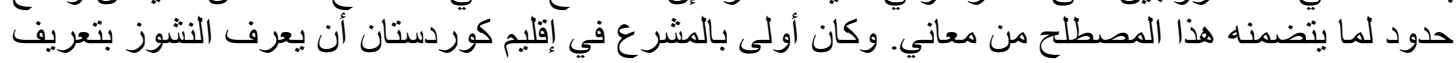




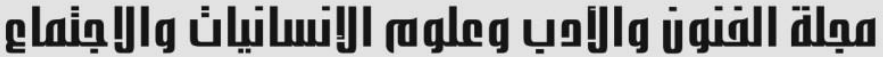

Luss

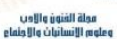

(1)
Journal of Arts, Literature, Humanities and Social Sciences www.jalhss.com

واضح، فتعريفه يحتاج إلى تعريف. وكان على المشرع في إقليم كوردستان أن يميز بين نشوز الزوجين التين. أنثاء

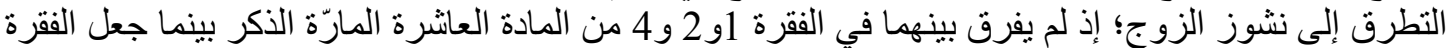

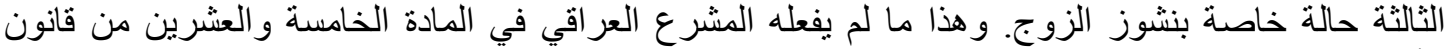

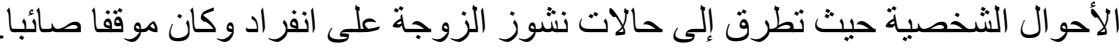

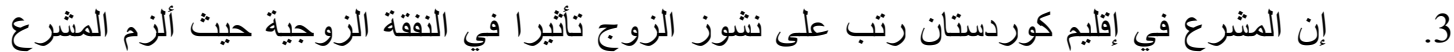

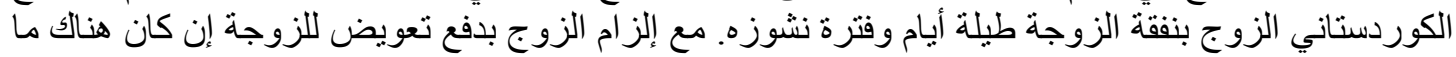
يقتضي ذللك.

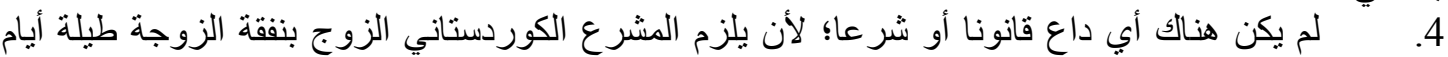

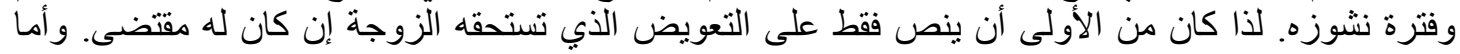

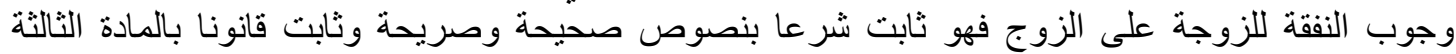

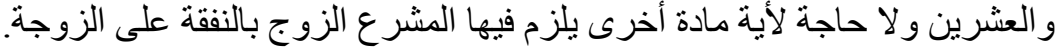

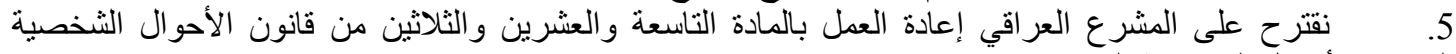
العر اقي الأحو ال الثخصية العر اقي. الثي.

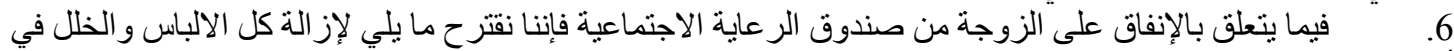

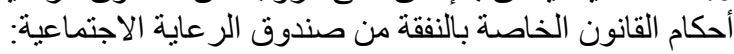

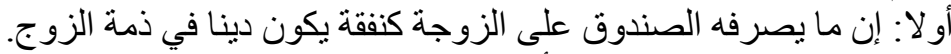

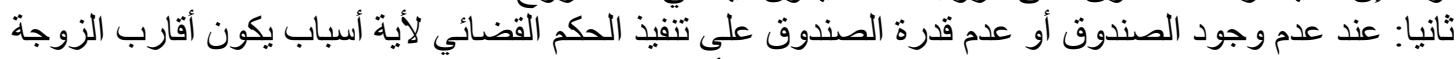

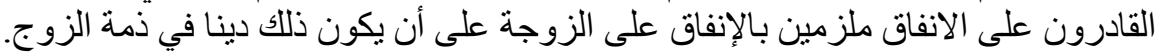

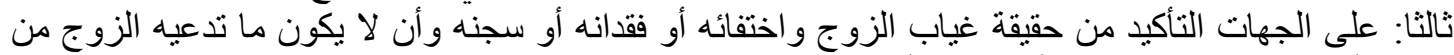

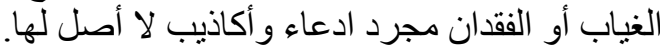

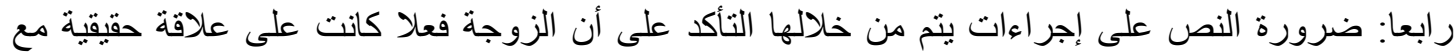

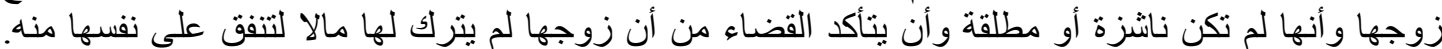
و هذا الاجر اء في غاية الأهمية والضروة الضروة. خامسا: ضرورة النص على أن النهاء الزوجة الموسرة لن تكون مشمولا باستحقاق النفقة من صندوق الرعاية الاجتماعية. سادسا: ينبغي على المشرع في إقليم كوردستان أن يحدد موقفه من الفترة التي يبدأ بها استحقاق الزوجة الغائب عنها زوجها النفقة من صندوق الرئر في الرعاية الاجتماعية. تم بحمد الله و عونها

\section{(المصادر

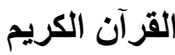

1. ابن الرفعة أبو العباس نجم الدين أحمد بن محمد بن علي (المتوفى: 710هـ)، سنة النشر م 2009، كفاية الطية النبيه في شرح التنبيه، تحقيق مجدي محمد سرور باسلوم، الطبعة الأولى، دار الكتب العنب العلمية.

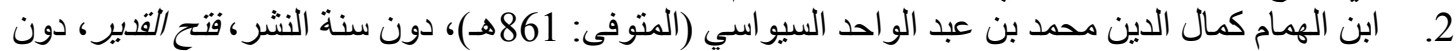

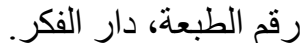

3.

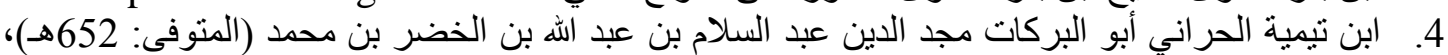
سنة النشر 1404هـ -1984مه، الدحرر في الفقه على مذهب الرئ الإمام أحدد بن حنبل، الطبعة الثنانية، مكتبة

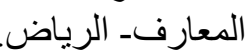
5. ابن حزم الظاهري محمد علي بن أحمد بن سعيد بن حزم الأندلسي القرطبي (المتوفى: 456هـ)، دون سنة

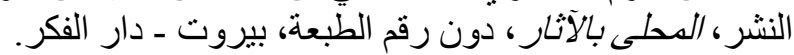

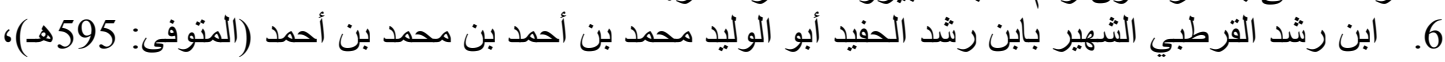

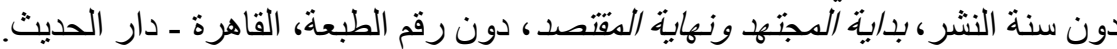




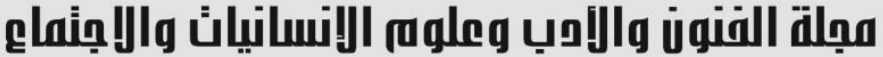

7. ابن عرفة الدسوقي محمد بن أحمد المالكي (المنوفى: 1230ه) -ي، دون سنة النشر، حاشية الدسوقي على

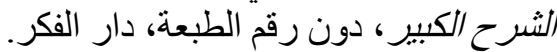
8. ابن قدامة المقدسي أبو محمد موفق الدين عبد الله بن أحمد بن محمد (المتوفى: 620هـ)، دون سنة النشر،

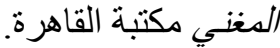
9. ابن منظور أبو الفضل جمال الدين محمد بن مكرم بن على الانصاري (المنوفى: 711هـ)، سنة النشر

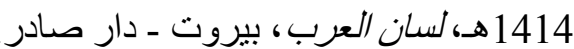

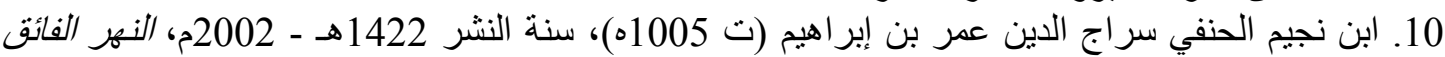

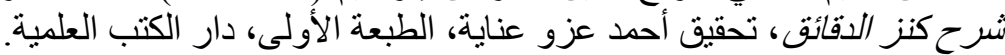

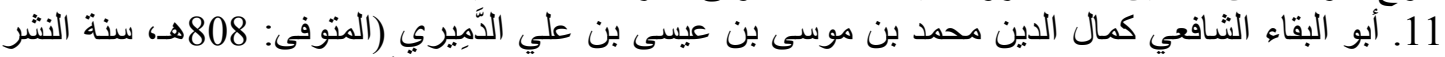

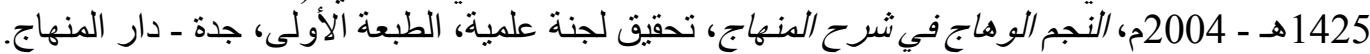

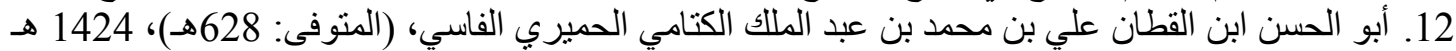

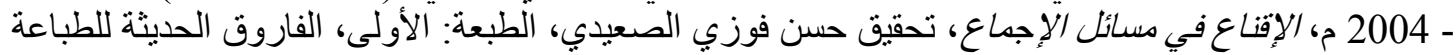

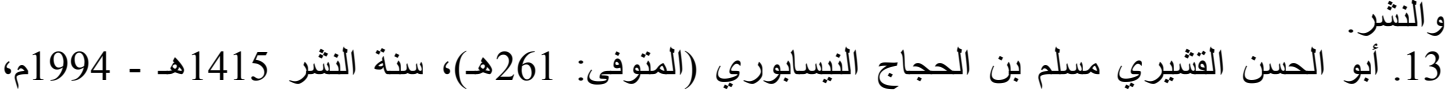

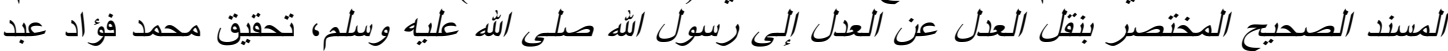

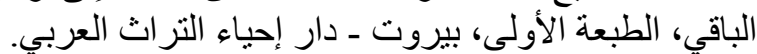

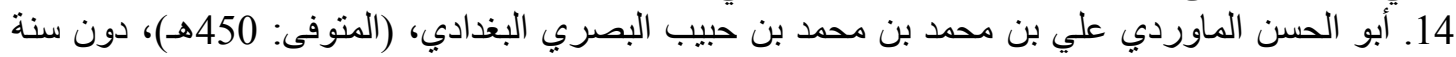

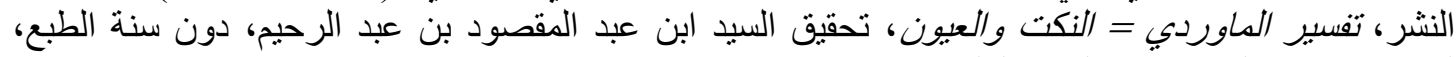
لبنان، بيروت / لبنان ـ دار الكتب العلمية.

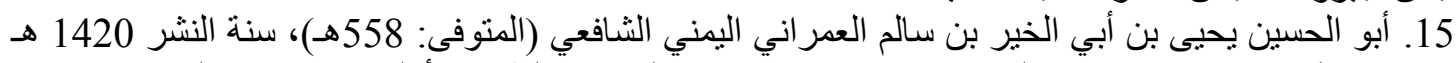

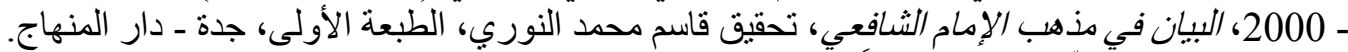

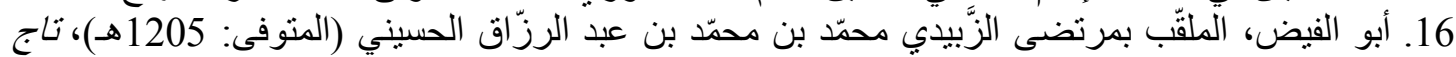

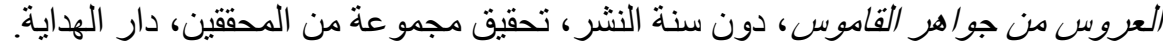

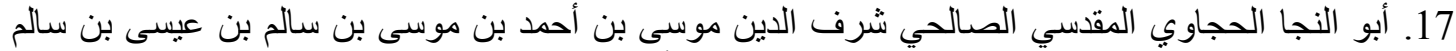

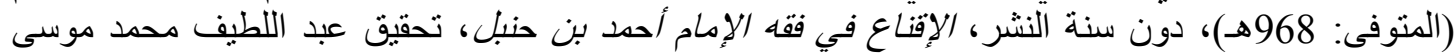

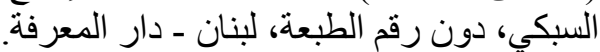

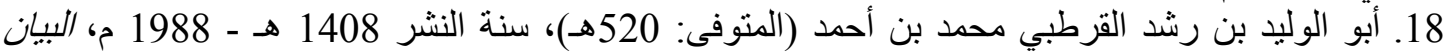

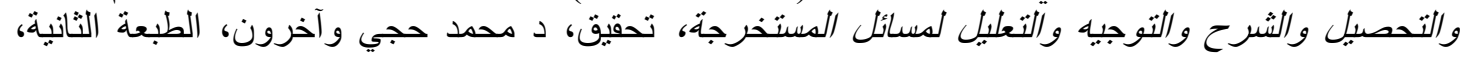

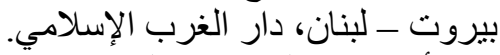

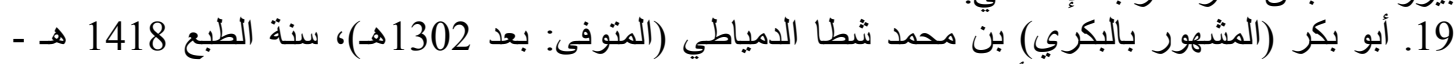

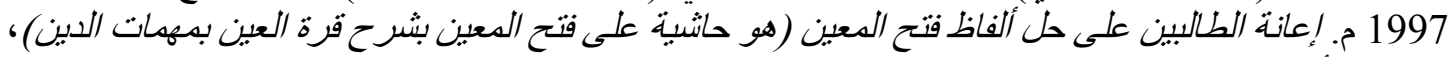
الطبعة الأولى، دار الفكر للطباعة والنش النشر والنتوريع.

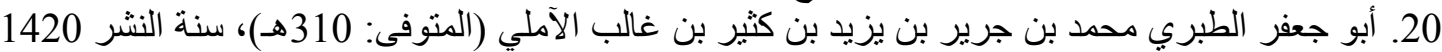

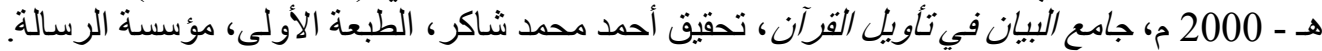

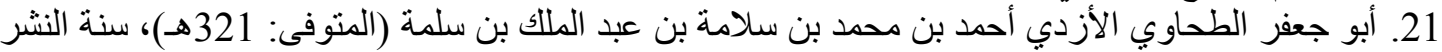
1417 هـ، مختصر اختلاف العلماء، تحقيق د. عبد الله نذير أحمد، الطبعة الثانية، بيروت ــ ــن دار البشائر

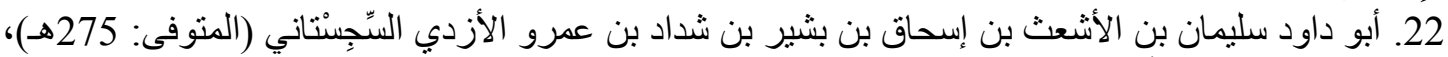

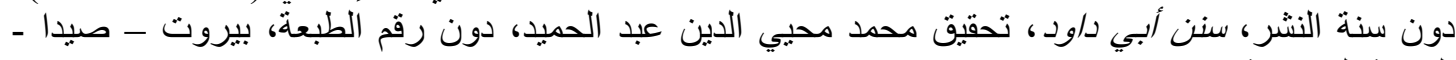
المكتبة العصرية.

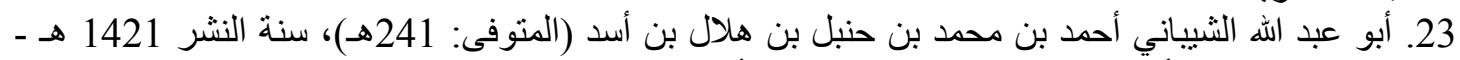

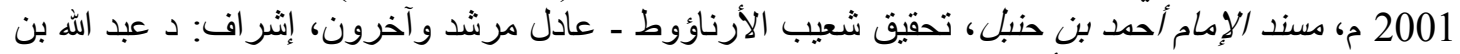
عبد المحسن التركي، الطبعة الأولى، مؤسسة الرسالة. 


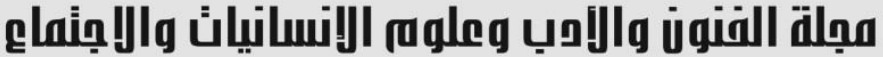

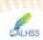

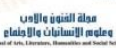

Journal of Arts, Literature, Humanities and Social Sciences www.jalhss.com

24. أبو محمد المالكي عبد الوهاب بن علي بن نصر الثُعلبي البخدادي (المتوفى: 422ه، دون سنة النشر ، الدعونة المبنة على مذهب عالم المدينة الإمام مالك بن أنس، تحقيق حميش عبد الحقّ، دون رقم الطبعة، مكة المكرمة ــ المكتبة التجارية. 25. أبو يحيى زكريا بن محمد بن زكريا الأنصاري، (المتوفى: 926هـ)، دون سنة النشر، أسنى المطالب في شرح روض الطالب، دون سنة ورقم الطبعة، دار الكتاب الإسلامي. 26. الأسيوطي شمس الدين محمد بن أحمد بن علي بن عبد الخالق القاهري الثافعي (المتوفى: 880هـ، سنة الإنة

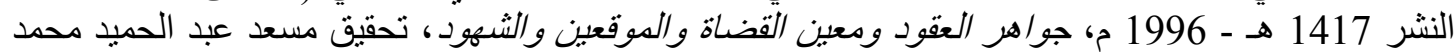
السعدني، الطبعة الأولى، بيروت مالـئ دار الكتب العلمبة.

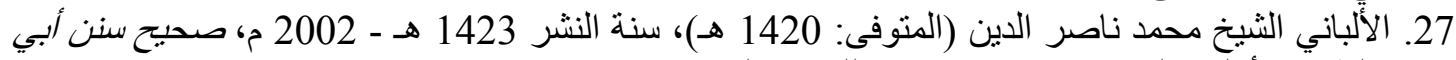

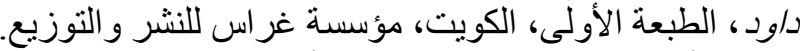

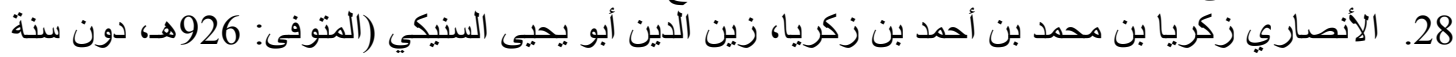

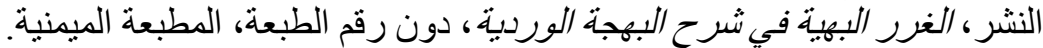

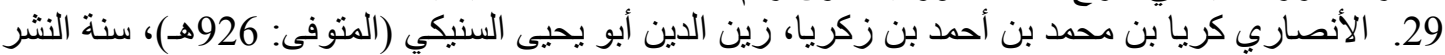

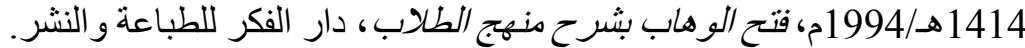

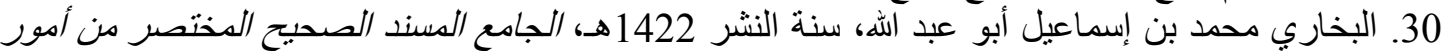

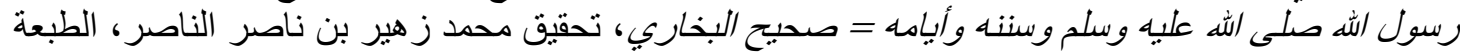

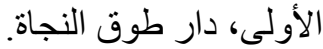

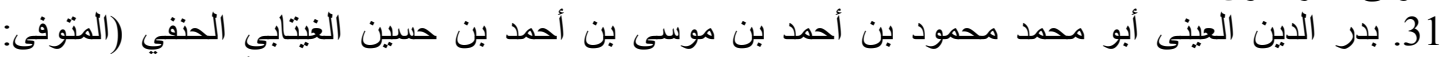

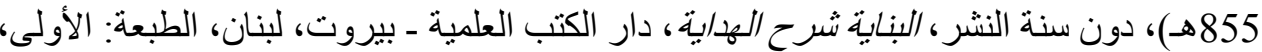

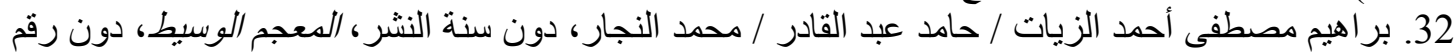
الطبعة، مجمع اللغة العربية ـ القاهرة، دار النوار الدعوة.

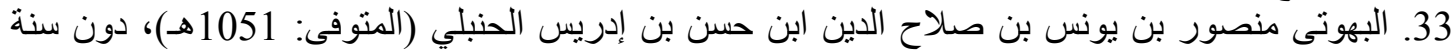

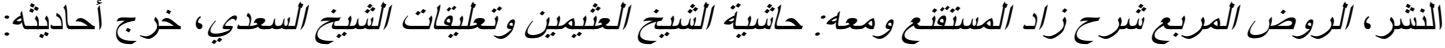

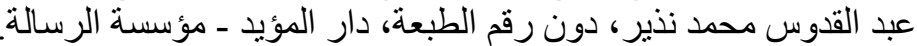

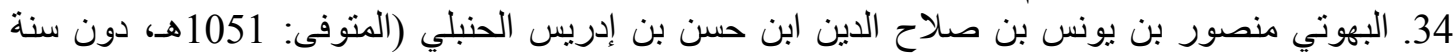

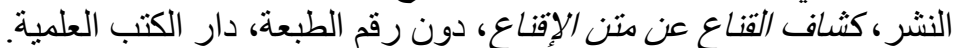

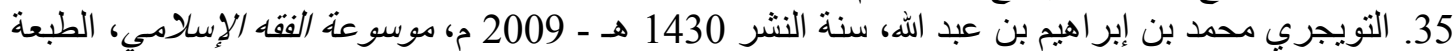
الأولى، بيت الأفكار الدولية.

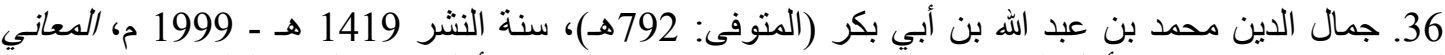

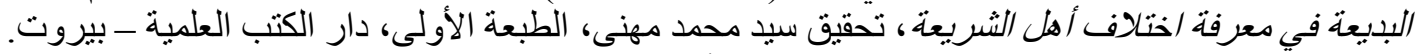

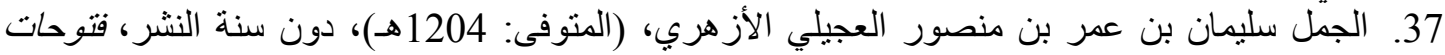

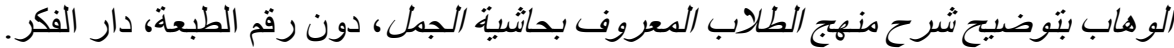

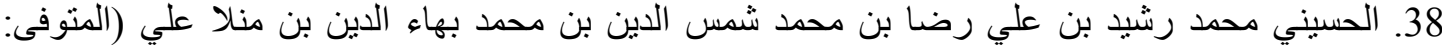

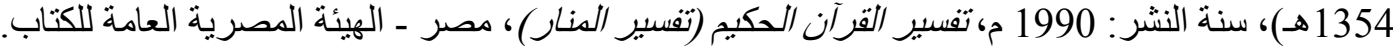

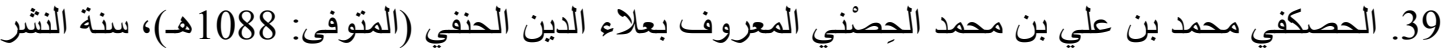

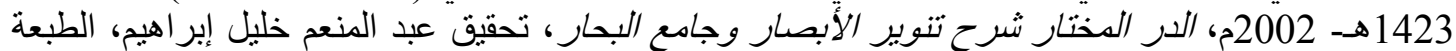
الأولى، لبنان - دار الكتب العلمية.

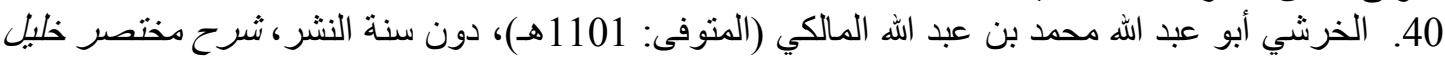
للخرشي، دون رقم الطبعة، بيروت ــ ـ دار الفكر للطباعة.

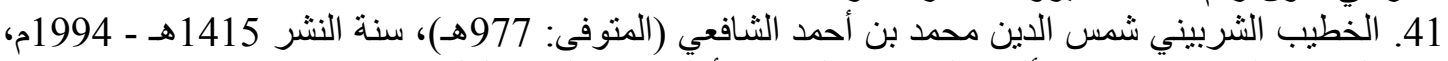

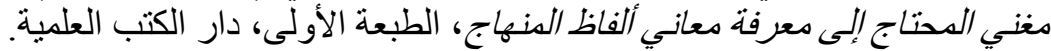

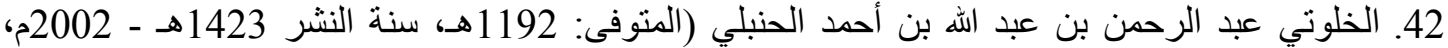

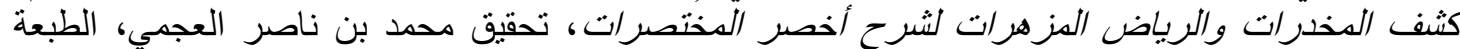
الأولى، لبنان/بيروت ـ دار البشائر الإسلامية. 


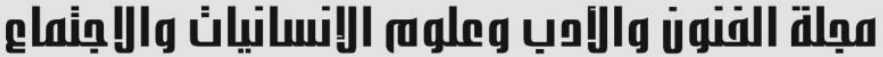

\& $\quad$ Journal of Arts, Literature, Humanities and Social Sciences www.jalhss.com

43. الزَّبيديّيّ أبو بكر بن علي بن محمد الحدادي العبادي (المتوفى: 800هـ)، سنة النشر 1322هـ، الجوهرة

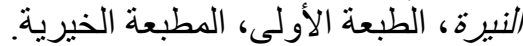
44. الزبيدي عثمان بن المكي التوزية النئية سنة النشر 1339 هـ، توضيح الأحكام شرح تحفة الحكام، الطبعة

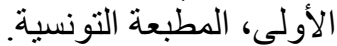
45. الزمخشري جار الله أبو القاسم محمود بن عمرو بن أحمد، (المنوفى: 538هـ)، سنة النشر 1407 هـ،

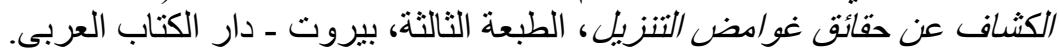

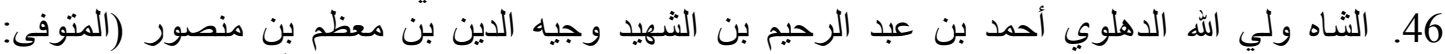

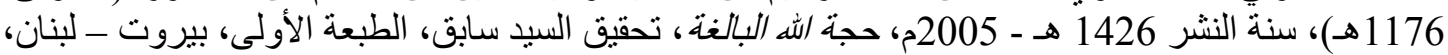

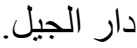
47. الثير ازي أبو اسحاق إبر اهيم بن علي بن يوسف (المتوفى: 476هـ)، دون سنة النشر ، الدهذب في فقه الإمام الثافعي، دار الكتب العلمية. 48. العاصمي القحطاني الحنبلي النجدي عبد الرحمن بن محمد بن قاسم (المنوفى: 1392هـ)، سنة النشر 1406

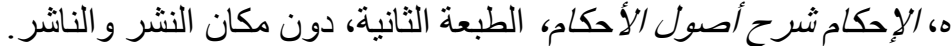

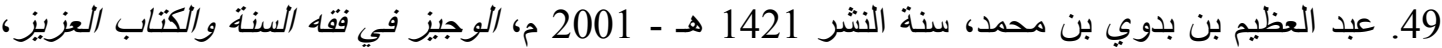

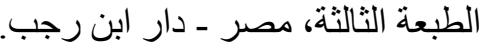
50. علاء الدين الكاساني الحنفي أبو بكر بن مسعود بن أحمد (المتوفى: 587هـ)، سنة النشر 1406هـ - 1986م.

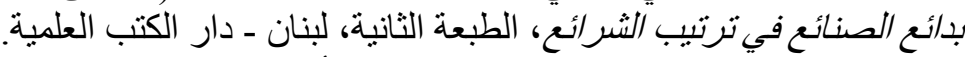

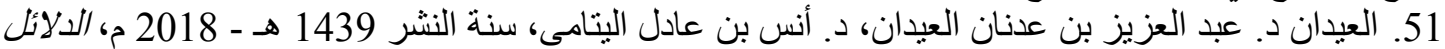

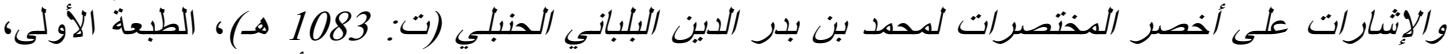

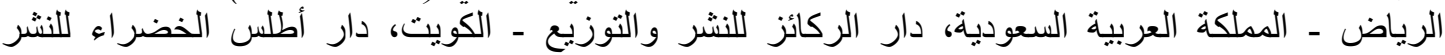

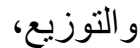

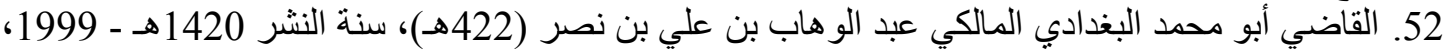

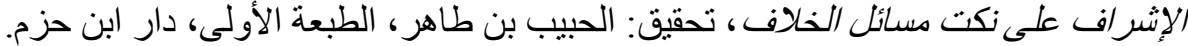

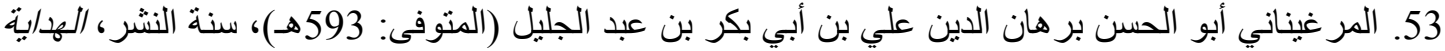

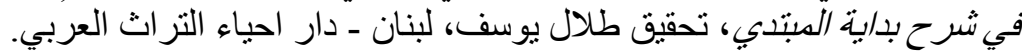

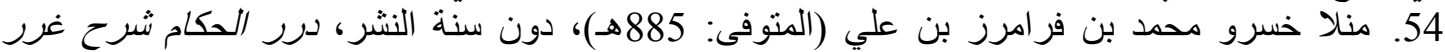
الأحكام، دون رقم الطبعة، دار إحياء الكتب العربية.

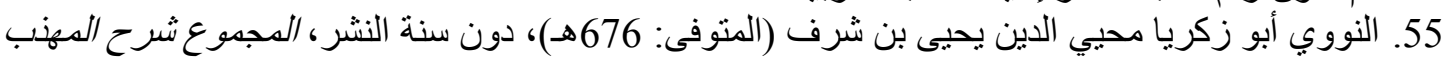

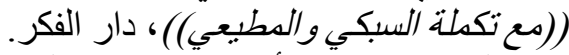

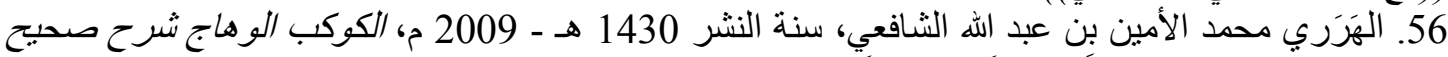

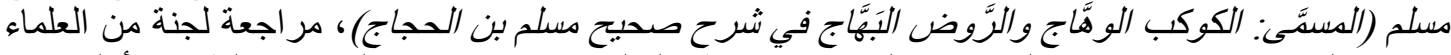

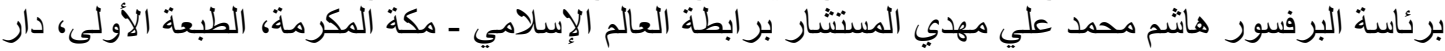
المنهاج - دار طوق النجاة. 


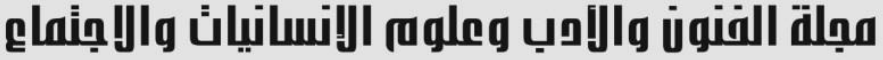 \\ Journal of Arts, Literature, Humanities and Social Sciences www.jalhss.com \\ Volume (54) July 2020 \\ العدد (54) يوليو 2020}

\section{References}

1. Abd al-Azim bin Badawi bin Muhammad, publication year 1421 AH - 2001 AD, Brief in jurisprudence of Al-Sunna and the Book Al-Aziz, Third Edition, Egypt - Dar Ibn Rajab.

2. Abu Abdullah Al-Shaybani Ahmad bin Muhammad bin Hanbal bin Hilal bin Asad (died: 241 AH), published year 1421 AH - 2001 AD, the series of Imam Ahmad bin Hanbal, investigated by Shuaib Al-Arnaout - Adel Murshid and others, supervised by Dr. Abdullah bin Abdul Al-Mohsen Al-Turki, first edition, Al-Resala Foundation.

3. Abu al-Faid, nicknamed Mortada al-Zubaidi Muhammad ibn Muhammad ibn Abd al-Razzaq al-Husayni (died: $1205 \mathrm{AH}$ ), the crown of the bride from the jewels of the dictionary, without the year of publication, investigated by a group of, Dar alHidaya.

4. Abu al-Hasan al-Mawardi Ali bin Muhammad bin Muhammad bin Habib al-Basri al-Baghdadi, (died: $450 \mathrm{AH}$ ), without the year of publication, Tafsir al-Mawardi, investigated by al-Sayyid Ibn Abd al-Maqsoud bin Abd al-Rahim, without the year of publication, Lebanon, Beirut / Lebanon- dar al kutub al ilmya>

5. Abu al-Hasan al-Qushairi Muslim ibn al-Hajjaj al-Nisaburi (died: $261 \mathrm{AH}$ ), publication year $1415 \mathrm{AH}-1994 \mathrm{CE}$, the correct short abbreviated transmission of justice from justice to the Messenger of God, may God bless him and grant him peace, the investigated by Muhammad Fouad Abd al-Baqi, first edition, Beirut - Dar Ihya al-Turath

6. Abu Al-Hassan Ibn Al-Qattan Ali bin Muhammad bin Abdul-Malik Al-Kutami Al-Humairi Al-Fassi (died: 628 AH), 1424 AH-2004 AD, persuasion in matters of consensus, investigated by Hassan Fawzi Al-Sa'idi's, Edition: First, Al-Faruq Modern for Printing and Publishing.

7. Abu al-Hussein Yahya bin Abi al-Khair bin Salem al-Amrani al-Yamani alShafi'i (died: $558 \mathrm{AH}$ ), published in the year $1420 \mathrm{AH}$ - 2000, the statement in the doctrine of Imam al-Shafi'i, investigated by Qasim Muhammad al-Nuri, first edition, Jeddah - Dar Al-Minhaj.

8. Abu al-Naja al-Hijawi al-Maqdisi al-Salhi Sharaf al-Din Musa bin Ahmad bin Musa bin Salem bin Isa bin Salem (died: $968 \mathrm{AH}$ ), without the year of publication, persuasion in the jurisprudence of Imam Ahmad bin Hanbal, investigated by Abd alLatif Muhammad Musa al-Sabki, without the edition number, Lebanon ebanon - Dar al-Maarifa.

9. Abu al-Walid bin Rushd al-Qurtubi Muhammad ibn Ahmad (died: 520 AH), published year $1408 \mathrm{AH}$ - $1988 \mathrm{CE}$, statement, collection, explanation, guidance, and explanation of issues extracted, investigated by Dr. Muhammad Hajji and others, second edition, Beirut - Lebanon, Dar Al-Gharb Al-Islami.

10. Abu al-Waqaa al-Shafi'i, Kamal al-Din Muhammad bin Musa bin Isa bin Ali alDamiri (died: $808 \mathrm{AH}$, published in the year $1425 \mathrm{AH}-2004 \mathrm{AD}$, the bright star in explaining the approach "Al Minhaj", investigated by scientific committee, first edition, Jeddah - Dar Al-Minhaj.

11. Abu Bakr (famously known as Al-Bakri) bin Muhammad Shata Al-Damyati (died: after 1302 AH), the year of publication 1418 AH - 1997 CE. Helping students 


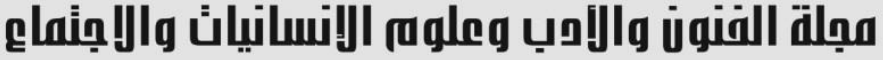 Journal of Arts, Literature, Humanities and Social Sciences www.jalhss.com \\ Volume (54) July 2020 \\ العدد (54) يوليو 2020}

to solve the terms of opening the assistant"Al Muieen", first edition, Dar Al-Fikr for printing, publishing and distribution.

12. Abu Dawud Suleiman bin Al-Ash'ath bin Ishaq bin Bashir bin Shaddad bin Amr Al-Azdi Al-Sajestani (deceased: $275 \mathrm{AH}$ ), without the year of publication, Sunan Abi Dawud, investigated by Muhammad Mohiuddin Abdul Hamid, without the edition number, Beirut - Saida - the modern library.

13. Abu Ja far al-Tabari Muhammad ibn Jarir ibn Yazid ibn Kathir ibn Ghaleb alAmali (died: $310 \mathrm{AH}$ ), published in the year $1420 \mathrm{AH}-2000 \mathrm{CE}$, collector of alBayan in the Interpretation of the Qur'an, investigated by of Ahmad Muhammad Shakir, first edition, the Risala Foundation.

14. Abu Ja`far al-Tahawi al-Azadi Ahmad ibn Muhammad ibn Salama ibn Abd alMalik ibn Salamah (died: $321 \mathrm{AH}$ ), published in $1417 \mathrm{AH}$, summarized the difference of scientists , investigated by d. Abdullah Nazir Ahmed, second edition, Beirut - Dar Al-Bashayer al-Islamiyyah.

15. Abu Muhammad al-Maliki Abd al-Wahhab bin Ali bin Nasr al-Thaalbi alBaghdadi (died: $422 \mathrm{AH}$, without the year of publication, Aid on the doctrine of the city scholar, Imam Malik bin Anas, investigated by of Hameesh Abdel-Haq, without the edition number, Mecca - Commercial Library.

16. Abu Yahya Zakaria bin Muhammad bin Zakaria Al-Ansari, (died: 926 AH), without the year of publication, the Hight demanding in the explanations of the student's garden, without a year and the edition number, Dar Al-Kitab Al-Islami.

17. Aladdin Al-Kasani Al-Hanafi Abu Bakr Bin Masoud Bin Ahmed (died: 587 AH), published year 1406 AH - 1986 AD. Delights just of Favors in Shari'a Arrangement, Second Edition, Lebanon - Dar Al-Kutub Al-Alami

18. Al-Aidan d. Abdul Aziz bin Adnan Al-Eidan, d. Anas bin Adel Al-Yatami, publication year $1439 \mathrm{AH}-2018 \mathrm{AD}$, evidence and references on the most short abbreviations of Muhammad bin Badr al-Din al-Balbani al-Hanbali (Tel: $1083 \mathrm{AH}$ ), first edition, Riyadh - Saudi Arabia, Dar al-Rakaez for publishing and distribution Kuwait, Atlas Green Publishing and Distribution،

19. Al-Ansari Kariya bin Muhammad bin Ahmed bin Zakaria, Zainuddin Abu Yahya al-Sunaiki (died: 926 AH), published in 1414 AH / 1994 AD, opening Al Wahab to explain the student's method, Dar Al-Fikr for printing and publishing.

20. Al-Ansari Zakaria bin Muhammad bin Ahmed bin Zakaria, Zainuddin Abu Yahya al-Sunaiki (died: $926 \mathrm{AH}$, without the year of publication, Gorgeous beginnings in explaining the rosy joy, without the number of the edition, Maimene Press.

21. Al-Asmi Al-Qahtani Al-Hanbali Al-Najdi Abdul Rahman bin Muhammad bin Qasim (died: $1392 \mathrm{AH}$ ), published in $1406 \mathrm{AH}$, The Attendants - Explanation of the Fundamentals of provision, the second edition, without the place of publication and the publisher.

22. Albanian Sheikh Muhammad Nasser al-Din (died: 1420 AH), publication year 1423 AH - 2002 CE, Correct of Sunan Abi Dawood, first edition, Kuwait, Grass Institution for Publishing and Distribution. 


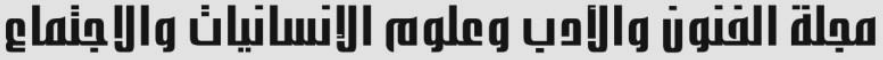 \\ Journal of Arts, Literature, Humanities and Social Sciences www.jalhss.com \\ Volume (54) July 2020 \\ العدد (54) يوليو 2020}

23. Al-Bhouti Mansour bin Younis bin Salah al-Din Ibn Hassan bin Idris al-Hanbali (died: $1051 \mathrm{AH}$ ), without the year of publication, Al-Rawd al-Murabba Sharh Zad alMustaqnih and with it: Sheikh al-Uthaymeen's footnote and Sheikh al-Sa'di's comments, his hadiths came out: Abd al-Quddus Muhammad Nazir, without the edition number, Dar Al-Moayad - Al-Resala Foundation.

24. Al-Bhouti Mansour bin Younis bin Salahuddin Ibn Hassan bin Idris Al-Hanbali (died: $1051 \mathrm{AH}$, without the year of publication, the uncover the mask on the body of persuasion, without the edition number, Dar Al-Kutub Al-Alamiya.

25. Al-Bukhari Muhammad bin Ismail Abu Abdullah, year of publication $1422 \mathrm{AH}$, Sahih Al-Bukhari, investigated by Muhammad Zuhair bin Nasser Al-Nasser, first edition, Dar Touq Al-Najat.

26. Al-Harari Muhammad Al-Amin Bin Abdullah Al-Shafi'i, Publishing Year 1430 AH - 2009 CE, The Shining Planet Explanation of Sahih Muslim, Review of a Committee of Scholars headed by Professor Hashem Muhammad Ali Mahdi, Advisor to the Muslim World League - Makkah Al-Mukarramah, First Edition, Dar Al-Minhaj - Dar Touq Al-Najat.

27. Al-Hasakfi Muhammad bin Ali bin Muhammad Al-Hosni known as Ala Al-Din Al-Hanafi (died: 1088 AH), published in the year 1423 AH-2002 AD, Selected jewels - Explanation of Vision Enlightenment and the collector of the Seas, investigated by Abdel-Moneim Khalil Ibrahim, first edition, Lebanon - Dar Al-Kutub Al-Alamiya.

28. Al-Husseini Muhammad Rashid bin Ali Reda bin Muhammad Shams al-Din bin Muhammad Bahaa al-Din bin Manla Ali (died: 1354 AH), published in 1990 AD, interpretation of the Qur'an (interpretation of al-Manar), Egypt - the Egyptian General Book Authority.

29. Al-Jamal Suleiman bin Omar bin Mansour Al-Ajili Al-Azhari, (died: 1204 AH), without the year of publication. The Wahhab openings clarify the explanation of the students 'method known as the footnote to the sentences, without the edition number, Dar Al-Fikr.

30. Al-Khatib Al-Sherbiny Shams Al-Din Muhammad Ibn Ahmad Al-Shafi'i (died: $977 \mathrm{AH}$ ), publication year $1415 \mathrm{AH}-1994 \mathrm{AD}$, a enough of needy of knowledge of the meanings of the curriculum words, first edition, Dar Al-Kutub Al-Alami.

31. Al-Khulouti Abd al-Rahman bin Abdullah bin Ahmad al-Hanbali (died: 1192 $\mathrm{AH}$, publication year $1423 \mathrm{AH}-2002 \mathrm{AD}$, drug and blooming garden to explain the shortest abbreviations, investigated by Muhammad bin Nasser Al-Ajami, first edition, Lebanon / Beirut - Dar Al-Bashayer al-Islamiyyah.

32. Al-Khurshi Abu Abdullah Muhammad bin Abdullah Al-Maliki (died: 1101 AH), without publication year, a brief explanation of Khalil Al-Khurshi, without the edition number, Beirut - Dar Al-Fikr for printing.

33. Al-Marghanani Abu Al-Hassan Burhan Al-Din Ali Bin Abi Bakr Bin Abdul-Jalil (died: $593 \mathrm{AH}$ ), year of publication, guidance in explaining the beginning of beginner, investigated by Talal Youssef, Lebanon - Dar Al-Ahyaa for Arab Heritage.

34. Al-Nawawi Abu Zakaria Mohy Al-Din Yahya bin Sharaf (died: 676 AH), without the year of publication, Al-Majmoo 'Sharh Al-Muhadhdh ("with the supplement of Al-Sibki and Al-Muti'i)", Dar Al-Fikr. 
35. Al-Shirazi Abu Ishaq Ibrahim bin Ali bin Youssef (died: $476 \mathrm{AH}$ ), without the year of publication, Refinement in jurisprudence of Imam Al-Shafi'i, Dar Al-Kutub Al-Alami

36. Al-Tuwaijri Muhammad bin Ibrahim bin Abdullah, published in the year 1430 AH - 2009 CE, Encyclopedia of Islamic Jurisprudence, First Edition, House of International Ideas.

37. Al-Zamakhshari Jarallah Abu Al-Qasim Mahmoud bin Amr bin Ahmed, (died: $538 \mathrm{AH}$ ), year of publication $1407 \mathrm{AH}$, searchlight the facts of the mysteries of the tanzeel "quran", the third edition, Beirut - Dar Al-Kitab Al-Arabi

38. Al-Zubaidi Abu Bakr bin Ali bin Muhammad Al-Haddadi Al-Abadi (died: 800 $\mathrm{AH}$ ), publication year $1322 \mathrm{AH}$, bright jewel, first edition, charitable press.

39. Al-Zubaidi Othman Bin Al-Makki Al-Tozari, Publication Year 1339 AH, Clarification of Rulings Explaining the judge's antique, First Edition, Tunisian Press.

40. Assiuti, Shams al-Din Muhammad bin Ahmed bin Ali bin Abd al-Khaliq alQahiri al-Shafi'i (died: 880 AH, publication year 1417 AH - $1996 \mathrm{CE}$ ), jewels of contracts and assistant of judges, signatories, and witnesses, investigated by Massaad Abdel Hamid Muhammad al-Saadani, first edition, Beirut - Dar al-Kutub al-Alami 41. Badr Al-Din Al-Ainy Abu Muhammad Mahmoud bin Ahmed bin Musa bin Ahmed bin Hussein Al-Ghettabi Al-Hanafi (died: 855 AH), without the year of publication, the building- Explanation of Guidance, House of Scientific Books Beirut, Lebanon, Edition: First،

42. Brahim Mustafa Ahmed Al-Zayat / Hamed Abdel-Qader / Mohamed Al-Najjar, without the year of publication, the intermediate dictionary, without the edition number, the Arabic Language Academy - Cairo, Dar Al-Dawa.

43. Ibn al-Hamam Kamal al-Din Muhammad ibn Abd al-Wahid al-Siwasi (died: 861 $\mathrm{AH}$ ), without the year of publication, Fattuhu al-Qadeer, without the edition number, Dar al-Fikr.

44. Ibn al-Rifa' Abu al-Abbas Najm al-Din Ahmad bin Muhammad bin Ali (died: $710 \mathrm{AH}$ ), published in $2009 \mathrm{AD}$, the enuogh of the smart in explaining the alert, investigated by Majdi Muhammad Surur Basalum, first edition, Dar Al-Kutub AlAlami

45. Ibn Arafa El-Desouky Mohamed Ibn Ahmed El-Malky (died: 1230 AH) - without the year of publication, a footnote to El-Desouky on the Great explanation, without the edition number, Dar Al-Fikr.

46. Ibn Baz, Fatwas of Sheikh Ibn Baz, the fatwa is posted on the following website: ttps: //binbaz.org.sa/fatwas/

47. Ibn Hazm al-Dhahiri Muhammad Ali bin Ahmed bin Saeed bin Hazm alAndalusi al-Qurtubi (died: $456 \mathrm{AH}$ ), without the year of publication, " supported by an aphorisms" Almuhalla bi Alathar, without the edition number, Beirut - Dar al-Fikr.

48. Ibn Manzoor Abu Al-Fadl Jamal Al-Din Muhammad Bin Makram Bin Ali AlAnsari (died: $711 \mathrm{AH}$ ), published in 1414 AH, Lisan "tongue" Al-Arab, Beirut - Dar Sader. 


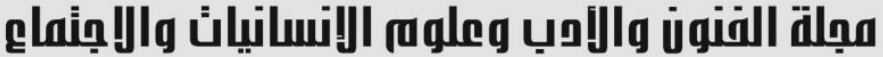

49. Ibn Najim al-Hanafi Serag al-Din Omar bin Ibrahim (d. 1005 AH), publication year 1422 AH - 2002 CE, The Super River, Explanation of the Treasury of particulars, Achievement by Ahmed Ezzo Enaya, First Edition, Dar Al-Kutub Al-Alami.

50. Ibn Qudamah al-Maqdisi Abu Muhammad Muwaffaq al-Din Abdullah bin Ahmad bin Muhammad (died: $620 \mathrm{AH}$ ), al-Mughni, without the edition number, Cairo Library.

51. Ibn Rushd al-Qurtubi, famous for Ibn Rushd, Al Hafeed Abu al-Walid Muhammad bin Ahmad bin Muhammad bin Ahmed (died: $595 \mathrm{AH}$ ), without the year of publication, the beginning of the diligent and the end of Al Muqtasid, the author, without the edition number, Cairo - Dar Al-Hadith.

52. Ibn Taymiyyah al-Harrani Abu al-Barakat Majd al-Din Abd al-Salam bin Abdullah bin al-Khudr bin Muhammad (died: $652 \mathrm{AH}$ ), published year $1404 \mathrm{AH}$ 1984 CE, Almuharrar "edit text" in jurisprudence on the doctrine of Imam Ahmad bin Hanbal, second edition, Library of Knowledge - Riyadh.

53. Jamal al-Din Muhammad bin Abdullah bin Abi Bakr (died: 792 AH), published in the year $1419 \mathrm{AH}$ - $1999 \mathrm{AD}$, the wonderful meanings of knowing the difference of the scientist of Sharia, investigated by Syed Muhammad Mehani, first edition, Dar AlKutub Al-Alami - Beirut.

54. Judge Abu Muhammad al-Baghdadi al-Maliki Abd al-Wahhab bin Ali bin Nasr (422 AH), publication year $1420 \mathrm{AH}$ - 1999, supervising on issues Observations' of dispute, investigation: Habib bin Tahir, first edition, Dar Ibn Hazm.

55. Manla Khusro Muhammad bin Framers bin Ali (died: $885 \mathrm{AH}$ ), without the year of publication, jewels of rulers explain the Gorgeous of provisions, without the edition number, the Arab Books Revival House.

56. Shah Wali Allah Al-Dahlawi Ahmad Bin Abdul Rahim Bin Al Shahid Wajih Al Din Bin Mohd Bin Mansour (died: 1176 AH), Publication Year 1426 AH - 2005 AD, eloquent evidence " Hajjah Allah Al-Balagh", Investigated by Sayyid Sabaq, First Edition, Beirut - Lebanon, Dar Al-Jeel.

$$
\begin{aligned}
& \text { الهوامش }
\end{aligned}
$$

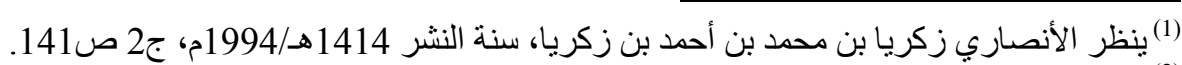

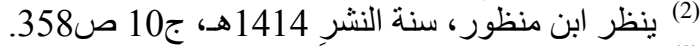

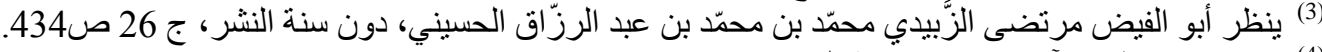

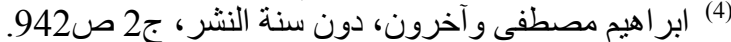

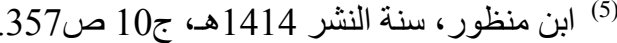

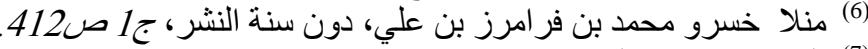

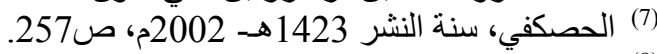

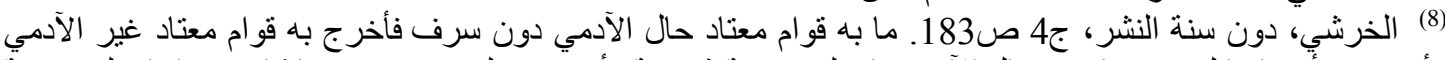

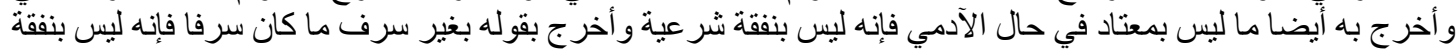

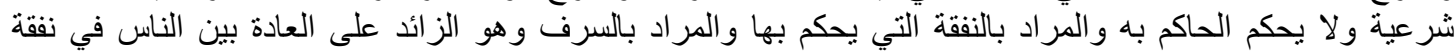

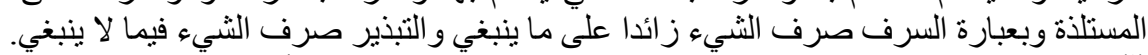

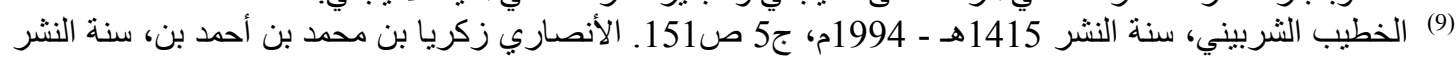




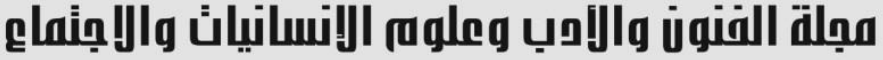

Journal of Arts, Literature, Humanities and Social Sciences
www.jalhss.com

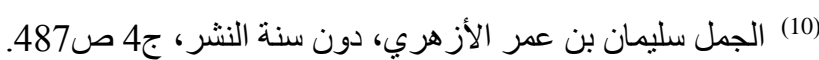

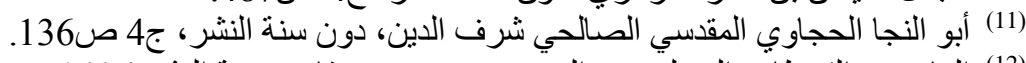

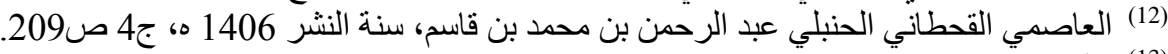
233] (13)

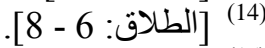

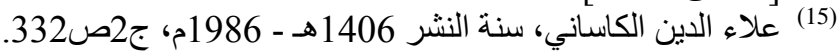

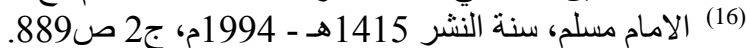

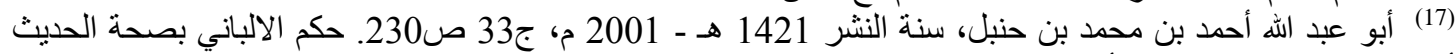

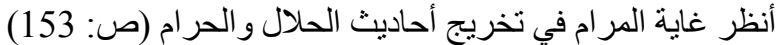

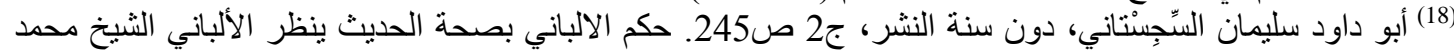

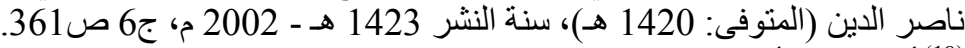

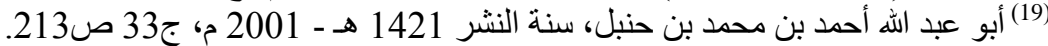

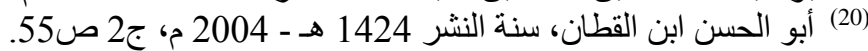

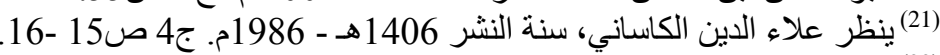

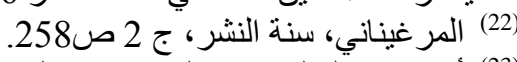

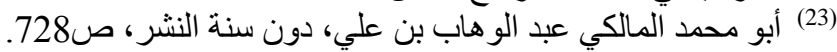

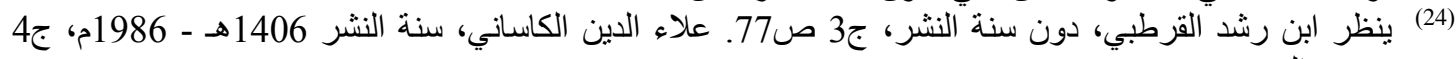

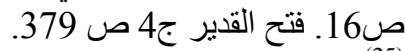

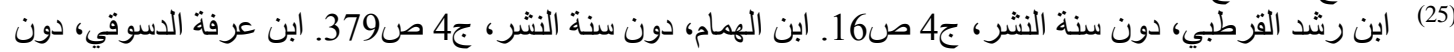

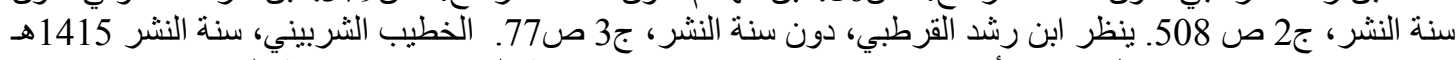

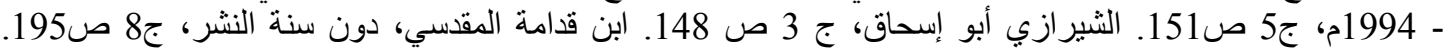

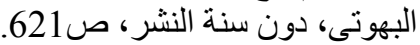

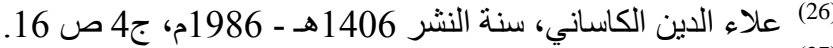

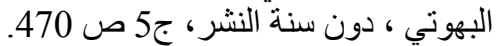

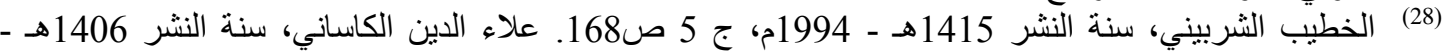

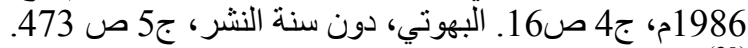

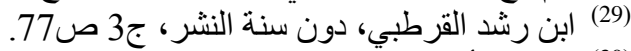

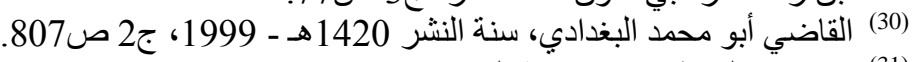

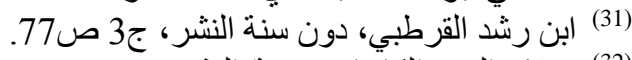

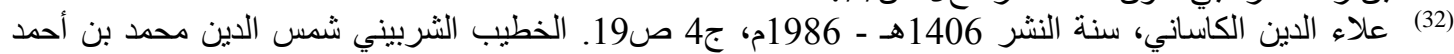

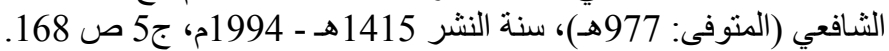

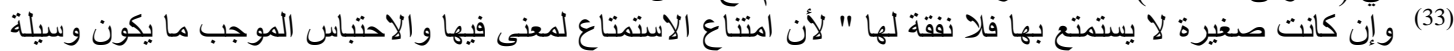

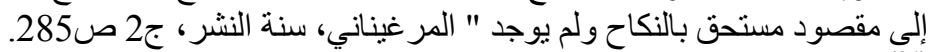

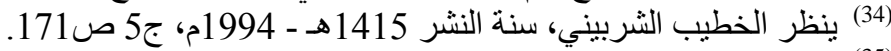

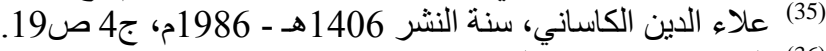

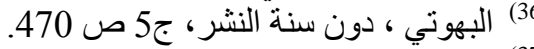

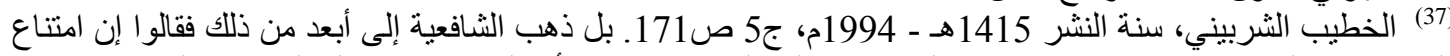

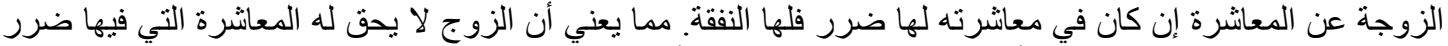

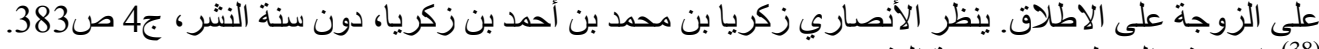

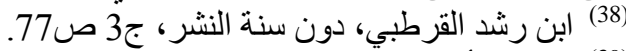

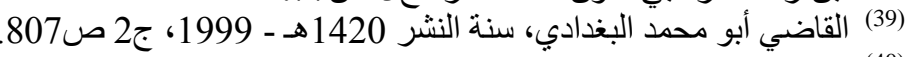

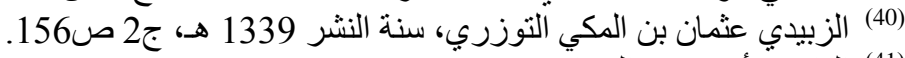

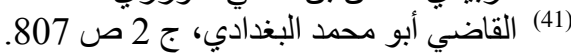

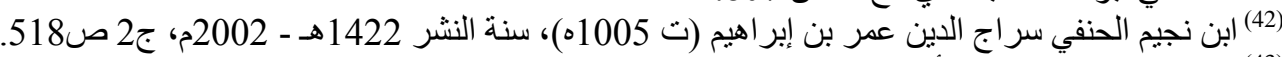

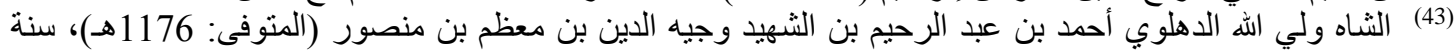

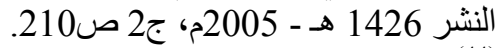
(44) عبد العظيم بن بدوي بن محمد، سنة النشر 1421 هـ ـ - 2001 م، ص301. 


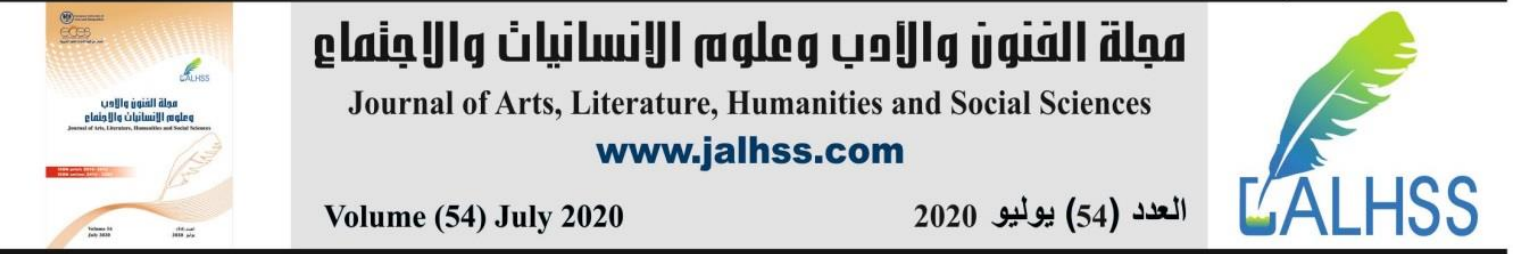

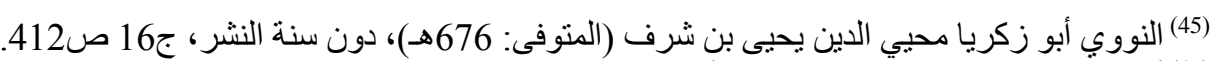

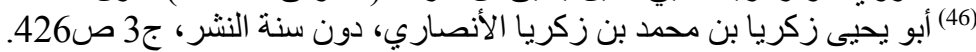

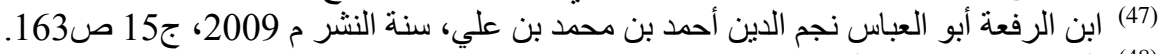

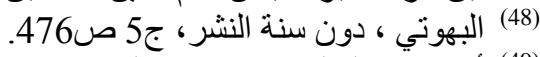

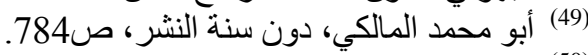

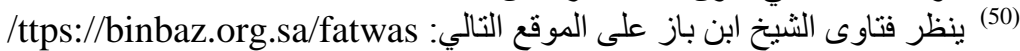

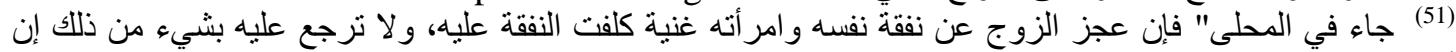

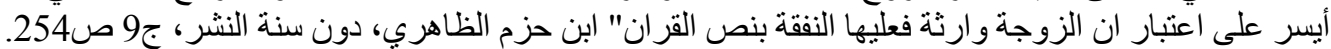

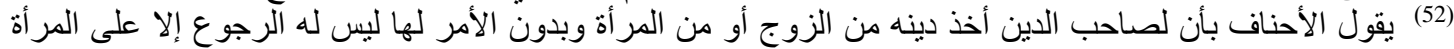

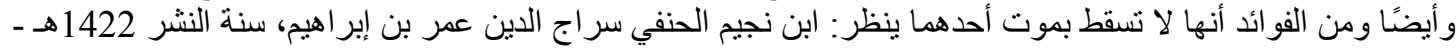

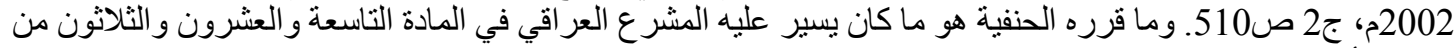
قانون الأحوال الثخصية العر اقي.

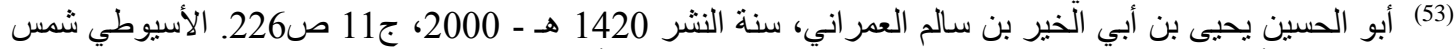

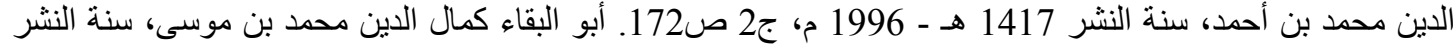

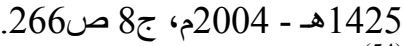

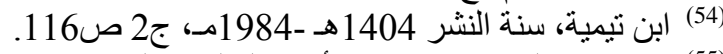

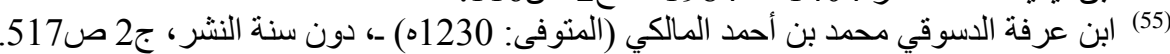

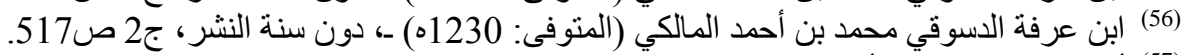

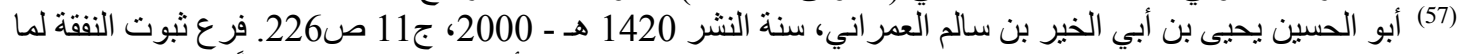

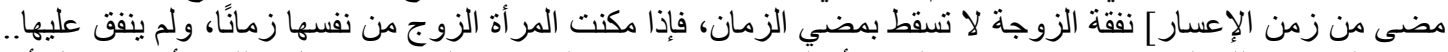

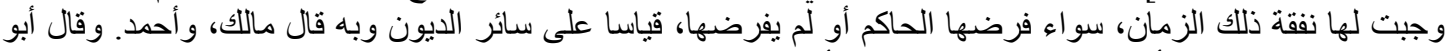

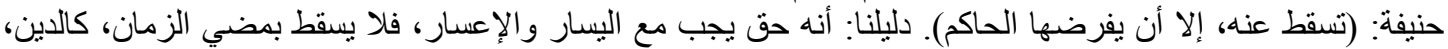
و وفيه احتراز من نفقة الأقارب..

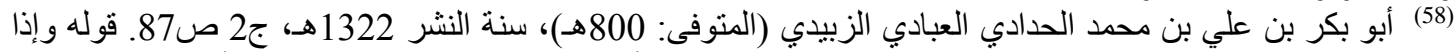

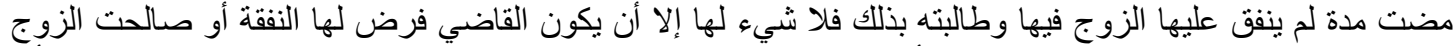

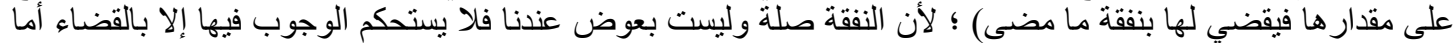

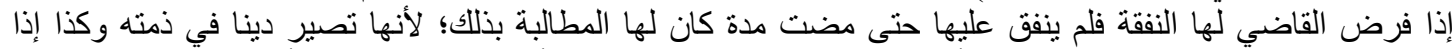

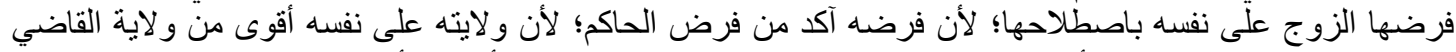

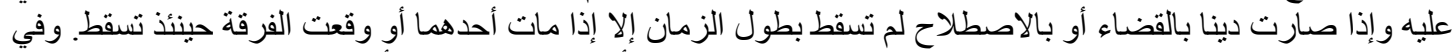

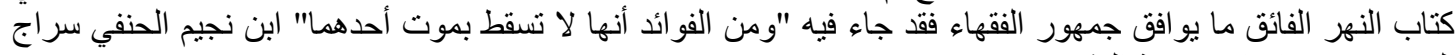

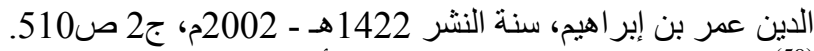

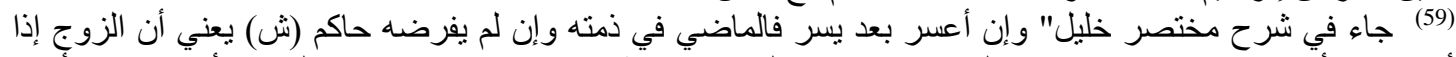

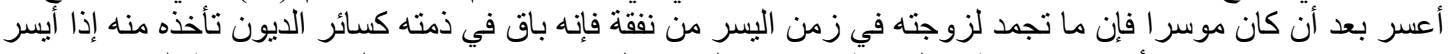

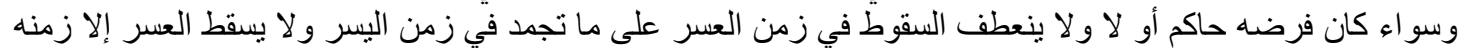

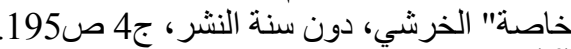
(60) ينظر أبو الحسين يحيى بن أبي الخير بن سالم العمراني اليمني الثافعي، سنة النشر 1420 هـ - 2000، ج11 (63) ينظر التويجري محمد بن إبراهيخ بن عبد الله، سنة النشر 1430 هـ - 2009 م، موسوعة الفقه الإسلامي، ج4 (64) يقول العمر اني دليلنا: أن النفقة تجب في مقابلة التمكين من الاستمتاع، وقد سقط التمكين من الاستمتاع، فسقطت نفقتها،

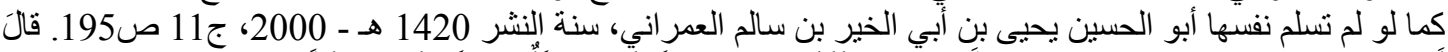

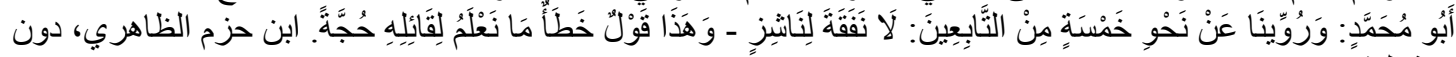




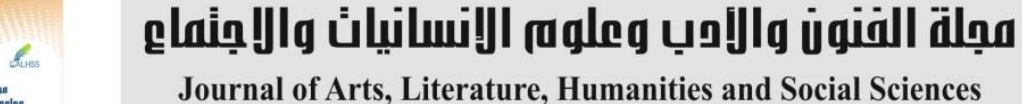

www.jalhss.com

(67) البخاري محمد بن إسماعيل، سنة النشر 1422هـ، ج3 ص1301. الامام أبو الحسن القثيري مسلم بن الحجاج

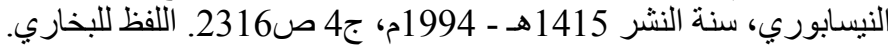

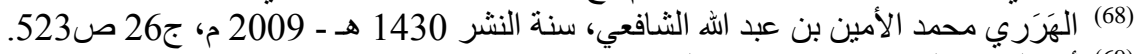

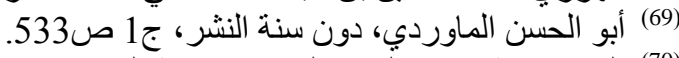

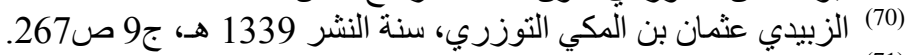

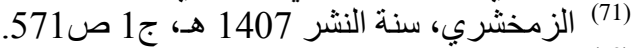

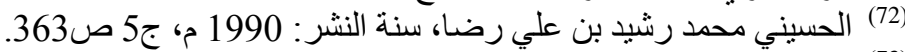

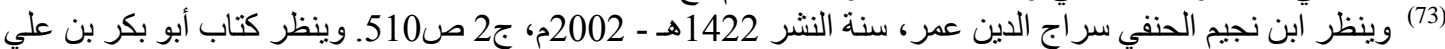

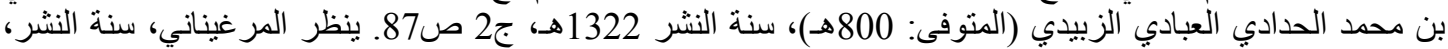
ج2 صن صند28

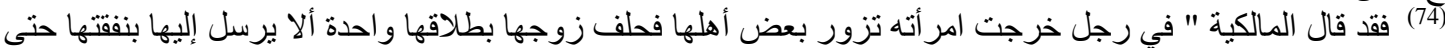

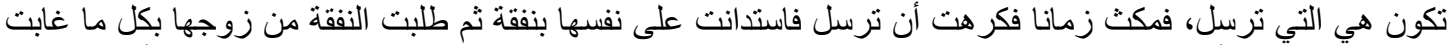

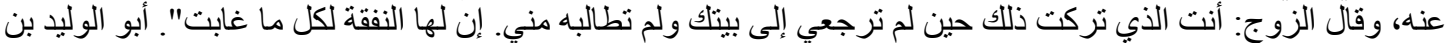

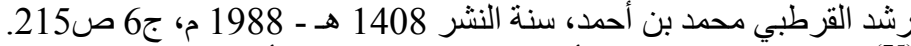

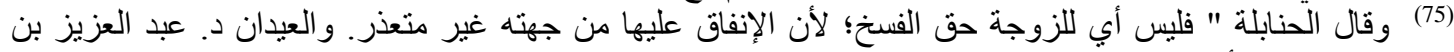

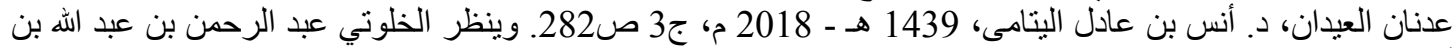

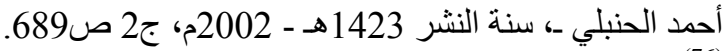

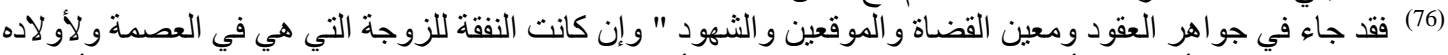

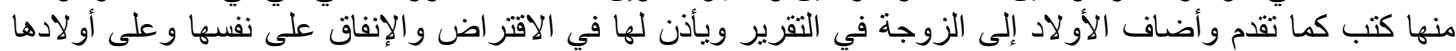

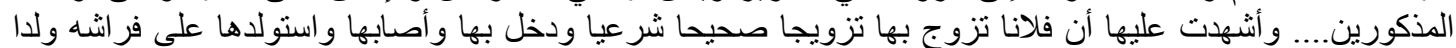

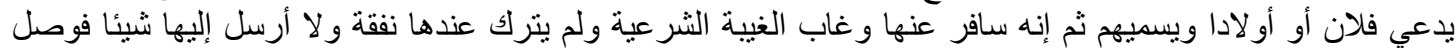

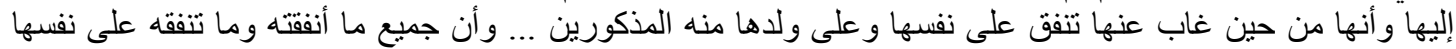

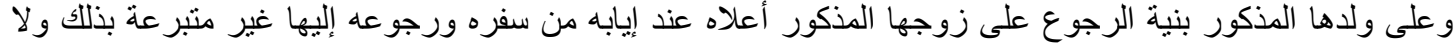

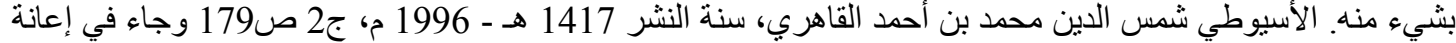

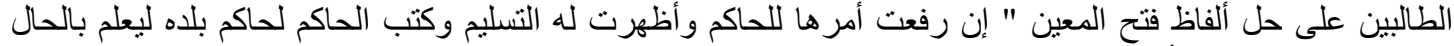

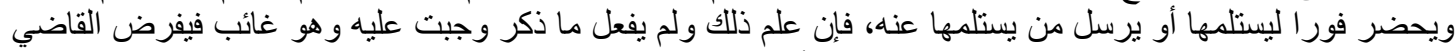

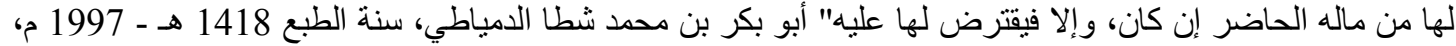

